UNIVERSIDADE DE SÃO PAULO

ESCOLA DE ENGENHARIA DE SÃo CARLOS DEPARTAMENTO DE ENGENHARIA DE ESTRUTURAS

THAís GOMES PEDROSA

\title{
OTIMIZAÇÃO DE RISCO DE TRELIÇAS SOB COLAPSO PROGRESSIVO
}





\section{THAÍS GOMES PEDROSA}

\section{OTIMIZAÇÃO DE RISCO DE TRELIÇAS SOB COLAPSO PROGRESSIVO}

\section{VERSÃO CORRIGIDA}

A versão original encontra-se na Escola de Engenharia de São Carlos

Tese apresentada ao Programa de PósGraduação em Engenharia Civil (Engenharia de Estruturas) da Escola de Engenharia de São Carlos da Universidade de São Paulo para obtenção do título de Doutor em Ciências.

Área de Concentração: Estruturas

Orientador: Prof. André Teófilo Beck, Ph.D.

São Carlos

Maio de 2020 


\section{AUTORIZO A REPRODUÇÃO TOTAL OU PARCIAL DESTE TRABALHO, POR QUALQUER MEIO CONVENCIONAL OU ELETRÔNICO, PARA FINS DE ESTUDO E PESQUISA, DESDE QUE CITADA A FONTE.}

Ficha catalográfica elaborada pela Biblioteca Prof. Dr. Sérgio Rodrigues Fontes da EESC/USP com os dados inseridos pelo(a) autor(a).

Pedrosa, Thaís Gomes
P3720 Otimização de risco de treliças sob colapso progressivo. / Thaís Gomes Pedrosa; orientador André Teófilo Beck. São Carlos, 2020.

Tese (Doutorado) - Programa de Pós-Graduação em Engenharia Civil(Engenharia de Estruturas) e Área de Concentração em Estruturas - - Escola de Engenharia de são Carlos da Universidade de são Paulo, 2020.

1. Otimização de Risco. 2. Estruturas de Treliças. 3. Análise Mecânica Não Linear Geométrica. 4. Colapso Progressivo. I. Título.

Eduardo Graziosi Silva - CRB - 8/8907 


\section{FOLHA DE JULGAMENTO}

Candidata: Engenheira THAís GOMES PEDROSA.

Título da tese: Otimização de riscos de treliças sob colapso progressivo".

Data da defesa: 01/04/2020.

Comissão Julgadora:

Resultado:

Prof. Associado André Teófilo Beck

Aprovado

(Orientador)

(Escola de Engenharia de São Carlos/EESC)

Prof. Associado Edson Denner Leonel

Aprovado

(Escola de Engenharia de São Carlos/EESC)

Profa. Associada Maíra Martins da Silva

Aprovado

(Escola de Engenharia de São Carlos/EESC)

Prof. Dr. Rafael Holdorf Lopez

- Reprovado

(Universidade Federal de Santa Catarina/UFSC)

Prof. Dr. Wellison José de Santana Gomes

Aprovado

(Universidade Federal de Santa Catarina/UFSC)

Coordenador do Programa de Pós-Graduação em Engenharia Civil (Engenharia de Estruturas):

Prof. Associado Vladimir Guilherme Haach

Presidente da Comissão de Pós-Graduação:

Prof. Titular Murilo Araujo Romero 

A todos que estiveram do meu lado e me apoiaram de muitas formas.

Em especial a minha família e minha madrinha. 



\section{AGRADECIMENTOS}

Agradeço aos meus pais, engenheiros civis experientes.

Gratidão à minha irmã pelos conselhos.

Agradeço ao meu orientador.

Agradeço aos professores em especial a aqueles que compuseram as bancas da qualificação e da defesa, pelos ensinamentos, pelas ideias e pelo apoio.

Agradeço aos doutores da minha família que me ajudaram a lidar com os momentos difíceis dessa jornada por meio de suas experiências e histórias.

Agradeço aos amigos que encontrei no Departamento de Engenharia de Estruturas, em especial aos também egressos da UFSCar, Margot Fabiana e Sérgio Cordeiro, aos "irmãos acadêmicos" Rodolfo Tessari e Henrique Kroetz e ao Arthur Álax pelas conversas e pelos chás.

À USP, através do programa de pós-graduação em Engenharia de Estruturas, pela oportunidade de capacitação e pela ajuda dos funcionários.

À CAPES, pelo auxílio financeiro.

Não posso deixar de citar a ajuda dos amigos que fiz durante as atividades de lazer que tanto ajudaram para clarear a mente e deixar que os pensamentos fluíssem. Para todos da dança e do CUME o meu muito obrigada.

Às amigas e psicólogas da vida, Marina Santos e Tatiana, a ajuda de vocês foi primordial.

Agradeço de coração ao meu companheiro e futuro marido, Paulo Burke, e ao nosso filho(a) que embora ainda com 3 meses de gestação, foram essenciais para me dar a força e perseverança para concluir esta etapa. 

"Design is not just what it looks like and feels like. Design is how it works." -Steve Jobs

A otimização de risco altera a visão de projeto reunindo todos os objetivos durante a etapa conceitual, preza-se não só pela aparência e leveza como também pelo desempenho e segurança. 



\section{RESUMO}

PEDROSA, T. G. Otimização de risco de treliças sob colapso progressivo. 2020. 99p. Tese (Doutorado em Ciências - Engenharia Civil (Engenharia de Estruturas)) - Escola de Engenharia de São Carlos, Universidade de São Paulo, São Carlos, 2020.

A otimização de risco objetiva a redução de custos esperados totais mantendo um nível desejado de desempenho e segurança da estrutura. No entanto, faltam metodologias para avaliação da confiabilidade e do ótimo sob o ponto de vista do risco ao colapso progressivo. Este trabalho explora essa lacuna realizando a otimização de estruturas treliçadas considerando a análise mecânica não-linear geométrica. Dada a inclusão do colapso progressivo na formulação mecânica do problema, é proposto um método de otimização baseado no coeficiente de vulnerabilidade ao colapso progressivo. A formulação proposta é capaz de reduzir a necessidade de análises estruturais de configurações instáveis ou sujeitas a altas probabilidades de falha durante o processo de otimização. As configurações otimizadas obtidas apresentam níveis aceitáveis de desempenho e confiabilidade em relação aos modos de falha considerados.

Palavras-chave: Otimização de Risco. Estruturas de Treliças. Análise Mecânica Não Linear Geométrica. Colapso Progressivo. 


\section{ABSTRACT}

PEDROSA, T. G. Risk optimization of trusses under progressive collapse. 2020. 99p.

Thesis (PhD. in Civil Engineering (Structural Engineering)) - School of Engineering of São Carlos, University of São Paulo, São Carlos, 2020.

Risk optimization aims at reducing the expected total cost while maintaining a desired level of structural performance and safety. However, there is a lack of methodologies for assessing reliability and optimum of structures regarding the progressive collapse risk. Here we explore this field by performing optimizations of truss structures considering geometrical non-linearities in the mechanical analysis. Given the inclusion of progressive collapse in the mechanical formulation of the problem, we propose an optimization method which is based on a coefficient of vulnerability to progressive collapse. This formulation is able to reduce the need to perform structural analysis of configurations which are unstable or ones with associated high probability of failure. The optimized configurations presented acceptable levels of performance and reliability regarding the failure modes considered.

Keywords: Risk Optimization. Truss Structures. Geometrical non-linearity mechanical analysis. Progressive Collapse. 


\section{LISTA DE ABREVIATURAS E SIGLAS}

\begin{tabular}{ll} 
ABNT & Associação Brasileira de Normas Técnicas \\
RBDO & Otimização Estrutural baseada em confiabilidade \\
EEL & Equação de Estado limite \\
EC & Elemento chave \\
RO & Otimização de Risco \\
RAPC & Análise de Risco do Colapso Progressivo \\
RBTO & Otimização topológica baseada em risco \\
RBSO & Otimização de sistemas \\
MCS & Simulação de Monte Carlo \\
RWA & Simulação Ranqueada Ponderada \\
WASM & Método de Simulação por média ponderada \\
ELS & Estado Limite de Serviço \\
ELU & Estado Limite Último \\
NLG & Não linearidade Geométrica \\
MEF & Método dos elementos finitos \\
StRAnD & Programa Structural Risk Analysis and Design \\
USP & Universidade de São Paulo \\
CVC & Coeficiente de Vulnerabilidade ao Colapso \\
CV & Coeficiente de Vulnerabilidade \\
CI & Coeficiente de Importância ao Colapso \\
CET & Custo Esperado Total \\
CEF & Custo Esperado de Falha \\
PSO & Otimização por enxame de partículas \\
OMG & Otimização Topológica Determinística \\
\hline AMento Automatizado de membros
\end{tabular}





\section{LISTA DE SÍMBOLOS}

$\begin{array}{cl}C_{c} & \text { Custo de Construção } \\ C_{f} & \text { Custo de Falha } \\ C_{E T} & \text { Custo Esperado Total } \\ C_{E F} & \text { Custo Esperado de Falha } \\ P_{f} & \text { Probabilidade de Falha } \\ A & \text { Área da seção transversal } \\ \boldsymbol{d} & \text { Vetor de variáveis de projeto determinísticas } \\ \boldsymbol{Z} & \text { Vetor de variáveis de projeto aleatórias } \\ \boldsymbol{X} & \text { Vetor de variáveis aleatórias } \\ g(\cdot) & \text { Equação de Estado Limite } \\ m & \text { Número de elementos } \\ P[.] & \text { Probabilidade de um evento } \\ \mu & \text { média ou valor esperado } \\ \sigma & \text { Desvio padrão } \\ \beta & \text { Índice de confiabilidade } \\ \sigma_{y} & \text { Tensão de Escoamento } \\ \Omega_{f} & \text { Domínio de Falha } \\ \nabla & \text { Função Gradiente } \\ \mathrm{K}_{\mathrm{t}} & \text { Matriz de Rigidez } \\ \mathrm{E}_{\mathrm{g}} & \text { Medida de deformação não linear de Cauchy-Green } \\ \mathbb{E} & \text { Módulo elástico tangente ou Mó } \\ \Pi & \text { Energia Potencial Total } \\ U_{e l} & \text { Energia Potencial Elástica } \\ & \end{array}$





\section{SUMÁRIO}

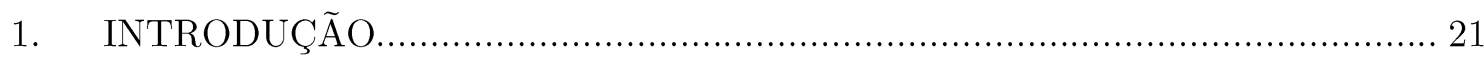

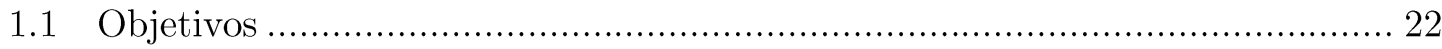

PARTE I. REFERENCIAL TEÓRICO E FORMULAÇÃO ..................................... 23

2. MECÂNICA ESTRUTURAL E OTIMIZAÇÃO ESTRUTURAL ...................... 25

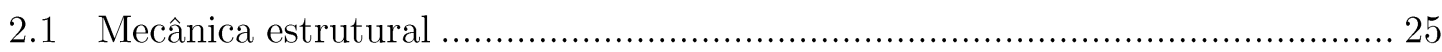

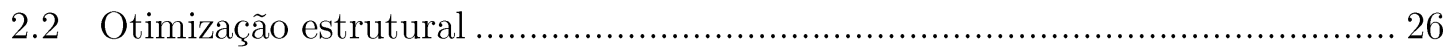

2.2.1 Abordagem da ground structure ............................................... 27

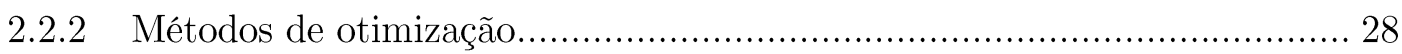

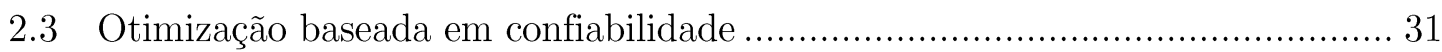

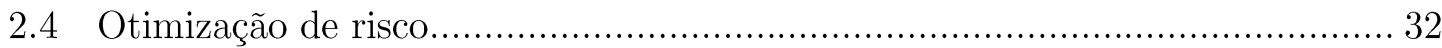

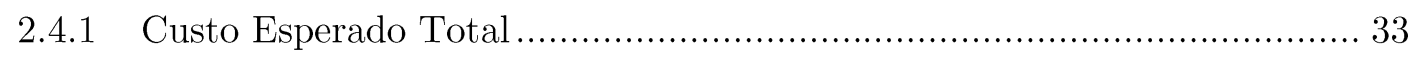

3. CONFIABILIDADE ESTRUTURAL E MECÂNICA ESTRUTURAL ............... 37

3.1 Restrições do Problema Probabilístico .......................................................... 38

3.1.1 Exemplo de avaliação das restrições..................................................... 41

3.2 Avaliação da Probabilidade de falha ........................................................... 42

3.2.1 Simulação de Monte Carlo (MCS) ...................................................... 43

3.2.2 Probabilidade de falha do sistema .................................................... 43

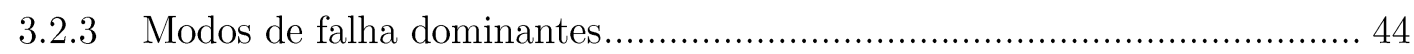

3.3 Análise de Risco do Colapso progressivo .................................................... 45

4. CONFIABILIDADE ESTRUTURAL E OTIMIZAÇÃO ESTRUTURAL ........... 49

4.1 Simulação por média ponderada classificada (RWASM) …........................... 50

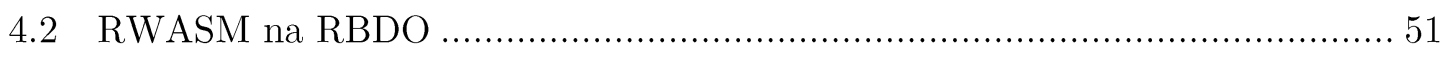

4.3 RWASM aplicado à otimização de risco................................................ 52

4.3.1 Dependência da EELs às VAs do problema....................................... 52

4.3.2 Valor de $\boldsymbol{\beta}$ - Ausência de restrição ................................................... 54 
4.3.3 Alteração da média das variáveis de projeto .55

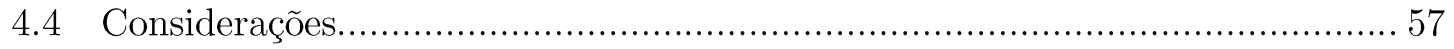

5. OTIMIZAÇÃO ESTRUTURAL E COLAPSO ESTRUTURAL PROGRESSIVO 59

5.1 Propriedades do CVC 60

5.2 Abordagem de minimização local pelo pseudo-gradiente................................. 61

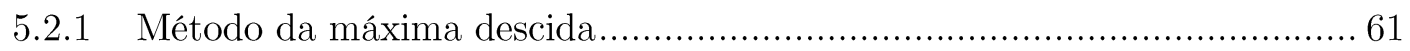

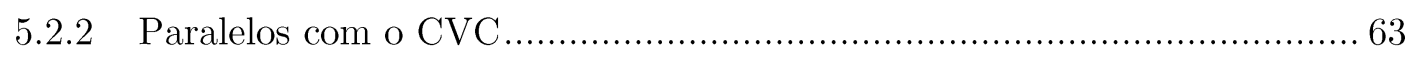

5.3 CVC-pseudo-gradiente - Otimização Local ............................................... 71

5.3.1 Fluxograma da otimização de risco com CVC-pseudo-gradiente............... 71

5.3.2 Estudos mais específicos sobre o método …...................................... 72

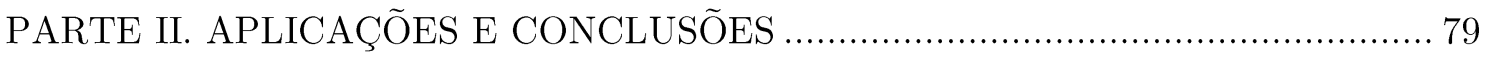

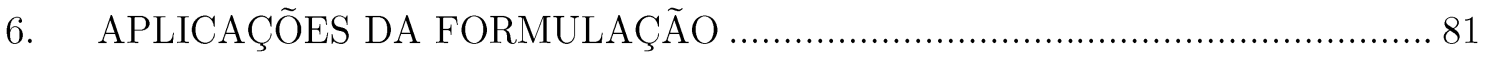

6.1 Otimização de tamanho utilizando formulação de risco …….......................... 81

6.1.1 Influência da resposta mecânica no projeto otimizado: Treliça de 2 barras81

6.1.2 Índice de confiabilidade otimizado e cenários de falha............................ 83

6.2 Otimização de risco com colapso progressivo............................................. 84

6.2.1 Incertezas nas variáveis: Treliça de 3 barras ......................................... 85

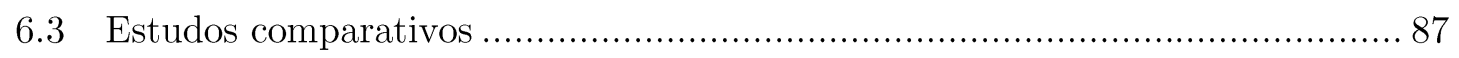

6.3.1 Influência do RAPC no ótimo do PSO: Treliça de 6 barras ..................... 87

6.3.2 Influência do passo no CVC-pseudo-gradiente: Treliça de 10 barras......... 90

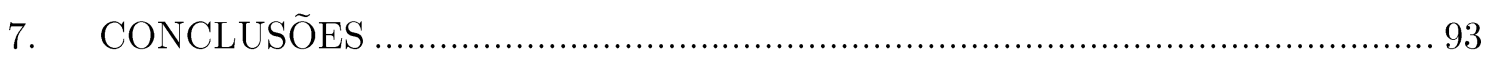

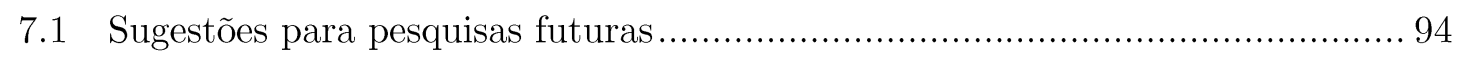

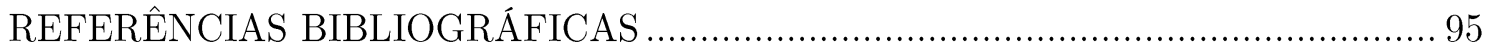




\section{INTRODUÇÃO}

A otimização estrutural pode ser entendida como um processo de aperfeiçoamento de uma estrutura previamente projetada de configuração conhecida ou não a cumprir determinada exigência. Todavia, a otimização estrutural em sua forma mais primitiva tem origem no projeto conceitual da estrutura. O projeto de uma estrutura é um processo minucioso no qual diversos propósitos conflitantes são almejados. Eficiência monetária, desempenho satisfatório, segurança e até mesmo inovação e criatividade são algumas das metas de um projetista. Na etapa conceitual do projeto são determinados os atributos que definem um sistema estrutural: função, forma e material. A função remete ao desempenho, a forma é relativa à estética e, junto com o material, definem os custos. Esses escopos unicamente são satisfeitos adequadamente quando considerados em paralelo e de forma integrada.

Não obstante, o desempenho pode ser afetado por propriedades materiais e do ambiente não exatamente conhecidas. Um desempenho indesejado caracteriza uma falha, cuja probabilidade de ocorrência pode ser calculada. Quando essa probabilidade é multiplicada pelas consequências de tal falha, afere-se o risco.

Para abordar o conflito entre custos e segurança, e ainda interações entre os parâmetros de projeto, os objetivos da otimização de risco são descritos unicamente em termos monetários de forma a minimizar os custos esperados totais. A minimização da soma dos custos iniciais e dos custos esperados de falha permite considerar adequadamente riscos de tratamento economicamente não justificável, como por exemplo, decorrentes de eventos com grande consequência negativa, porém baixa probabilidade de ocorrência.

A solução do problema de otimização de risco compreende as variáveis que definem a configuração otimizada e os índices de confiabilidade de cada modo de falha. A consideração de incertezas implica em múltiplas avaliações mecânicas estruturais para avaliar a 
probabilidade de falha quantitativamente. O estudo do colapso progressivo consiste na propagação de uma falha inicial, de modo semelhante a uma reação em cadeia que conduz à falha parcial ou total da estrutura.

Este trabalho concentra-se na inclusão do colapso progressivo na formulação mecânica do problema e consequentemente, análise de risco de colapso progressivo para avaliação das probabilidades de falha e introdução de custos esperados de falha por colapso na função objetivo do problema de otimização de risco. A originalidade desta tese consiste no desenvolvimento de uma métrica e sua posterior utilização como parâmetro em um método de otimização específico para o tipo de problema em questão.

\subsection{Objetivos}

O objetivo principal desta pesquisa é desenvolver uma metodologia para solução de problemas de otimização de risco de estruturas treliçadas bidimensionais sujeitas a colapso progressivo.

A inclusão do colapso progressivo em problemas de otimização parte da sua introdução na mecânica estrutural do problema. Sendo assim, é avaliado o desempenho do código computacional mecânico para análises mecânicas lineares e não lineares geometricamente. Em um segundo passo, lida-se com as incertezas atreladas ao risco, onde pretende-se melhorar o desempenho de rotinas para estimativa de probabilidade de falha de eventos primários e também de colapso progressivo para problemas não deriváveis e conferir o desempenho de métodos de simulação de confiabilidade para problemas de otimização de risco. O terceiro passo refere-se à integração de um método de otimização viável ao tipo de problema em questão. Nesta parte, métodos de otimização serão discutidos e analisados a fim de encontrar a melhor formulação. Por fim, a metodologia gerada será discutida e serão feitos exemplos teóricos específicos a fim de quantificar o desempenho da metodologia. 


\section{PARTE I. REFERENCIAL TEÓRICO E}

\section{FORMULAÇÃO}

Nesta parte, os temas serão tratados em conjunto levando em conta o seu desenvolvimento na formulação de risco. São abordados 4 tópicos: Mecânica, Otimização, Confiabilidade e Colapso Progressivo.

No entanto, esses conceitos se fundem. A função objetivo da otimização de risco depende de parcelas de custo que estão associadas à geometria da seção e à probabilidade de falha da estrutura. Por sua vez, as análises de otimização e de confiabilidade estão sujeitas a sucessivas avaliações de equilíbrio mecânico da estrutura. A determinação das características geométricas é feita pelo algoritmo de otimização e a avaliação da probabilidade de falha pelo módulo estocástico de confiabilidade. A Figura 1 mostra os conceitos e o produto da relação entre eles. 


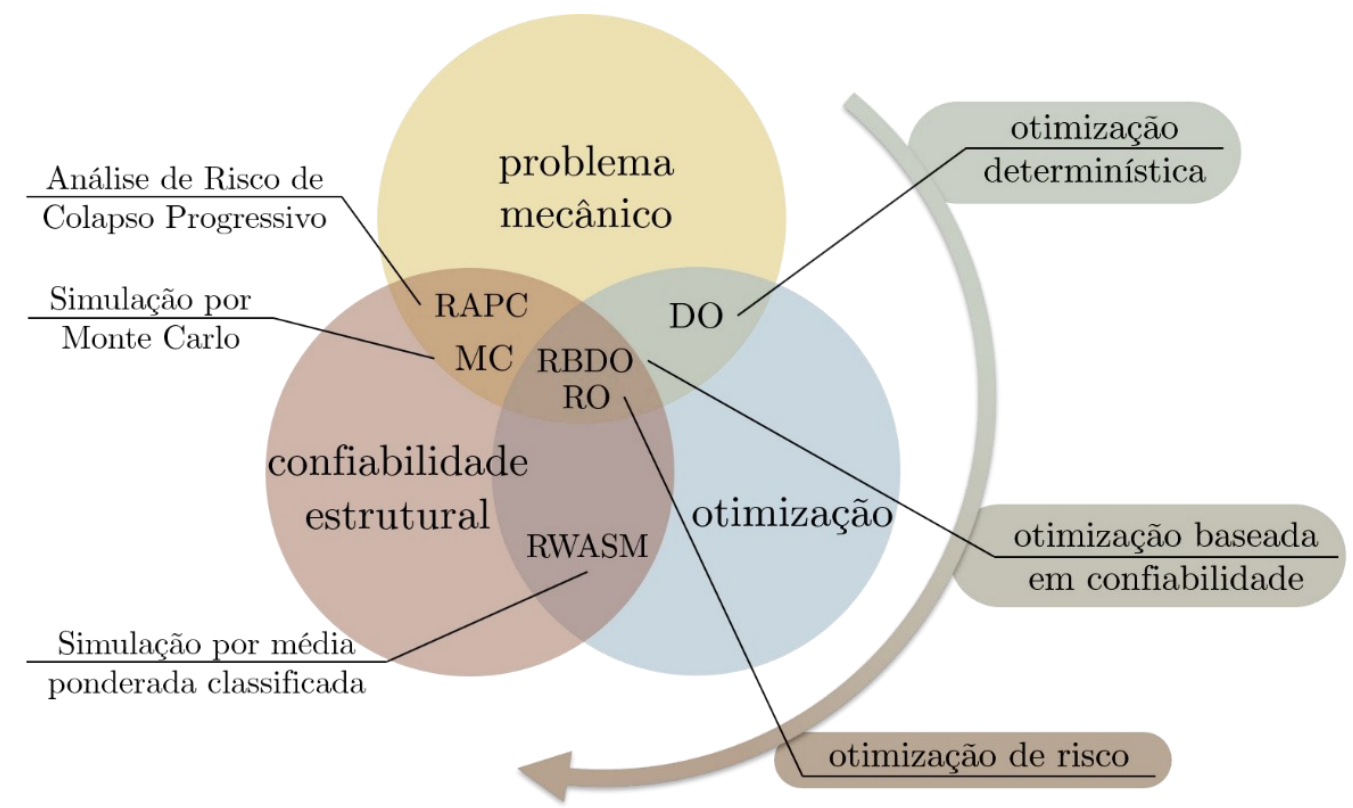

Figura 1 -Interseção dos conceitos. Fonte: Adaptado de Pedrosa e Beck (2018).

O estudo de cada grande área separadamente dá suporte ao entendimento e acoplamento entre:

i. modelagem do sistema (análise mecânica e colapso progressivo);

ii. quantificação do desempenho (descrição das funções de estado limite);

iii. análise estocástica (quantificação das incertezas) e;

iv. otimização estrutural (tipos de otimização e métodos locais e globais). 


\section{MECÂNICA ESTRUTURAL E OTIMIZAÇÃO} ESTRUTURAL

A escolha por estruturas de barras advém da facilidade de caracterizar a falha destes elementos com precisão de modo discreto e bilateral (falha ou sobrevivência). Neste sentido, opta-se por não entrar no mérito de estudos de comportamento pós crítico (flambagem inelástica e plastificação, por exemplo). O uso de estruturas reticuladas permite a análise de problemas maiores a partir da discretização do domínio em elementos reticulares elementares.

\subsection{Mecânica estrutural}

No presente trabalho, a resposta estrutural dos elementos de barra está baseada no método dos elementos finitos (MEF) baseado em posições. A formulação utilizada foi desenvolvida e implementada nos trabalhos de Coda e Greco (2004), Greco et al. (2006) e validada em Coda e Paccola (2011). Na formulação posicional, as equações de equilíbrio são avaliadas segundo a configuração deslocada da estrutura e portanto, adequa-se a situação de grandes deformações e deslocamentos. A mecânica estrutural empregada está fundamentada na não linearidade geométrica (NLG) que consiste na consideração dos efeitos de segunda ordem advindos da consideração do equilíbrio na posição deslocada da estrutura e na concepção de material frágil permitindo traçar possibilidades de colapso progressivo.

O mapeamento das posições iniciais e atuais da estrutura é feito pela função mudança de configuração e seu gradiente. A mudança da configuração do elemento finito de barras simples é descrita pela medida de deformação não-linear de Cauchy-Green, definida a partir dos comprimentos final e inicial do elemento. 


$$
E_{g}=\frac{1}{2}\left(\frac{L^{2}}{L_{0}^{2}}-1\right)
$$

onde $E_{g}$ especifica a medida de deformação não linear através do índice $g$ de Green. $\mathrm{O}$ comprimento inicial $L_{0}$ é dado pela diferença entre as posições dos nós iniciais e o comprimento atual ou final $L$ pelas posições atuais.

O modelo constitutivo utiliza o conjugado energético da deformação de Green, a tensão de Piola- Kirchhoff de segunda espécie e a relação constitutiva de Saint Venant-Kirchhoff. A solução do equilíbrio estático estrutural é feita pelo módulo mecânico desenvolvido por Tessari (2016) e acoplado ao software de análise de confiabilidade (StRAnD) do grupo de pesquisa em que este trabalho está inserido. Este módulo mecânico, chamado de StRAnD-FEA utiliza um solver não linear iterativo baseado no método de Newton-Raphson. A identificação das falhas é realizada durante as etapas de carregamento para identificar falhas durante a trajetória de equilibrio.

A implementação neste trabalho está de acordo com os resultados esperados, tendo sido comparada com outros softwares como Ftool $^{\circledR}$ (Martha, 2018) para análises lineares e AcadFrame $^{\circledR}$ (Coda e Paccola, 2009) para análises lineares e NLG.

\subsection{Otimização estrutural}

Um problema de otimização estrutural determinística pode ser posto como:

$$
\begin{gathered}
\boldsymbol{d}^{*}=\arg \min \left[C(\boldsymbol{d}): g_{j}(\boldsymbol{d}) \leq 0, h_{k}(\boldsymbol{d})=0 ; \boldsymbol{d} \in S\right] \\
\operatorname{para} j=1, \ldots, n_{g} \text { e } k=1, \ldots, n_{h}
\end{gathered}
$$

onde $\mathrm{C}$ é a função objetivo que geralmente se refere ao volume de materiais ou aos custos de fabricação. Os valores de $j$ e $k$ definem, respectivamente, o número de restrições de desigualdade $n_{g}$ e de igualdade $n_{h} . S=\left\{d_{i}^{\text {min }} \leq d_{i} \leq d_{i}^{\max }, i=1, \ldots, n\right\}$ é o espaço de projeto admissível formado pelos limites impostos a cada variável $d_{i}$ e $n$ é o número total de variáveis de projeto. O vetor $\boldsymbol{d}$ contém as variáveis de projeto, ou seja, aquelas variáveis cujo valor se deseja determinar de modo a obter o menor valor possível da função objetivo. Essas variáveis podem 
ser área dos elementos, coordenadas nodais, e/ou densidade dos elementos que compõem os três tipos principais de otimização: tamanho, forma e topológica, respectivamente.

A formulação determinística permite encontrar uma configuração estrutural que é ideal em termos de comportamento mecânico ou capacidade de carga, enquanto a segurança da estrutura pode ser considerada indiretamente pelo emprego de coeficientes de segurança.

\subsubsection{Abordagem da ground structure}

Para abordar treliças na otimização, é preciso modelar esse tipo de estrutura e seus conceitos básicos. A ground structure, ilustrada na Figura 2.1, é a estrutura com todos os possíveis nós e membros. No português, o termo pode ser entendido como estrutura fundamental ou base na qual demais estruturas se baseiam. Esta abordagem foi inicialmente desenvolvida por Dorn et al. (1964), aprimorada e aplicada por vários autores como Achtziger et al. (1992), Martínez et al. (2007) e Hagishita e Ohsaki (2009). Segundo a metodologia, deve existir, preferencialmente, um membro entre cada par de nós, incluindo nós dos apoios.

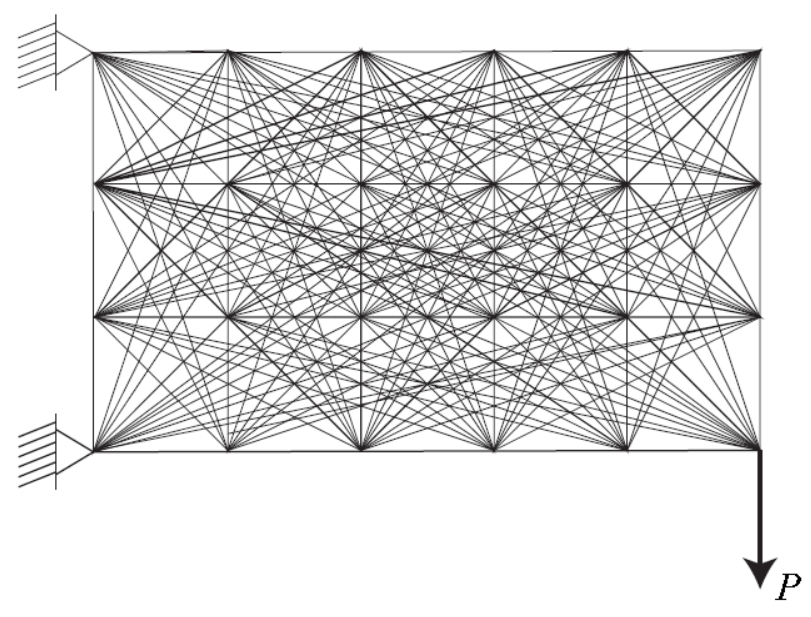

Figura 2.1 - Estrutura com dominio estendido altamente conectada. Fonte: Ohsaki (2010)

Além da malha base, é necessário definir um nível de conectividade $L v l_{\text {conect }}$, exemplificado na Figura 2.2. 
a)

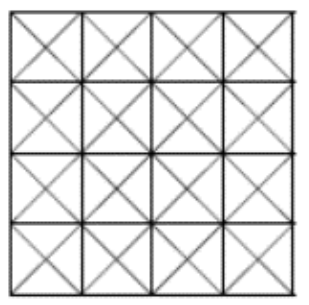

b)

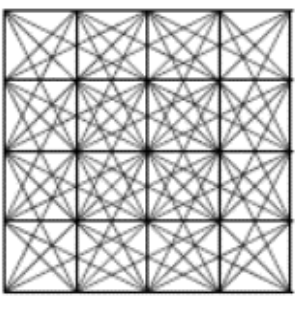

c)

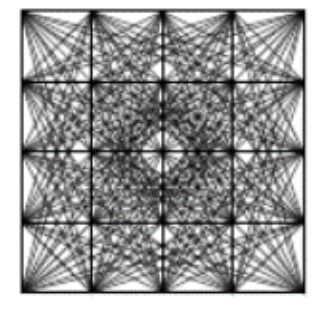

Figura 2.2 - Nível de conectividade dos nós para malha $\left(N_{x}^{u}, N_{y}^{u}\right)=(5,5)$. a) nivel 1; b) nível 2; c) nível máximo. Fonte: Adaptado de Bendsøe e Sigmund (2000)

A eliminação dos elementos é feita usando a variação contínua da área da seção transversal das barras como variável de projeto e incluindo a possibilidade de áreas nulas. A estrutura otimizada é então, um subconjunto de todos os elementos, inicialmente escolhidos pelas conexões entre os pontos nodais ou pelo conjunto de elementos finitos, que conecta as condições de contorno impostas (OHSAKI, 2010).

O número de elementos $n_{e}$ resultante é dado por

$$
n_{e}=\sum_{i=1}^{m} b_{i}
$$

onde $b_{i} \epsilon\{0,1\}$ é usado para designar a existência $b_{i}=1$ e não existência $b_{i}=0$ dos i-ézimos membros da estrutura base. Sendo que $n_{e} \leq m$, onde $m$ é igual ao número de elementos da estrutura base. Os limites para definição de $b_{i}$ são dados em Petersson (2001) e Svanberg e Werme (2009).

\subsubsection{Métodos de otimização}

Por se tratar de problemas multimodais e de natureza geral, em que a função objetivo é não-convexa, não-linear e não-diferenciável, e até mesmo descontínua, são necessários métodos de otimização global. Os métodos de otimização global podem ser determinísticos ou estocásticos. Os artigos de revisão de Hasançebi et al. (2009) e Stolpe (2015) fazem uma revisão das principais formulações meta-heurísticas para problemas de otimização de treliça.

Métodos estocásticos podem ser aplicados em qualquer tipo de função, até funções com estruturas desconhecidas e que são calculadas apenas por meio de simulação numérica. São caracterizados por possuírem algum tipo de aleatoriedade durante o procedimento de 
otimização, como o uso de um gerador de números pseudo-aleatórios. Métodos estocásticos, como, por exemplo, o PSO, têm mostrado sua eficiência em problemas de grande escala, embora não garantam otimalidade da solução.

\section{Particle Swarm optimization - PSO}

O PSO foi introduzido por Kennedy e Eberhart (1995) e é um algoritmo meta-heurístico baseado em população, inspirado no comportamento animal. Neste artigo, os autores se referem ao PSO como paradigma de otimização que simula a habilidade das sociedades humanas de processar conhecimento. O PSO foi implementado com sucesso em problemas de otimização de treliças como em: Fourie e Groenwold (2002), Li et al. (2007), Dimou e Koumousis (2009), Li et al. (2009) e Mortazavi e Toğan (2016). O artigo de Moreno-de-Luca e Carrillo (2013) faz uma revisão sobre o tema na área de projetos estruturais e arquitetônicos e dentre outros métodos, cita o PSO para a resolução deste tipo de problema. O trabalho de Coello e ReyesSierra (2006) é apontado para uma revisão sobre a aplicabilidade do PSO a estes problemas. A escolha do algoritmo se dá pela sua simplicidade de formulação e implementação computacional, além da facilidade de paralelização em múltiplos processadores.

As equações que regem o PSO são a equação dos vetores de posição $\boldsymbol{x}$ e da velocidade das partículas $\boldsymbol{v}_{i}$ que depende da melhor posição da própria partícula $\boldsymbol{p}_{b e s t, i}^{k}$ e da melhor posição de todo o conjunto $\boldsymbol{g}_{\text {best }}$. Matematicamente, a velocidade contempla: a velocidade anterior da partícula; a melhor posição da partícula e; a melhor posição obtida por qualquer partícula da população até o momento da iteração, cada uma multiplicada por um peso. Este peso é um parâmetro do algoritmo do PSO definido a priori ou um número aleatório, ou ambos no caso das posições locais e globais.

$$
\boldsymbol{v}_{\boldsymbol{i}}^{k+1}=\omega \boldsymbol{v}_{i}^{k}+c_{p} r_{p}\left(\boldsymbol{p}_{\text {best }, i}^{k}-\boldsymbol{x}_{i}^{k}\right)+c_{g} r_{g}\left(\boldsymbol{g}_{\text {best }}-\boldsymbol{x}_{i}^{k}\right)
$$

Os índices $p$ e $g$ indicam a própria partícula e a população (swarm), respectivamente. Os parâmetros $r \sim U(0,1)$ são números aleatórios usados para manter a diversidade da população. 
Eles permitem explorar maior parcela do domínio do problema, o que em geral aumenta a probabilidade de encontrar o ótimo, embora com um custo computacional adicional. Soma-se a velocidade à posição de cada partícula para determinar as novas posições.

$$
x_{i}^{k+1}=x_{i}^{k}+v_{i}^{k+1}
$$

A Figura 2.3 mostra a atualização da posição de uma partícula de forma esquemática.

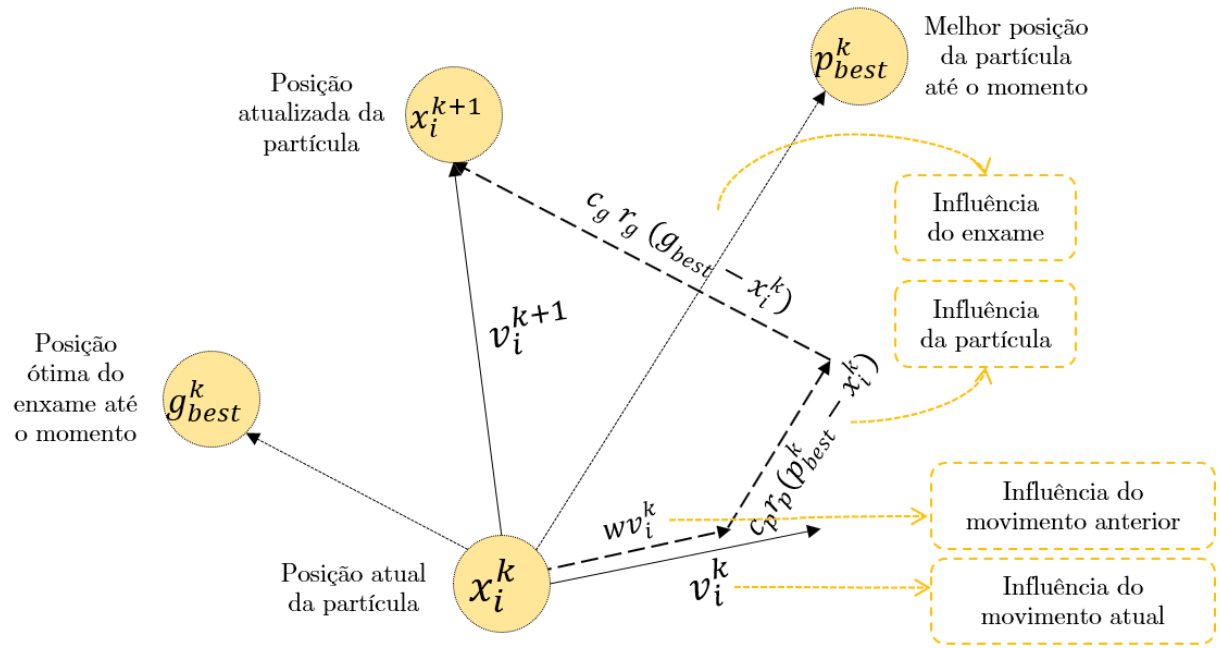

Figura 2.3 - Atualização da posição e velocidades do PSO. Fonte: Adaptação de Perez e Behdinan (2007)

A literatura tal como: Kennedy e Eberhart (1995), Shi e Eberhart (1998) e Parsopoulos e Vrahatis (2002) propõe valores dos coeficientes do PSO para manter um equilíbrio entre a capacidade de pesquisa global e local do algoritmo. No entanto, é de conhecimento que o valor ótimo dos três parâmetros $\omega, c_{g}$ e $c_{p}$ dependem do problema, segundo Schutte e Groenwold (2003), e testes exaustivos devem ser realizados para encontrar o melhor conjunto dos parâmetros do PSO para um determinado tipo de problema.

A base do algoritmo PSO aqui utilizado é de Tada (2018). O algoritmo contempla as modificações relacionadas ao uso da melhor posição, velocidade máxima, inércia, aleatoriedade expostas no artigo de Fourie e Groenwold (2002). São usados critérios de parada em função do valor da função objetivo e também das variáveis de projeto. 
Os parâmetros utilizados são reunidos na Tabela 2.1.

Tabela 2.1 - Parâmetros do PSO. Fonte: Adaptado de Tada (2018).

\begin{tabular}{|c|c|c|}
\hline Parâmetro & $\begin{array}{c}\text { Valor } \\
\text { Varia } \\
\text { conforme } \\
\text { problema }\end{array}$ & $\begin{array}{r}\text { Número de partículas/tamanho da } \\
\text { população }\end{array}$ \\
\hline $\boldsymbol{n}_{\boldsymbol{p}}$ & 0,9 & parâmetro de inércia \\
\hline $\boldsymbol{\omega}^{\mathbf{0}}$ & 2 & Parâmetro de intenção próprio/cognitivo \\
\hline $\boldsymbol{c}_{\mathbf{1}}=\boldsymbol{c}_{\boldsymbol{p}}$ & 2 & Parâmetro de intenção do enxame/social \\
\hline $\boldsymbol{c}_{\mathbf{2}}=\boldsymbol{c}_{\boldsymbol{g}}$ & $510^{-3}$ & Parâmetro de busca aleatória \\
\hline $\boldsymbol{c}_{\mathbf{3}}$ & 0.5 & Limite do comprimento da velocidade \\
\hline $\boldsymbol{v}_{\boldsymbol{m a x}}$ & 0.1 & Parâmetro de perturbação da velocidade \\
\hline $\boldsymbol{v}_{\boldsymbol{r a n d}}$ & & \\
\hline
\end{tabular}

\subsection{Otimização baseada em confiabilidade}

A natureza não-determinística inerente das seções transversais dos elementos, das propriedades físicas do material e das forças externas torna complicada a tarefa de encontrar o melhor projeto. Na maioria dos casos, variáveis aleatórias com funções de distribuição e parâmetros de distribuição estimados com base em dados estatísticos e/ou subjetiva são suficientes para quantificar as incertezas. O Comitê conjunto de Segurança Estrutural - JCSS (2001) apresenta um conjunto quase completo de modelos probabilísticos para a maioria das situações encontradas em problemas práticos de engenharia.

$\mathrm{Na}$ Reliability-Based Design Optimization (RBDO), as incertezas são tomadas objetivamente e modeladas probabilisticamente, em adição, as probabilidades de falha são usadas como restrição de projeto. Artigos clássicos de RBDO, como o de Qu e Haftka (2004), referem-se ao seguinte problema:

$$
\boldsymbol{d}^{*}=\arg \min \left[C_{\text {inicial }}(\boldsymbol{d}): \boldsymbol{d} \in \boldsymbol{S}, P_{f} \leq P_{f_{\text {admissivel }}}\right]
$$

onde $S=\left\{d_{i}^{\text {min }} \leq d_{i} \leq d_{i}^{\max }, i=1, \ldots, n\right\}$ é o espaço de projeto admissível formado pelos limites impostos a cada variável $d_{i}$ e $n$ é o número total de variáveis de projeto. $C_{\text {inicial }}$ é o custo inicial ou de produção, que pode incluir custo de materiais (calculados a partir do volume) e custos de mão-de-obra; $P_{f_{\text {admissivel }}}$ é a restrição em termos de probabilidade de falha 
admissível. Cada equação de estado limite (EEL) dá origem a uma restrição em termos de probabilidades de falha admissível.

A solução de problemas de RBDO depende diretamente da avaliação da confiabilidade estrutural, que pode ser feita por métodos aproximativos ou por meio de simulações estocásticas. O custo computacional para avaliação das restrições é particularmente significativo, uma vez que a análise de confiabilidade é realizada dentro de uma estrutura de otimização, onde os cálculos são repetidos centenas a milhares de vezes (DU e CHEN, 2004).

A RBDO é aplicada a diferentes formulações, tais como: a sistemas (SRBDO - System Reliability-based Design Optimization); problemas topológicos (RBTO - Reliability-based Topology Optimization); problemas geométricos (RBSO - Reliability-based Size Optimization) e a otimização de ciclo-de-vida (LCRO - Life Cicle Risk Optimization) ou de risco (RO - Risk Optimization). Para maiores detalhes consultar os trabalhos de: Thampan e Krishnamoorthy (2001) para otimização de sistemas; Murotsu et al. (1994) para geometria; Kharmanda et al. (2004) para topologia e; Frangopol et al. (1997) para ciclo de vida.

\subsection{Otimização de risco}

A otimização de risco é uma expansão da otimização de ciclo de vida. A otimização de ciclo de vida (life-cycle optimization) foi introduzida por Frangopol et al. (1997) pelo estudo de custos de ciclo de vida feito por Chang e Shinozuka (1996). Ambas se distinguem das formulações de otimização estrutural anteriores por levarem em consideração o equilíbrio e o efeito de incertezas em termos de probabilidades dentro da função objetivo na forma de custos esperados:

$$
\boldsymbol{d}^{*}=\arg \min \left[C_{E T}(\boldsymbol{d}): \boldsymbol{d} \in S\right]
$$

onde $S=\left\{d_{i}^{\text {min }} \leq d_{i} \leq d_{i}^{\text {max }}, i=1, \ldots, n\right\}$ é o espaço de projeto admissível formado pelos limites de cada variável $d_{i}$, $\boldsymbol{d}_{\text {min }}$ e $\boldsymbol{d}_{\max }$ são os limites inferiores e superiores das variáveis de projeto (coordenadas nodais, área dos elementos, densidade dos elementos) e $n$ é o número total de variáveis de projeto. $C_{E T}$ representa os custos esperados totais da estrutura. Observa- 
se que nesta formulação as probabilidades de falha não são usadas como restrições e sim associadas a uma medida quantitativa de custo esperado de falha.

\subsubsection{Custo Esperado Total}

A literatura fornece muitas fórmulas para custo de ciclo de vida como em Frangopol e Maute (2003), Gomes e Beck (2013) ou ainda Saad et al. (2013). Essas formulações apresentam muitas semelhanças. Por exemplo, Sarma e Adeli (2002) classificam o custo total como a soma dos custos de construção inicial, manutenção, inspeção, reparo, operação, falha e desmontagem. Cheng (2002) divide o custo total em custo inicial e custo de dano.

A abordagem de custos esperados totais leva em consideração não só custos de ciclo de vida como também custos esperados de falha. O custo esperado de falha é uma parcela essencial pois, por um lado, afeta significativamente a solução otimizada e por outro, é difícil de ser avaliado. Estudos de Wen (2001) mostram que o projeto é altamente dependente das consequências de falha associadas a cada modo de falha e sensível de forma moderada ao pressuposto de vida útil estrutural.

O presente trabalho foca na estimativa dos custos de falha, considerando os demais custos constantes. Negligenciar os demais custos de vida acentua o teor de risco da função objetivo, principal diferença entre a otimização de ciclo-de-vida e a de risco. Uma vez constantes, estes custos não afetam o processo de otimização, e o custo total pode ser simplificado pela soma dos custos iniciais $C_{i}$ e custos esperados de falha $C_{E F}$ :

$$
C_{E T}(\boldsymbol{d}, \boldsymbol{Z}, \boldsymbol{X})=C_{i}+\sum_{i=1}^{N_{f}} E\left(C_{E F}\right)
$$

onde $E$ ( ) é o operador valor esperado e $N_{f}$ é o número total de falhas. A variáveis de projeto determinísticas (Deterministic Design Variables - DDV) identificadas pelo vetor $\boldsymbol{d}$ são definidas dentro do laço de otimização e as variáveis aleatórias (VAs ou Random Variables - RV) descritas por $\boldsymbol{X}$ são definidas no laço de confiabilidade. A função objetivo $C_{E T}$ pode, ainda, incluir variáveis de projeto que são aleatórias (Random Design Variables - RDV) identificadas 
pelo vetor $\boldsymbol{Z}$, estas possuem propriedades de $\boldsymbol{d}$, sendo variáveis de projeto mas no módulo de confiabilidade são avaliadas como aleatórias, da mesma forma que o vetor $\boldsymbol{X}$.

\section{Custo de construção}

Dentre os custos iniciais, considera-se aquele que pode ser obtido com maior precisão em função das variáveis de projeto. Define-se o custo de construção de um único elemento como o custo de material obtido a partir do volume de material multiplicado pelo custo unitário de material por unidade de volume, $c_{u}$.

$$
C_{C_{i}}(\boldsymbol{d}, \boldsymbol{Z})=c_{u} A_{i} L_{i}
$$

Considerando as contribuições dos $m$ elementos da estrutura obtemos o custo de construção da estrutura, Eq.(2.10).

$$
C_{i}=C_{C}(\boldsymbol{d}, \boldsymbol{Z})=c_{u} \sum_{i=1}^{m} A_{i} L_{i}
$$

Outro custo de interesse é o custo de referência, que é constante e avaliado a partir do volume inicial da estrutura. Este custo serve de parâmetro para definir custos de reconstrução da estrutura em caso de colapso.

$$
C_{R E F}=C_{C_{0}}
$$

\section{Custo esperado de falha}

A definição do custo esperado de falha $\left(C_{E F}\right)$ é obtida pela relação linear entre consequências (custo) e a probabilidade de falha para cada modo de falha $n$ tal como exemplifica a Eq. (2.12).

$$
C_{E F_{n}}=C_{f_{n}} P_{f_{n}}
$$

A determinação do custo de falha $C_{f}$ pode usar uma abordagem simplificada em função do custo de construção, tal como em Aoues (2008). Para esta abordagem, deve ser mantido o custo de construção inicial como referência uma vez que o custo de construção tende a diminuir 
com a minimização do CET. Portanto, as consequências de falha são dadas pela Eq. (2.13) onde $\alpha$ é um fator de proporcionalidade.

$$
C_{f}=\alpha C_{R E F}
$$

Cada modo de falha pode assumir um fator de proporcionalidade de acordo com suas consequências. Modos de falha locais tendem a ter consequências mais brandas e, portanto, assumem, por exemplo, $\alpha=1$. Para falhas globais é necessário adotar valores maiores para o fator de proporcionalidade, por exemplo $\alpha=5$ ou ainda $\alpha=10$, devido às consequências mais severas de uma possível falha. Diferentes fatores podem levar a diferentes soluções pois se trata de um coeficiente que determina o grau de importância do modo de falha dentro da função objetivo.

Os modos de falha também podem ser divididos em falhas de serviço e falha última. As falhas de serviço são medidas a partir da violação das equações de estado limite locais (para cada membro). Essa violação implica em um custo de reparo, aqui admitido como igual ao custo de construção deste elemento individual. Somente barras hiperestáticas estão sujeitas a falha de serviço, pois a falha de uma barra isostática define um estado de limite último. Mecanismos não são considerados. Portanto, o número de falhas de serviço que podem ser somadas é igual ao grau de hiper-estaticidade da estrutura $g_{h}$.

Por sua vez, falhas últimas são divididas em diretas e indiretas de acordo com:

$$
C_{f_{u}}=\left\{\begin{aligned}
C_{R E F} & \rightarrow \text { colapso progressivo } \\
10 C_{R E F} & \rightarrow \text { colapso direto }
\end{aligned}\right.
$$

podendo a probabilidade de falha do sistema avaliada tal como em Beck et al. (2019) ser substituída pela probabilidade falha por colapso progressivo definida em Felipe et al. (2018) por meio da metodologia RAPC (Risk Analysis of Progressive Collapse).

Neste caso de falhas de serviço e falhas últimas, o somatório dos custos é dado por:

$$
C_{E T}(\boldsymbol{d}, \boldsymbol{Z}, \boldsymbol{X})=C_{c}+\sum_{j=1}^{h} C_{f_{j}} P_{f_{j}}+C_{f_{u}} P_{\text {colapso }}
$$

onde $h$ é o número de falhas hiperestáticas 



\section{CONFIABILIDADE ESTRUTURAL E MECÂNICA}

\section{ESTRUTURAL}

A solução de problemas de otimização de risco muitas vezes envolve três loops representativos das grandes áreas adotadas neste trabalho. O primeiro loop, ou loop externo procura o conjunto de variáveis de projeto que minimiza o custo, como a função de custo depende do valor da probabilidade de falha, a mesma é calculada no espaço das variáveis aleatórias (confiabilidade) em um loop interno. Por sua vez, a probabilidade de falha só pode ser calculada com a resposta mecânica do problema, que por sua natureza não linear é também iterativa. A Figura 3.1 esquematiza este processo.

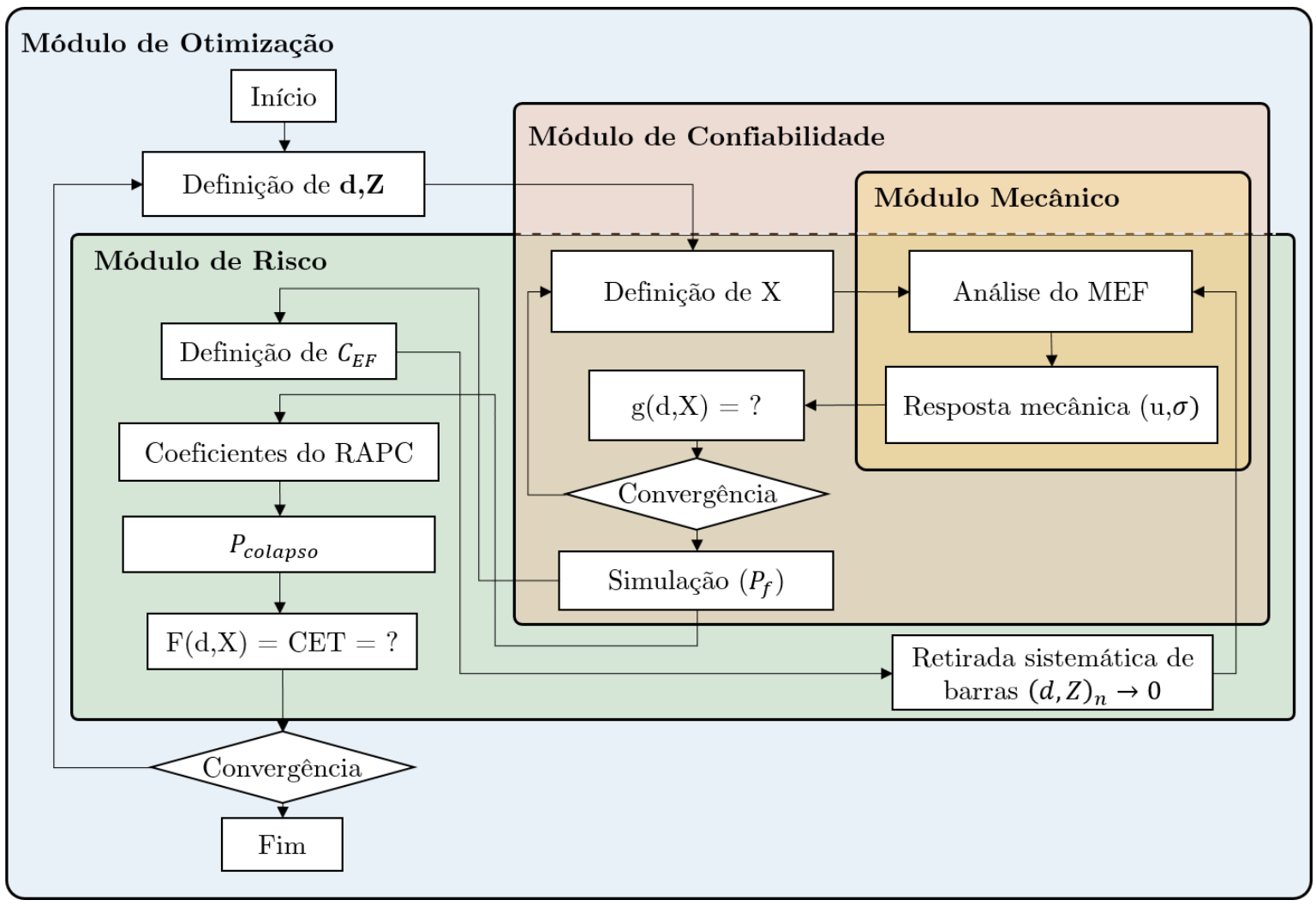

Figura 3.1 - Encadeamento dos módulos para projeto otimizado de risco. Fonte: Adaptado de Pedrosa e Beck (2018). 
O código computacional desenvolvido conta com um conjunto de arquivos de entrada. A Figura 3.2 apresenta de forma resumida as principais informações de cada módulo. Esta entrada é também dependente entre si, os módulos de entrada de confiabilidade e de otimização fornecem os parâmetros aleatórios para as variáveis mecânicas.

\begin{tabular}{|c|c|c|}
\hline Confiabilidade & Cenário Mecânico & Otimização \\
\hline $\begin{array}{ll}\text { - } & \text { Tipo de problema } \\
\text { - } & \text { Túmero de EEL de análise } \\
& \text { mecânica } \\
\text { - } & \text { Dados de Vas ou RVs } \\
\text { - } & \text { Opções de VAs } \\
& \text { Opcões de métodos } \\
& \text { de simulação }\end{array}$ & $\begin{array}{l}\text { - Parâmetros do MEF } \\
\text { • Materiais } \\
\text { • Seções } \\
\text { • Nós } \\
\text { • Forças } \\
\text { - Elementos } \\
\text { - Tipo de análise } \\
\text { - Tipo de Tensão } \\
\text { Passos de Carga }\end{array}$ & 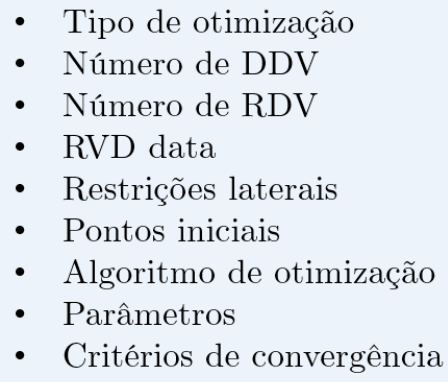 \\
\hline
\end{tabular}

Figura 3.2 - Composição dos arquivos de entrada de cada módulo.

Fonte: elaborado pela autora.

\subsection{Restrições do Problema Probabilístico}

Seja $g_{i}^{j}(\boldsymbol{d}, \boldsymbol{Z}, \boldsymbol{X})$ uma função de estado limite (EEL) que representa as restrições mecânicas. As funções $g_{i}^{j}(\boldsymbol{d}, \boldsymbol{Z}, \boldsymbol{X})$ são escritas em função da resposta da estrutural do problema. No entanto, a avaliação de $g_{i}^{j}(\boldsymbol{d}, \boldsymbol{Z}, \boldsymbol{X})$ não é feita diretamente pois é necessário um processo numérico baseado no modelo mecânico iterativo de elementos finitos posicionais (para os casos de não linearidade geométrica) para avaliar esforços e deslocamentos da estrutura.

O índice $j$ se refere às falhas de caráter local a cada elemento. São elas: falhas por tensão de tração (escoamento) e de compressão (esmagamento e falhas por flambagem elástica) e falhas por instabilidade devido a snap-through. As falhas são caracterizadas localmente pois o algoritmo de colapso progressivo analisa cada elemento individualmente. Neste sentido, a flambagem é conduzida apenas localmente. 


\section{Tensão}

Os autores Mogami et al. (2006) destacam que tanto o domínio da probabilidade de ocorrência de falhas relacionadas à tração quanto de compressão devem ser considerados uma vez que a mudança de configuração durante a otimização pode levar a uma inversão do comportamento dos elementos. De acordo com as simplificações adotadas no problema, admitese que ocorre falha ao se atingir a tensão de escoamento admissível. As EELs para esmagamento por compressão e ruptura por tração são encontradas relacionando tensão admissível do material com a tensão devido às forças internas atuantes no elemento. No caso, as equações são escritas em força, dadas por:

$$
\begin{gathered}
g_{i}^{\text {comp }}(\boldsymbol{d}, \boldsymbol{Z}, \boldsymbol{X})=-\sigma_{y_{i}} A_{i}(\boldsymbol{d}, \boldsymbol{Z})+N_{i}(\boldsymbol{d}, \boldsymbol{Z}, \boldsymbol{X}) \\
g_{i}^{\text {tração }}(\boldsymbol{d}, \boldsymbol{Z}, \boldsymbol{X})=\sigma_{y_{i}} A_{i}(\boldsymbol{d}, \boldsymbol{Z})-N_{i}(\boldsymbol{d}, \boldsymbol{Z}, \boldsymbol{X})
\end{gathered}
$$

É importante salientar que a tensão nas barras removidas não é conferida, pois considerase que essas barras não contribuem para o equilíbrio da estrutura.

\section{Flambagem}

Na flambagem elástica a peça pode perder sua estabilidade sem que o material tenha atingido a sua tensão de escoamento. A tensão crítica para ocorrer a flambagem elástica não depende da tensão de escoamento do material, mas sim de seu módulo de Young $(E)$.

No caso de treliças, os elementos estão ligados a nós articulados. Sendo assim, o comprimento efetivo $L_{e}$ é igual ao comprimento do elemento $\left(L_{i}\right)$, escritos simplificadamente por L. Para falha por flambagem elástica considera-se a tensão crítica de Euler, escrita em função da esbeltez $\lambda$, definida em função do raio de giração $k$ :.

$$
\sigma_{i}^{c r}=\frac{\pi^{2} E A}{\lambda^{2}} \text { onde } \lambda=\frac{L}{k}, k=\sqrt{\frac{I}{A}}
$$


onde $i$ identifica a barra analisada, $I$ é a inércia da seção e $A$ é a área da seção transversal da barra.

Assumindo a área das barras como circular, a tensão crítica de Euler é proporcional à área da seção transversal de cada barra $i$, uma vez que a inércia da seção circular é um quarto da sua área $\left(I=\frac{1}{4} A\right)$

$$
\sigma_{i}^{c r}=-\frac{\pi^{2} E_{i} A_{i}}{4 L_{i}^{2}}, i=1, \ldots, m
$$

a tensão crítica na barra $i$, assume valor negativo correspondente a tensão de compressão. $L_{i}, E_{i}, A_{i}$ são o comprimento, o modulo de elasticidade e a área da seção transversal para cada barra $i$.

As EELs de flambagem são dadas por:

$$
g_{i}^{\text {flamb }}= \begin{cases}\frac{\sigma_{y_{i}}}{\sigma_{i}^{c r}}-1 \leq 0 & \text { se } A_{i}>A_{i}^{L} \\ 1 & \text { se } A_{i}=A_{i}^{L}\end{cases}
$$

onde $A_{i}^{L}$ é a área mínima ou limite inferior da área do elemento $i$.

Da mesma forma, somente as equações de estado limite de barras remanescentes são avaliadas. Para assegurar que as restrições sejam avaliadas tanto no regime pré como pós falha, propõe-se que a força normal nos elementos seja comparada a cada passo de carga até o carregamento total. Considera-se, para cada elemento, o valor mais crítico entre os três estados limites.

\section{Falhas de instabilidade por snap- through}

A falha por snap-through capturada pelo modelo mecânica não linear geométrico é descrita comparando-se forças internas atuantes no elemento à força limite da estrutura. A força limite é obtida a partir da constatação de autovalores negativos em dado passo de carga do algoritmo mecânico.

$$
g_{\text {instab }}=P_{\text {limit }}-P
$$


onde $P_{\text {limit }}$ é expresso em $\mathrm{kN}$, equivalendo à uma porcentagem do carregamento aplicado e portanto, a comparação é feita com a força equivalente $(P)$ em cada barra contabilizando as diferentes seções transversais.

\subsubsection{Exemplo de avaliação das restrições}

Neste exemplo, utiliza-se uma treliça abatida de duas barras, cuja configuração, carregamento e propriedades geométricas das barras estão dispostas na Figura 3.3

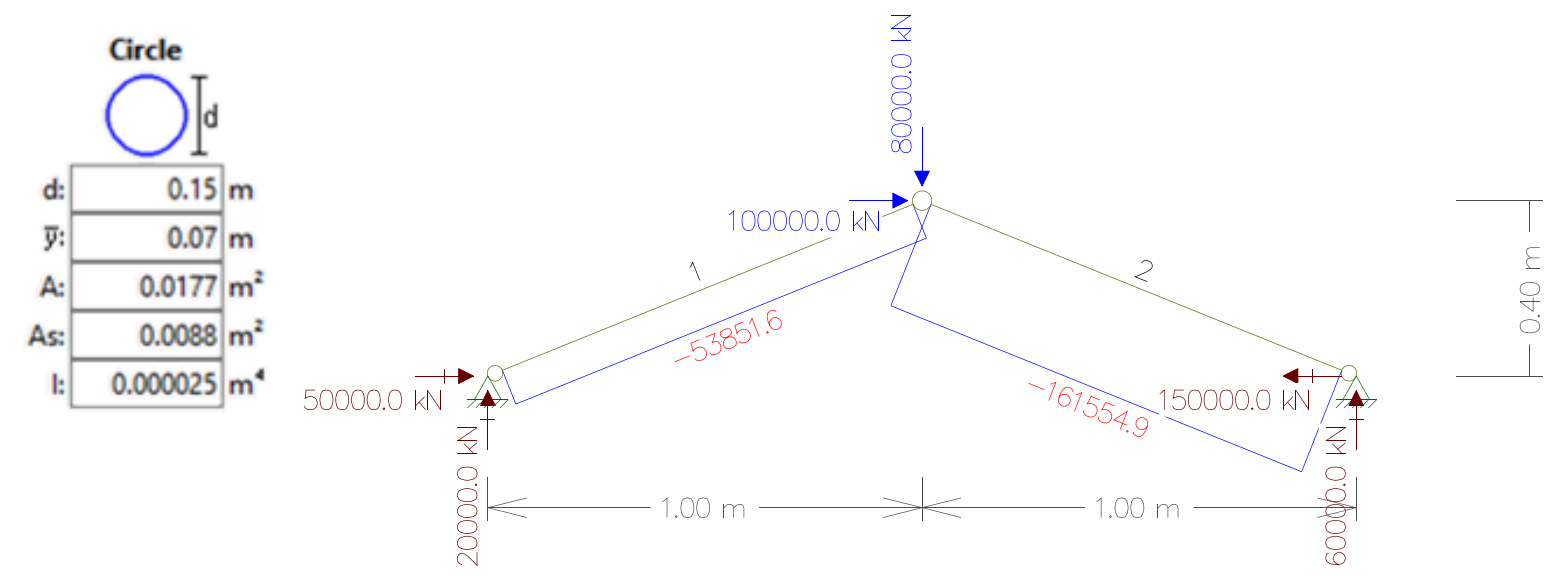

Figura 3.3 - Solução linear da treliça abatida de duas barras pelo Software Ftool ${ }^{\circledR}$ (Martha, 2018).

Os dados foram inseridos no modelo mecânico do problema gerando três tabelas, da Tabela 3.1 a Tabela 3.3 que foram replicadas de acordo com a saída do programa afim de valida-lo. Na Tabela 3.1, a primeira coluna se refere à tensão axial, ou força normal nas barras, as colunas seguintes se referem às EELs de: tração - Eq. (3.2), compressão - Eq.(3.1), flambagem - Eq. (3.5) e falha por instabilidade - Eq. (3.6). Após inflexão das barras no passo 0.9, as barras que estavam sendo comprimidas passar a ser tracionadas e novos modos de falha são considerados.

Caso apenas o passo final fosse verificado, somente seriam computadas falhas por tração. No entanto, a análise dos passos de carga permite verificar falhas por flambagem e compressão no passo anterior à inflexão (passo 0.8). Os valores considerados para as EELs, no caso NLG, são os menores valores de cada coluna, ou seja, a pior situação para cálculo da $P_{f}$, vide Tabela 
3.2. Enquanto no caso linear, o carregamento é aplicado em sua totalidade, proporcional ao passo 0.1 , vide Tabela 3.3.

Tabela 3.1 - Valores de saída do StRAnD-FEA ${ }^{\circledR}$ :análise não linear geométrica. Fonte: elaborado pela autora.

\begin{tabular}{|c|c|c|c|c|c|}
\hline USS & \multicolumn{5}{|c|}{ LoadStep: 0.10} \\
\hline $1 \mid$ & $-5.6031 E+06 \mid$ & $1.0000 \mathrm{E}+001$ & $7.5621 \mathrm{E}+06$ & $3.7741 \mathrm{E}+07 \mid$ & $0.0000 \mathrm{E}+$ \\
\hline & $-1.6346 \mathrm{E}+07 \mid$ & $1.0000 \mathrm{E}+001$ & $-3.1804 \mathrm{E}+06$ & $2.6998 \mathrm{E}+07 \mid$ & $0.0000 E+$ \\
\hline \multicolumn{6}{|c|}{ LoadStep: 0.80} \\
\hline 1| & $-7.3043 E+07 \mid$ & $1.0000 \mathrm{E}+001$ & $-5.9877 \mathrm{E}+07 \mid$ & $-2.9698 \mathrm{E}+07 \mid$ & .0 \\
\hline & -1.5 & $1.0000 \mathrm{E}+001$ & $-1.4340 \mathrm{E}+$ & & 0.0 \\
\hline \multicolumn{6}{|c|}{ LoadStep: 0.90} \\
\hline 1 & $1.3577 \mathrm{E}+08$ & $.2261 \mathrm{E}+08 \mid$ & $1.0000 \mathrm{E}+$ & $1.0000 \mathrm{E}+001$ & -1.35 \\
\hline & $3.7084 E+07 \mid$ & $2.3918 E+07 \mid$ & $1.0000 \mathrm{E}+001$ & $1.0000 \mathrm{E}+001$ & $-3.7084 \mathrm{E}+$ \\
\hline \multicolumn{6}{|c|}{ LoadStep: 1.00} \\
\hline & & & $1.0000 \mathrm{E}+$ & & \\
\hline 21 & $4.0246 E+07 \mid$ & $-2.7080 E+07 \mid$ & $1.0000 \mathrm{E}+001$ & $1.0000 \mathrm{E}+001$ & $0.0000 \mathrm{E}+$ \\
\hline
\end{tabular}

Tabela 3.2 - Valores de saída do StRAnD-FEA ${ }^{\circledR}$ :análise não linear. Fonte: elaborado pela autora.

\begin{tabular}{r|rl|l|l|l} 
\#TRUSS | & AXIAL FORCE | & YIELDING | & SQUASHING | & BUCKLING | & SNAP \\
$1 \mid$ & $1.5008 \mathrm{E}+08 \mid$ & $-1.3691 \mathrm{E}+08 \mid$ & $-5.9877 \mathrm{E}+07 \mid$ & $-2.9698 \mathrm{E}+07 \mid$ & $-1.3577 \mathrm{E}+07$ \\
$2 \mid$ & $4.0246 \mathrm{E}+07 \mid$ & $-2.7080 \mathrm{E}+07 \mid$ & $-1.4340 \mathrm{E}+08 \mid$ & $-1.1322 \mathrm{E}+08 \mid$ & $-3.7084 \mathrm{E}+06$
\end{tabular}

Tabela 3.3 - Valores de saída do StRAnD-FEA ${ }^{\circledR}$ :análise linear. Fonte: elaborado pela autora.

\begin{tabular}{|c|c|c|c|c|c|}
\hline \#TRUSS & AXIAL FORCE I & YIELDING & SQUASHING I & BUCKLING | & SNAP \\
\hline 11 & $-5.3852 E+07 \mid$ & $1.0000 \mathrm{E}+001$ & $-4.0686 \mathrm{E}+07 \mid$ & $-1.0507 \mathrm{E}+07 \mid$ & $0.0000 \mathrm{E}+00$ \\
\hline 21 & $-1.6155 E+08 \mid$ & $1.0000 \mathrm{E}+001$ & $-1.4839 E+081$ & $-1.1821 E+08 \mid$ & \\
\hline
\end{tabular}

\subsection{Avaliação da Probabilidade de falha}

Seja a probabilidade de falha, $P_{f_{i}^{j}}$, dada por:

$$
P_{f}=P\left[g_{i}^{j}(\boldsymbol{d}, \boldsymbol{Z}, \boldsymbol{X}) \leq \mathbf{0}\right]
$$

Valores próximos de zero são obtidos quando a probabilidade de violação do limite é pequena. Desta forma, a probabilidade de falha equivale a uma medida de violação da equação de estado limite.

As probabilidades individuais da Eq. (3.7) são computadas por métodos de confiabilidade bem estabelecidos como FORM ou Simulação de Monte Carlo. Maiores detalhes da teoria de confiabilidade estrutural podem ser obtidos também em Ang e Tang (2007). 


\subsubsection{Simulação de Monte Carlo (MCS)}

A simulação de Monte Carlo consiste em avaliar o valor das funções de desempenho em diferentes pontos do domínio e contabilizar o número de falhas sobre o número total de simulações analisadas. Utiliza-se a função indicadora $I\left[\boldsymbol{x}_{i}\right]=0$ para $\boldsymbol{x} \notin D_{f}$ ou sob o domínio de sobrevivência e $I\left[\boldsymbol{x}_{i}\right]=1$ para $x \in D_{f}$, pertencente ao domínio de falha. De forma que o valor da $P_{f}$ pode ser estimado $\left(\hat{P}_{f}\right)$, com base em uma amostra de tamanho finito por:

$$
\hat{P}_{f}=\frac{1}{n_{s}} \sum_{i=1}^{n_{s}} I\left[\boldsymbol{x}_{i}\right]=\frac{n_{f}}{n_{s}}
$$

Onde $n_{f}$ é o número de falhas encontradas quando $I\left[\boldsymbol{x}_{i}\right]=1$. Quanto menor a $P_{f}$, maior é o número de simulações $n_{s}$ necessário para se obter uma estimativa com baixo coeficiente de variação.

\subsubsection{Probabilidade de falha do sistema}

No caso de estruturas isostáticas (sistema em série, Figura 3.4a), onde não há redundância, a falha de um componente implica na falha da estrutura. Na Figura $3.4^{\mathrm{a}}$, quando o elemento $E_{2}$ falha, cria-se um caminho de falha a partir deste elemento. Para estruturas hiperestáticas (sistema em paralelo, , Figura 3.4b), a falha do sistema é considerada a partir da falha do primeiro membro isostático $\left\{g_{i} \leq 0\right\}$, dado que tenham ocorrido falhas primárias nos membros hiperestáticos $\left\{h_{i} \leq 0\right\}$. No sistema da Figura $3.4 \mathrm{~b}$, a falha do elemento $E_{2}$ não implica falha do sistema, sendo este elemento caracterizado como redundante.

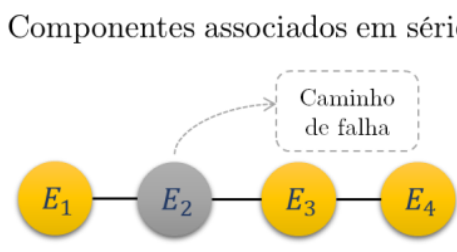

a)

Figura 3.4 - Elementos associados em: a) série e; b) paralelo. Fonte: elaborado pela autora.

Cada elemento hiperestático falhado inicia um caminho de falha mutualmente exclusivo. Segundo Beck et al. (2019), a probabilidade de falha do sistema pode ser avaliada como: 


$$
P_{\text {sys }}=\sum_{i=1}^{m}\left(P\left[\left\{h_{i} \leq 0\right\}\right] P\left[\bigcup_{j=1, j \neq i}^{m}\left\{g_{i} \leq 0\right\}\right]\right)
$$

Para as estruturas isostáticas, derivadas ou não de estruturas hiperestáticas, a probabilidade de falha do sistema é:

$$
P_{\text {sys }}=P\left[\bigcup_{j=1}^{m-h_{g}}\left\{g_{j} \leq 0\right\}\right]
$$

onde $h_{g}$ é o grau hiperestático da estrutura inicial. A avaliação da $P_{f}$ do sistema $\left(P_{s y s}\right)$ para $h_{g}>2$ não é trivial e soluções baseadas em matriz como em Song e Kang (2009) e Nguyen et al. (2010) podem ser aplicadas. Para maiores informações e aprimoramentos sobre confiabilidade de sistemas recomenda-se os trabalhos de Madsen et al. (2006), Ditlevsen e Madsen (2007), Fiondella e Xing (2015) e Melchers e Beck (2018).

\subsubsection{Modos de falha dominantes}

Muitos modos de falha advêm de caminhos de falha semelhantes e, portanto, alguns são mais representativos que outros. Existem estudos que, como alternativa para evitar a necessidade de detectar todos ou grande parte dos modos de falha, consideram apenas os modos de falhas dominantes.

Os métodos para identificar os modos de falha dominantes são classificados em: $i$. Métodos de abordagem probabilística baseados em simulação, e; ii. Métodos de abordagem determinística (SHAO; MUROTSU, 1999). Os métodos determinísticos utilizam valores caraterísticos das variáveis aleatórias de carga e resistência para aumentar a velocidade de busca, mas não asseguram a identificação de todos os modos dominantes.

A abordagem probabilística é representada pela simulação de Monte Carlo e métodos baseados no mecanismo de plastificação como o branch and bound proposto inicialmente por Land e Doig (1960). Este método utiliza um algoritmo de pesquisa probabilística para determinar caminhos de falha, enumerando os caminhos de falha segundo a sua probabilidade de ocorrência. Os caminhos que levam ao colapso da estrutura podem conter rótulas plásticas 
essenciais (que não podem ser retirados do caminho completo de falha) e redundantes (que não contribuem para formação do mecanismo de colapso). O passo a passo pode ser consultado em Pospísilová e Leps (2012), Cerveira et al. (2013) e Wang et al. (2013). Outras técnicas consistem em aplicar programação matemática, especialmente programação linear para procurar sistematicamente os modos de falhas dominantes tal como adotado por Shao e Murotsu (1999) e Kim et al. (2013) ou ainda utilizando meta-modelagem como em Bichon et al. (2011).

\subsection{Análise de Risco do Colapso progressivo}

Até então, a estimativa da probabilidade de falha de um dado evento crítico toma a configuração estrutural como imutável. No entanto, no decorrer do problema de otimização, o evento crítico pode se alterar, e é necessária uma reavaliação das falhas a cada iteração. Sendo assim, é necessária uma abordagem capaz de lidar com variações das propriedades do sistema a cada estimativa da probabilidade de falha do evento crítico.

A avaliação de risco do colapso progressivo (RAPC) desenvolvida por Felipe (2017) verifica o colapso progressivo baseando-se na análise de confiabilidade de sistemas. Nesta formulação modela-se o colapso a partir de perda súbita de força ou ocorrência de fraturas, levando à redistribuição das cargas. Essas falhas estão relacionadas a degradação de rigidez e resistência pelo carregamento ou ainda devido a fenômenos geometricamente não-lineares. Não são considerados efeitos de regime plástico ou impactos e carregamentos adicionais devido a partes desconexas. A metodologia RAPC substitui as metodologias anteriores, de avaliação da $P_{f}$ por árvores de falha ou busca por modos de falha dominantes, por avaliar o risco de falhas progressivas de forma automatizada no decorrer da otimização.

Do ponto de vista de custo computacional, a RAPC necessita de análises mecânicas e de confiabilidade para computar a probabilidade de falha por colapso progressivo, porém não necessita de uma análise prévia da redistribuição de esforços e de uma descrição complexa das possíveis falhas condicionais que possam existir. À medida em que a configuração se altera essas 
falhas são calculadas diretamente, tornando o RAPC um método eficiente e preciso para medir o colapso progressivo durante mudanças de configuração.

Seja, $P\left[\boldsymbol{F}_{i}\right]$ a probabilidade de falha de um elemento estrutural $E_{i}$ dado os $n$ diferentes modos de falha e $\boldsymbol{F}$ um vetor que engloba os múltiplos modos de falha da estrutura. As probabilidades de falha condicionais de um segundo elemento estrutural falhar dado a falha do primeiro $P\left[\boldsymbol{F}_{j} \mid \boldsymbol{F}_{i}\right]$ utilizam as EELs já definidas, mas consideram a redistribuição de esforços. Essa redistribuição de esforços é feita assumindo áreas ínfimas $\left(A \approx 0\right.$ da ordem $\left.10^{-10} \mathrm{~m}\right) \mathrm{a}$ elementos que falharam. Já $P\left[\boldsymbol{F}_{k} \mid \boldsymbol{F}_{i, j}\right]$ representa probabilidades condicionais duplas de um terceiro elemento estrutural falhar dado que o primeiro e o segundo falhem. Como hipótese do método, assume-se que a falha do terceiro elemento resulta em colapso total (sem possibilidade de redistribuição de esforços).

A probabilidade de ocorrência do caminho de falha $c_{i}$, iniciado pela falha do Ei, é dada por:

$$
P\left[c_{i}\right]=\sum_{\substack{i=1 \\ j \neq i}}^{m} P\left[\boldsymbol{F}_{i}\right] \cdot P\left[\boldsymbol{F}_{j} \mid \boldsymbol{F}_{i}\right] \cdot P\left[\bigcup_{\substack{k=1 \\ k \neq i \\ k \neq j}}^{m}\left(\boldsymbol{F}_{k} \mid \boldsymbol{F}_{i, j}\right)\right]
$$

e a probabilidade de colapso do sistema é dada pela somatória das probabilidades de colapso dos subsistemas individuais ou caminhos de falha iniciados pelo elemento $E_{i}$. De forma mais geral tem-se:

$$
P_{\text {colapso }}=\sum_{i=1}^{n} \sum_{\substack{j=1 \\ j \neq i}}^{n} P\left[\boldsymbol{F}_{i}\right] \cdot P\left[\boldsymbol{F}_{j} \mid \boldsymbol{F}_{i}\right] \cdot\left(\sum_{\substack{m=1 \\ m \neq i \\ m \neq j}}^{n} P\left[\overline{\boldsymbol{F}}_{m}\right]-\sum_{\substack{m=2 \\ m \neq i \\ m \neq j}}^{n} \sum_{\substack{k \neq 1 \\ k \neq j \\ k<m}}^{m-1} P\left[\overline{\boldsymbol{F}}_{m} \mid \overline{\boldsymbol{F}}_{k}\right] \cdot P\left[\overline{\boldsymbol{F}}_{k}\right]\right)
$$

A $P_{\text {colapso }}$ avalia a probabilidade de falha da estrutura independente da causa. É uma expressão mais geral na avaliação do risco do colapso progressivo. Engloba termos de primeira 
e segunda ordem das probabilidades de falhas condicionais e a contribuição da redundância que cada subsistema vai proporcionar na redistribuição de esforços.

Essa metodologia assume independência dos eventos, no entanto, considera termos de segunda ordem pois embora as probabilidades de falha possam ser pequenas, o custo esperado de falha pode assumir ordem de grandeza compatíveis.

Admitindo a independência de tais eventos, o coeficiente de vulnerabilidade ao colapso progressivo (CVC) de um elemento é definido pela multiplicação entre os coeficientes de vulnerabilidade (CV) e de importância para o colapso (CIC) (CHEN et al., 2016).

$$
C V C_{i}=C V_{i} \cdot C I C_{i}
$$

O diagrama da Figura 3.5 representa esta definição:

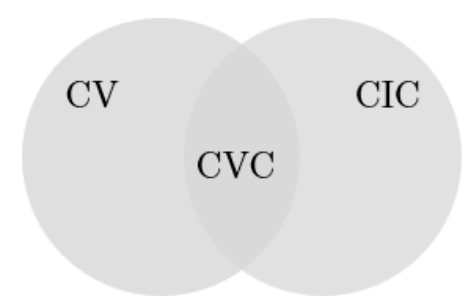

Figura 3.5 - Representação esquemática do CVC. Fonte: Felipe (2017).

O coeficiente de vulnerabilidade $(\mathrm{CV})$ é dado pela relação entre a probabilidade de falha deste elemento $P\left[\boldsymbol{F}_{i}\right]$ e a soma das probabilidades de falha de todos os elementos no subsistema.

$$
C V_{i}=\left(\frac{P\left[\boldsymbol{F}_{i}\right]}{\sum_{i=1}^{m} P\left[\boldsymbol{F}_{i}\right]}\right)
$$

O coeficiente de importância para o colapso (CIC) de um elemento $E_{i}$ é definido como a relação entre a probabilidade de ocorrência do caminho de falha $c_{i}$, iniciado pela falha do $E_{i}$, pela probabilidade de falha do máximo caminho $P\left[c_{i}\right]$, dado pela Eq. (3.11). A equação que define o CIC é expressa por:

$$
C I C_{i}=\left(\frac{P\left[c_{i}\right]}{\max P\left[c_{i}\right]}\right)
$$

Maiores detalhes dos coeficientes da RAPC são mostrados no Item 5.1 



\section{CONFIABILIDADE ESTRUTURAL E}

\section{OTIMIZAÇÃO ESTRUTURAL}

A partir da treliça de duas barras usada para exemplificar os diferentes modos de falha, é feita a verificação do algoritmo de confiabilidade. A Tabela 4.1 mostra valores médios do índice de confiabilidade $(\beta)$ para EELs com $P_{f}$ de diferentes ordens de grandeza. O índice $\beta$ está relacionado com a $P_{f}$ a partir da função de distribuição acumulada normal padrão (ANG e TANG, 2007):

$$
P_{f}=\Phi(-\beta)=1-\Phi(\beta)=1-\int_{-\infty}^{\beta} \frac{1}{\sqrt{2 \pi}} \exp \left[\frac{z^{2}}{2}\right] d z=\int_{-\infty}^{-\beta} \frac{1}{\sqrt{2 \pi}} \exp \left[\frac{-z^{2}}{2}\right] d z
$$

Valores de $\beta$ acima de 3 indicam $P_{f} \cong 10^{-3}$ enquanto valores menores indicam $P_{f}$ mais elevadas, valores negativos indicam $P_{f}>0.5$.

A análise de confiabilidade por FORM só é possível para casos nos quais as EELs são deriváveis. No entanto, a utilização de módulos mecânicos para avaliar o equilíbrio estrutural dificulta a construção de EELs analíticas e explicitadas em função das VAs do problema.

No problema em questão, as EELs da resposta mecânica linear foram descritas analiticamente por se tratar de um problema simples, possibilitando a avaliação pelo FORM para comparação. Na Tabela 4.1, o FORM é avaliado uma única vez a partir da média das VAs e comparado ao MC simples, que é aplicável a problemas de otimização de risco apesar de pouco eficiente. Os valores de $\beta$ pelo MC representam uma média entre 50 simulações com $10^{4}$ realizações por simulação tanto do $\mathrm{MC}$ simples quanto do $\mathrm{MC}$ com amostragem por hipercubo latino (LHS) descrito e implementado no Software por Santos (2014). 
Tabela 4.1 - Índice de confiabilidade médio para casos linear e não linear geométrico. Fonte: elaborado pela autora.

\begin{tabular}{|c|c|c|c|c|c|}
\hline \multirow{2}{*}{ Linear } & & $\boldsymbol{\beta}_{\text {comp }_{\mathbf{2}}}$ & $\boldsymbol{\beta}_{\text {tração }_{\mathbf{1}}}$ & $\boldsymbol{\beta}_{\text {flamb }_{\mathbf{2}}}$ & $\boldsymbol{\beta}_{\text {snap }}$ \\
\cline { 2 - 7 } & FORM & 0.031172 & 0.822913 & 1.95356 & 8.8419 \\
\cline { 2 - 7 } & MC simples & 0.0529377 & 0.822607 & 1.97149 & - \\
\cline { 2 - 7 } NLG & MC+LHS & 0.052498 & 0.826061 & 1.9691 & - \\
\hline & MC simples & 0.476025 & -0.05270 & 2.22718 & 0.50816 \\
\cline { 2 - 6 } & MC + LHS & 0.476071 & -0.04931 & 2.22838 & 0.509608 \\
\hline
\end{tabular}

Para simplificar, foi exposto somente o valor do índice de confiabilidade $\beta$ para os modos de falha por compressão na barra $2\left(\beta_{c o m p}\right)$, por tração na barra $1\left(\beta_{\text {tração }_{1}}\right)$, por flambagem na barra $2\left(\beta_{\text {flamb }_{2}}\right)$ e por instabilidade da estrutura devido a snap-through $\left(\beta_{\text {snap }}\right)$. Para as simulações foi usado o modelo mecânico do StRAnD-FEA com análise linear e não linear geométrica (NLG). Entre as simulações com Monte Carlo, a utilização do LHS mostrou menor variação dos resultados quando comparado à amostragem simples. Na análise NLG, as EELs apresentaram diferentes valores de $\beta$ evidenciando diferenças claras entre as análises mecânicas linear e NLG. No entanto, a análise NLG tem custo computacional maior que justifica a busca por alternativas para avaliar a confiabilidade de forma mais econômica ou até mesmo, um número menor de vezes.

\subsection{Simulação por média ponderada classificada (RWASM)}

A necessidade de gerar amostras para cada iteração da otimização na simulação de Monte Carlo bruta e seu acoplamento com a mecânica NLG, torna a confiabilidade muito custosa computacionalmente. Uma maneira mais eficiente que a simples aplicação do MC pode ser a adoção Método de Simulação por Média Ponderada Classificada (RWASM) de Rashki et al. (2012) e Okasha (2016).

O RWASM pondera os pontos amostrais por um peso segundo sua importância e depois classifica-os, a fim de considerar apenas aqueles mais significativos. De acordo com os autores, o método pode ser dividido em três etapas: $i$ ) geração do domínio de amostragem; ii) avaliações 
dos pesos e classificação e; iii) estimativa da probabilidade de falha. Recomenda-se a leitura dos artigos para uma descrição detalhada das etapas.

\subsection{RWASM na RBDO}

Para aplicação do RWASM em problemas de RBDO, depois da amostragem uniforme, é necessário avaliar a função indicadora $I_{F}$ de todos os pontos amostrais e separar o conjunto de pontos amostrais no domínio de segurança $\boldsymbol{S}$.

$$
\left.\boldsymbol{S}=\left\{\bar{X}_{l}, \bar{Z}_{l}\right\} \in(\boldsymbol{X}, \boldsymbol{Z}) \mid I_{F}\left[g\left(\bar{X}_{l}, \bar{Z}_{l}\right)\right]=0\right\}, i=1, \ldots, n_{s}
$$

onde $n_{s}>n_{a}$, ou seja, o número de pontos amostrais no domínio de segurança $\left(n_{a}\right)$ é menor que o número de pontos amostrais totais $\left(n_{s}\right)$.

Então, o peso de todas as amostras é avaliado. A posição de cada variável de projeto é considerada como valor médio da VA, assim a j-ésima amostra tem média $\mu_{z}=$ $\left[d_{1 j}, d_{2 j}, \ldots, d_{n_{z} j}\right]^{T}$. E, de acordo com Rashki et al. (2014), o peso é calculado por:

$$
W_{j}=\left\{\prod_{i=1}^{n_{x}} P D F\left(\boldsymbol{X}_{i}, \mu_{X_{i}}, \sigma_{X_{i}}\right)\right\} \cdot\left\{\prod_{k=1}^{n_{z}} P D F\left(\boldsymbol{Z}_{\boldsymbol{k}}, d_{X_{k}}, \sigma_{k}\right)\right\}
$$

Agora a $P_{f}$ pode ser avaliada de acordo com:

$$
P_{f_{j}}=\frac{\sum_{i=1}^{n_{a}} I_{F}(i) w_{j}(i)}{\sum_{i=1}^{n_{a}} w_{j}(i)}
$$

No passo final, as soluções candidatas pertencentes ao conjunto $\{\boldsymbol{S}\} \operatorname{com} P_{f} \leq P_{f_{\text {alvo }}}$ são separadas.

$$
\left.\boldsymbol{R}=\left\{\bar{X}_{l}, \bar{Z}_{l}\right\} \in\{\boldsymbol{S}\} \mid P_{r}\left[g\left(\bar{X}_{l}, \bar{Z}_{l}\right)<0\right] \leq P_{f_{\text {alvo }}}\right\}, i=1, \ldots, n_{s}
$$

onde $\{\boldsymbol{R}\}$ é o domínio viável.

A eficiência do RWASM está na utilização de uma única amostragem para avaliação da $P_{f}$ durante todo o problema de otimização devido a característica de flexibilidade dos pesos quando são usadas variáveis de projeto aleatórias. Quando os intervalos são escolhidos adequadamente, a abordagem apresenta bons resultados em termos de número de avaliações 
da EEL vs. precisão, ou seja, concordância com a $P_{f_{\text {alvo }}}$ e baixo coeficiente de variação entre simulações.

\subsection{RWASM aplicado à otimização de risco}

Diferente da RBDO, a otimização de risco não possui restrições em termos de confiabilidade. Nestes problemas, a confiabilidade da estrutura só é conhecida após a solução pois o valor do vetor $\boldsymbol{\beta}$ depende dos custos atribuídos na função objetivo. Por $\beta$ ser uma solução da otimização, a otimização de risco permite identificar modos de falha críticos e, posteriormente, definir estratégias diretas para diminuir custos esperados de falha.

Após revisar a literatura, entende-se que a adoção do RWASM na otimização de risco ainda não foi estudada em detalhes e carece de informações para: i) gerar um domínio de amostragem sem conhecer a ordem de grandeza de $\beta$ da estrutura ótima; ii) lidar com múltiplas EELs e estimar quantitativamente múltiplas probabilidades de falha; e; dentro da otimização topológica, iii) lidar com VAs de projeto com domínio laterais maiores que o domínio de amostragem e alteração da média durante a otimização e, consequentemente, do domínio de amostragem das mesmas.

\subsubsection{Dependência da EELs às VAs do problema}

A escolha do intervalo de simulação para cada variável aleatória é uma etapa importante do RWASM. Admitindo-se $\beta$ conhecido, o domínio de amostragem pode ser calculado pela Eq. (4.6) que substitui a tabela 1 de Rashki et al. (2012), vide Tabela 4.2. A expressão da Eq. (4.6) correlaciona o valor $\epsilon$, definidos um a um no artigo de Rashki et al. (2012), a $\beta$ somando uma correção $\varepsilon=2$, onde $\Phi_{C D F}$ é a função de probabilidade acumulada gaussiana padrão da variável em questão:

$$
\epsilon=\Phi_{C D F}(-(\beta+\varepsilon))
$$


Desta forma, $\beta$ pode ser usado para definir o tamanho dos intervalos sem necessidade de avalia-los um a um de acordo com a tabela do artigo de Rashki et al. (2012). A Figura 4.1 mostra a coerência entre os valores da tabela e da Eq. (4.6).

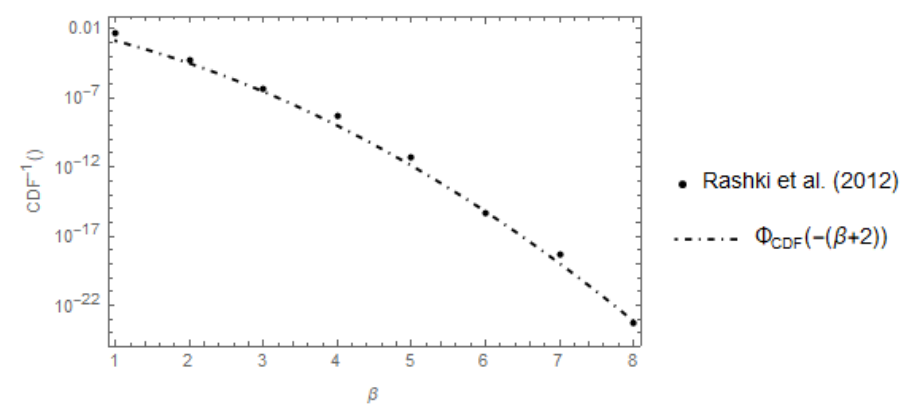

Figura 4.1 - Função que substitui a tabela dos autores Rashki et al. (2012).

Fonte: elaborado pela autora.

\begin{tabular}{|c|c|c|c|c|c|c|c|c|}
\hline Assumed reliability index & 1 & 2 & 3 & 4 & 5 & 6 & 7 & 8 \\
\hline $\begin{array}{l}\text { Lower point of proposed } \\
\text { interval }\end{array}$ & $F^{-1}\left(5 \times 10^{-3}\right)$ & $F^{-1}\left(5 \times 10^{-5}\right)$ & $F^{-1}\left(5 \times 10^{-7}\right)$ & $F^{-1}\left(5 \times 10^{-9}\right)$ & $F^{-1}\left(5 \times 10^{-12}\right)$ & $F^{-1}\left(5 \times 10^{-16}\right)$ & $F^{-1}\left(5 \times 10^{-19}\right)$ & $F^{-1}\left(5 \times 10^{-24}\right)$ \\
\hline $\begin{array}{l}\text { Upper point of proposed } \\
\text { interval }\end{array}$ & $\begin{array}{l}F^{-1}(1- \\
\left.5 \times 10^{-3}\right)\end{array}$ & $\begin{array}{l}F^{-1}(1- \\
\left.5 \times 10^{-5}\right)\end{array}$ & $\begin{array}{l}F^{-1}(1- \\
\left.5 \times 10^{-7}\right)\end{array}$ & $\begin{array}{l}F^{-1}(1- \\
\left.5 \times 10^{-9}\right)\end{array}$ & $\begin{array}{l}F^{-1}(1- \\
\left.5 \times 10^{-12}\right)\end{array}$ & $\begin{array}{l}F^{-1}(1- \\
\left.5 \times 10^{-16}\right)\end{array}$ & $\begin{array}{l}F^{-1}(1- \\
\left.5 \times 10^{-19}\right)\end{array}$ & $\begin{array}{l}F^{-1}(1- \\
\left.5 \times 10^{-24}\right)\end{array}$ \\
\hline
\end{tabular}

Tabela 4.2 - Reprodução da tabela 1. Fonte: Rashki et al. (2012).

O espaço de amostragem é obtido a partir das VAs. No entanto, existe um erro associado a amostragem de variáveis aleatórias que são incorretamente associadas a uma EEL. Isto porque as EELs são implícitas e nem todas dependem do conjunto completo das VAs. Este erro manifesta-se na quantificação do produto do $w_{i}$ de cada ponto amostral e, consequentemente, no número de pontos amostrais suficientes, calculados a partir do valor $k$, para estimar a $P_{f}$.

Para entender a consequência desse produto de pesos não necessários, é escolhido um problema de confiabilidade simples, como o da treliça de duas barras. Analisa-se somente uma EEL, por exemplo, a de falha por flambagem de Euler para a barra 1. A $P_{f}$ foi estimada usando quatro conjuntos diferentes de variáveis aleatórias, sendo que em todos os casos, somente uma VA é necessária para avaliar a EEL, que é a área da barra 1. A Figura 4.2 mostra a variação, a cada incremento $k$, de três coeficientes do método RWASM: o produto de pesos sobre o peso total $\left(w_{r} / w_{t}\right)$ após classificação; o resto e; a valor da $P_{f}$. A linha azul, acima, é a referência correta. 
a)

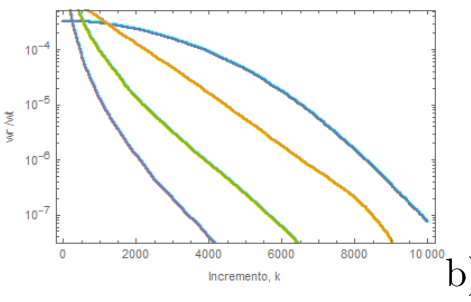

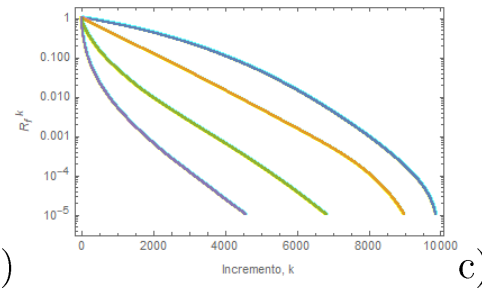

c)

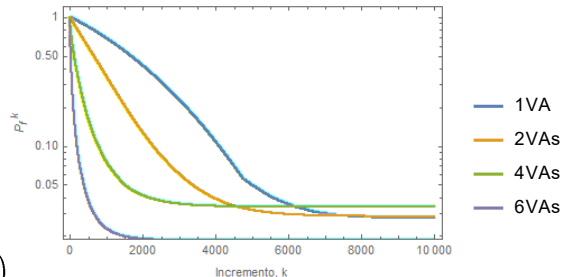

- 4VAs - 6VAs

Figura 4.2 - Influência do excesso de VAs na estimativa da $P_{f}:$ a) $\left.w_{r}^{k} / w_{t} ; b\right) R_{f}^{k} e$; c) $P_{f}^{k}$.

Fonte: elaborado pela autora.

O aumento de VAs usadas para gerar os pontos amostrais altera a avaliação e ordenação dos pesos que por sua vez, seleciona um valor menor de $k$ levando a diferenças significativas na estimativa da $P_{f}$.

\subsubsection{Valor de $\beta$ - Ausência de restrição}

O item anterior admitiu a existência de um $\beta_{\text {alvo }}$ conhecido para cada EEL. Contudo, o

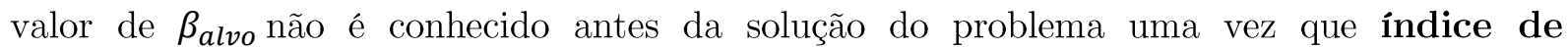
confiabilidade $\beta$ da estrutura é um resultado da otimização de risco.

Diferentes valores de $\beta$, refletem em diferentes intervalos de amostragem das VAs conforme mostrado na Figura 4.3a). Valores menores de $\beta$ estão associados a domínio de amostragem menores, consequentemente, a representatividade dos pontos amostrais varia pouco, como se verifica no decréscimo suave da primeira curva de cima para baixo (azul) da Figura 4.3b). Conforme o valor de $\beta$ aumenta maior é inclinação de decréscimo da curva de $R_{f}^{k}$. Domínios extensos apresentam mais pontos amostrados sobre as caudas das distribuições. Nestes casos, a variabilidade dos pesos calculados é maior e somente alguns pontos irão possuir representatividade significativa.

a)

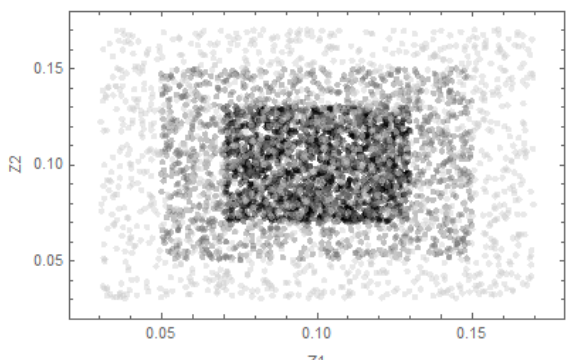

Figura 4.3 - a) Distribuição Uniforme das variáveis Z1 e Z2 no intervalo em função de método II - $\beta_{\text {alvo }}$; b) Variação de $R_{f}^{k}$ após decréscimos sucessivos $w_{r_{k}} / w_{t}$.

Fonte: elaborado pela autora. 
A Figura 4.3 exemplifica o conjunto de pontos amostrados (1500) para diferentes casos, tendo por base duas variáveis com distribuição normal $Z 1: N \sim(0,1 ; 0,01)$ e $Z 2: N \sim(0,1 ; 0,01)$. À direita, para os mesmos casos, mostra-se o decréscimo incremental pesos relativos $w_{r_{i}} / w_{\text {total }}$, iniciando por $k=1$, de maior representatividade. A medida dessa subtração é dada por $R_{f}^{k}$, a soma de $k=n_{S}$ incrementos tende a anula-la.

É possível assumir, após as verificações, que o domínio de amostragem das EELs deve ser definido somente pelas VAs que a compõem, usando a ordem de grandeza de $\beta_{\text {alvo }}$ exata para avaliar os limites. A utilização de mais VAs ou de limites irregulares por arbitrar $\beta_{\text {alvo }}$ inicialmente ou considera-lo homogêneo, diminui a eficácia do método, gerando estimativas ruins de $P_{f}$.

O artigo que introduz o método não faz alusão a EELs com diferentes $P_{f_{\text {alvo }}}$ uma vez que a RBDO não precisa da estimação correta da $P_{f}$ somente sua relação entre $P_{f_{\text {alvo }}}$ é suficiente para avaliar a restrição. Recentemente, Hamzehkolaei et al. (2018) exploraram a temática resolvendo problema multiobjetivo de RBDO aplicando o método de simulação ponderado -WSM. Um estudo mais detalhado é necessário para avaliar a aplicabilidade desta solução a problemas de otimização topológica de risco.

\subsubsection{Alteração da média das variáveis de projeto}

A presença da $P_{f}$ na função objetivo da RO implica que a confiabilidade de cada configuração otimizada seja concluída para que o próximo passo da otimização sugira uma nova configuração otimizada. No entanto, é possível que as novas variáveis de projeto tenham-se alterado significativamente a ponto de o intervalo inicial não representar a nova iteração. Isto acontece porque o domínio de busca do problema topológico é maior e incompatível com os domínios do problema de confiabilidade impossibilitando uma boa estimativa da probabilidade de falha. 
Segundo Rashki et al. (2014), o problema de otimização pode usar variáveis de projeto aleatórias desde que os limites laterais da otimização sejam compatíveis com os limites (métodos I e II) definidos em Rashki et al. (2012), contribuindo para gerar resultados mais precisos. Neste caso, o problema de otimização estará limitado à região próxima ao ponto inicial das variáveis de projeto, permitindo que a confiabilidade seja avaliada com a mesma amostragem para todos os pontos.

No entanto, o domínio de busca das variáveis de projeto da otimização topológica deve ser suficientemente grande a fim de não inferir ou viciar qualquer resultado. Ao restringir o espaço de busca inicial, altera-se o tipo de otimização, pois intervalos de busca menores em torno de uma média propiciam uma otimização mais restrita. De tal forma que, a utilização do WASM para problemas de otimização de risco fica restrita a um problema de otimização de tamanho.

Por sua vez, problemas de tamanho tem menores chances de apresentar colapso progressivo de elementos devido aos limites impostos na variação da área dos elementos e à impossibilidade de assumir ausência de elementos.

O esquema da Figura 4.4 sintetiza as informações sobre limites para avaliação da confiabilidade e limites laterais dos diferentes tipos de otimização. Os formatos adotados são arbitrários.

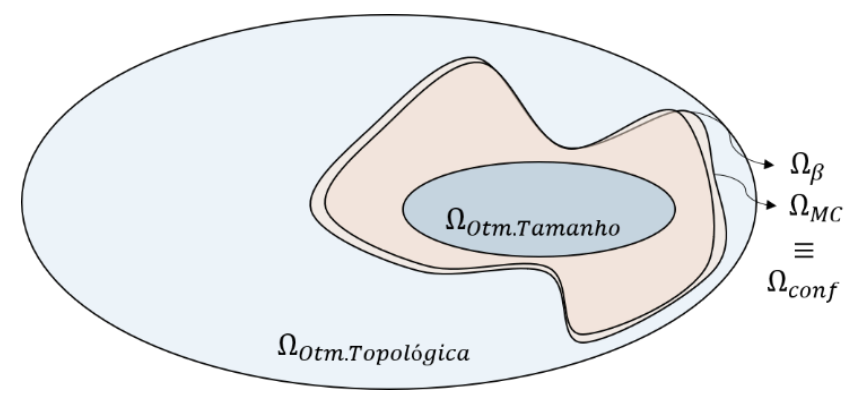

Figura 4.4 - Dominio de amostragem e limites laterais. Fonte: elaborado pela autora.

A otimização topológica possui limites mais abrangentes pois os intervalos de busca possuem limites inferiores bem baixos, próximos a zero, para designar membros que não atuarão estruturalmente para o equilíbrio e que, portanto, poderiam ser retirados da estrutura. Esta 
representação revela que o problema de otimização topológica não pode ser resolvido com uma única amostragem do WASM, pois amostras maiores para o WASM não darão a precisão necessária para os valores da $P_{f}$.

\subsection{Considerações}

A necessidade de gerar diversos conjuntos de amostragem para diversas EELs aproxima o método à amostragem múltipla feita pelo MC bruto. A definição das EELs explicitamente em função das variáveis aleatórias, poderia solucionar o problema de amostragem, mas também permitiria por exemplo, a utilização de métodos de confiabilidade mais simples como o FORM. O uso de $\beta_{\text {alvo }}$ único por sua vez, interfere na confiabilidade individual de cada EEL, um dos resultados da RO. Como é necessário avaliar quantitativamente a $P_{f}$, o método RWASM como foi proposto não apresenta ganho de eficiência para problemas de otimização de risco.

Em vista dos pontos observados e das características do problema em questão, a confiabilidade de cada EEL será avaliada pela simulação de Monte Carlo com variáveis de projeto com limites laterais amplos, possibilitando uma otimização topológica com ocorrência de colapso progressivo. 



\section{OTIMIZAÇÃO ESTRUTURAL E COLAPSO ESTRUTURAL PROGRESSIVO}

A eficiência dos algoritmos de otimização, sejam determinísticos ou estocásticos em problemas de otimização de risco consiste num importante tópico a ser estudado. A função objetivo, ou o custo esperado total (CET) pode ser função de muitas variáveis de projeto e representar vários mínimos locais e descontinuidades, além disso, necessita da avaliação quantitativa da $P_{f}$. Esses problemas necessitam de algoritmos eficientes e capazes de buscar o mínimo global mesmo nessas circunstâncias.

Este trabalho propõe a utilização de um índice atrelado a cada elemento que indica a sua vulnerabilidade ao colapso como medida para auxiliar a otimização. O coeficiente de vulnerabilidade ao colapso (CVC) da RAPC se refere ao elemento na sua atual configuração, sendo assim, as coordenadas nodais são mantidas como constantes e as variáveis de projeto consistem exclusivamente nas áreas das seções transversais.

A aplicação da RAPC diretamente na otimização tem por objetivo direcionar a busca por soluções com baixa vulnerabilidade ao colapso progressivo diminuindo o número de avaliações estruturais com alta probabilidade de falha.

Essa abordagem utiliza os conceitos de otimização irrestrita, descritos em Vanderplaats (1984), para, de modo mais direto possível, propor uma direção de minimização da função objetivo (CET) baseada no CVC. A minimização das áreas é feita segundo a importância de cada elemento evitando a retirada de elementos chave e retirando área dos elementos redundantes. 


\subsection{Propriedades do CVC}

Vamos analisar a equação que define o CVC descrita em Felipe (2017):

$$
C V C_{i}=C V_{i} \cdot C I C_{i}=\left(\frac{P\left[F_{i}\right]}{\sum_{i=1}^{n} P\left[F_{i}\right]}\right)\left(\frac{P\left[c_{i}\right]}{\max \left[P\left[c_{i}\right]\right.}\right)
$$

O CVC é descrito pela multiplicação de probabilidades de falhas associadas ao evento e ao caminho analisado, ambas positivas e menores ou iguais à unidade. O CVC cada elemento, $C V C_{i}$, é um número sempre positivo e menor que 1 . A soma dos $C V C_{i}$ é também positiva e menor ou igual a 1 .

Nas estruturas isostáticas, todo e qualquer caminho resulta em falha, e a probabilidade de ocorrência dos caminhos de falha é proporcional à falha do primeiro membro, $P\left[c_{i}\right]$ é igual a $P\left[\boldsymbol{F}_{i}\right]$ obtidos a partir de uma única análise de confiabilidade da estrutura. Portanto, o CVC dos elementos de estruturas isostáticas pode ser calculado diretamente.

Em uma estrutura redundante e robusta, com probabilidade de falha tendendo a zero, o índice de vulnerabilidade ao colapso progressivo para todas as barras é igual, não havendo distinção entre elas.

$$
C V C_{i}=C V C_{j} \quad \operatorname{para}_{j=1, \ldots, m}^{i=1, \ldots, m}
$$

Como esse índice refere-se a uma probabilidade relativa à estrutura como um todo, a somatória do índice de todas barras é igual a unidade.

$$
\sum_{i=1}^{m} C V C_{i}=1
$$

Portanto, considerando a Eq. (5.2) e a Eq.(5.3), o índice de vulnerabilidade ao colapso progressivo de uma estrutura sem distinção de falha entre elementos é igual a:

$$
C V C_{i}=1 / m \quad i=1, \ldots, m
$$


Estruturas otimizadas por critérios de solicitação/tensão devem, por hipótese apresentar $C V C_{i}>1 / m$ para os elementos remanescentes pois na configuração final todos os elementos estão sendo solicitados e, portanto, são vulneráveis. Os membros retirados apresentariam baixa vulnerabilidade e $C V C_{i}$ próximos de zero devido a sua irrelevância na estrutura otimizada. Para estruturas otimizadas por critérios como o de risco (minimização de CET), não existe um padrão definido para o $C V C_{i}$ dos membros remanescentes pois os mesmos têm contribuições diferentes no equilíbrio estrutural.

\subsection{Abordagem de minimização local pelo pseudo-gradiente}

Neste item serão introduzidos rapidamente os conceitos básicos da otimização irrestrita focando no método da máxima descida. O conhecimento desses conceitos auxiliará na definição de medidas análogas utilizando o CVC da RAPC. Os demais itens se reservam a: organização do algoritmo de busca irrestrita baseado no CVC e comentários sobre o desempenho do algoritmo.

\subsubsection{Método da máxima descida}

Sabe-se que o gradiente é o vetor que indica o sentido e a direção na qual, por deslocamento a partir do ponto especificado, obtém-se o maior incremento possível no valor de uma grandeza. O gradiente de uma função é dado por:

$$
\nabla f\left(d_{i_{0}}\right)=\sum^{i} \frac{\partial f}{\partial d_{i}} \hat{\mathrm{e}}_{i}
$$

O método da máxima descida, bem estabelecido na otimização irrestrita, utiliza o sentido de busca como o sentido contrário ao gradiente. Ou seja, a direção $\alpha_{i_{0}}$ é a direção do antigradiente da função objetivo no ponto $d_{i_{0}}$.

$$
\alpha_{i_{o}}=-\nabla f\left(d_{i_{0}}\right)
$$

Tendo definido a direção (e sentido), a atualização da variável de projeto segue o procedimento iterativo: 


$$
d_{k}=d_{i_{0}}+t \alpha_{i_{0}}
$$

Em que $\alpha_{i_{0}}$ é a direção de busca e $t$ é o tamanho do passo dado ao longo de $\alpha_{i_{0}}$, e $d_{k}$ é uma tentativa do vetor de variáveis de projeto na iteração $k$ da busca pelo melhor passo. A maioria dos métodos determinam o tamanho do passo $t$ por meio de uma busca pelo mínimo da função objetivo localizado na linha determinada pela direção de busca $\alpha_{i_{0}}$ :

$$
t=\arg \min _{t^{*} \geq 0} f\left(d_{k}+t^{*} \alpha_{i_{0}}\right)
$$

esse processo é chamado de busca linear (LUENBERGER e YE, 2008).

\section{Gradiente da função objetivo da otimização de risco}

O Custo Esperado Total (CET), é uma função implícita, e a obtenção do gradiente analítico não é direta. No entanto, é possível estima-lo, por exemplo, pelo método das diferenças finitas.

O método das diferenças finitas é um método de resolução de equações diferenciais que se baseia na aproximação obtida a partir da série de Taylor da função derivada. A derivada primeira pode ser escrita de três formas distintas: progressivas, regressivas ou centradas. A fórmula das diferenças progressivas é exemplificada abaixo:

$$
f^{\prime(x)}=\frac{f(x+h)-f(x)}{h}+o(h)
$$

O termo $h$ é um número muito pequeno, mas grande o suficiente para que não cause instabilidades numéricas nas aproximações das derivadas.

No problema em questão, $h$, corresponderia a um acréscimo ou decréscimo de área em cada elemento. Porém, tal acréscimo de ordem ínfima pode não garantir variação considerável nos custos esperados de falha. Eventualmente podem existir mudanças no valor da função objetivo que são atribuídas às incertezas do problema. Portanto, conforme testes, a avaliação do gradiente por diferenças finitas não proporcionou a informação necessária para verificações no valor da função objetivo do tipo de problema a ser analisado. Além do mais, caso fosse 
adotada, as derivadas parciais com relação às variáveis de projeto (áreas dos elementos) dependeriam da análise RAPC para verificação do colapso progressivo. Tal processo requer um número ainda maior de avaliações da função objetivo.

Surge neste ponto, a ideia de usar as informações do CVC, coeficiente da RAPC, como correspondente às derivadas parciais das variáveis de projeto do problema de otimização. Desta maneira, evita-se a avaliação do gradiente, utilizando um coeficiente já avaliado e que dispõe de uma informação relevante à otimização.

\subsubsection{Paralelos com o CVC}

É possível fazer uma analogia do gradiente com o índice CVC, uma vez que ambos apontam a direção e sentido de crescimento da função CET e da $P_{\text {colapso }}$ respectivamente. De maneira semelhante aos métodos baseados em gradiente, procura-se estabelecer uma métrica, referida como $\nabla_{\mathrm{CVC}}$, que permita direcionar a busca para soluções otimizadas. A Eq. (5.10) reescreve à função objetivo que define o problema da otimização de risco para mostrar a relação entre as medidas de gradiente.

$$
C_{E T}(\boldsymbol{A}, \boldsymbol{Y}, \boldsymbol{X})=\underbrace{C_{c}+\sum_{j=1}^{h} C_{f_{j}} P_{f_{j}}+\underbrace{C_{f_{u}} P_{\text {colapso }}}_{\widehat{\nabla}_{\mathrm{CVC}}\left(d_{k}\right)}}_{\nabla f\left(d_{k}\right)}
$$

Embora a métrica $\nabla_{\mathrm{CVC}}$ se restrinja às informações de colapso progressivo, nestas informações estão incluídas as falhas elementares dos elementos e também o seu custo de construção, usado na definição do custo esperado de falha. Desta forma, em problemas cujas falhas por colapso progressivo são significativas, a métrica será usada para representar a função como um todo.

Além disso, com o uso do CVC, a informação elemento a elemento é mais direta e simples que as informações extraídas do vetor $\nabla f$ do problema em questão. A substituição das derivadas 
parciais pelo CVC permite obter informações individuais e específicas a partir da ordenação quantitativa dos elementos a cada mudança de configuração.

As propriedades da métrica direta do CVC, no entanto, são distintas das propriedades do gradiente de uma função, que varia não só em intensidade, mas também em sentido. Os próximos tópicos lidam com essas propriedades.

\section{Divisão entre elementos redundantes e vulneráveis}

Para definir a medida de intensidade a partir do CVC e possibilitar uma variação compatível e simultânea (reduções e inclusões em um mesmo passo), estipula-se um valor dentro do intervalo dos valores do CVC que separe os elementos que devem receber área e os que devem perder área. A separação dos elementos dá origem a sentidos distintos dentro do vetor gradiente.

Partindo da estrutura isostática redundante, quando uma falha se sobressai, a vulnerabilidade deste elemento é alterada partindo-se dessa situação de igualdade entre os elementos. Consequentemente, este valor $p=1 / m$ divide os elementos vulneráveis dos redundantes, respectivamente os que devem receber: inclusão e redução de área.

$$
\begin{array}{cc}
C V C_{i}-p>0 & \text { Elemento vulnerável } \\
C V C_{i}-p<0 & \text { Elemento redundante }
\end{array}
$$

Esse limite não sofre alteração com a "retirada" de elementos, pois todos elementos são levados em conta no colapso progressivo. Para que ocorra colapso progressivo, o sistema estrutural deve ser hiperestático, portanto, o número de elementos é limitado por $m \geq 3$. Consequentemente, o intervalo que divide os elementos é assimétrico. A Figura 5.1 mostra os intervalos de valores possíveis para CVC e para os dois tipos de elementos que surgem após a limitação por $p$. Os pontos indicam o limite $p$ em função do número de elementos $m$. 


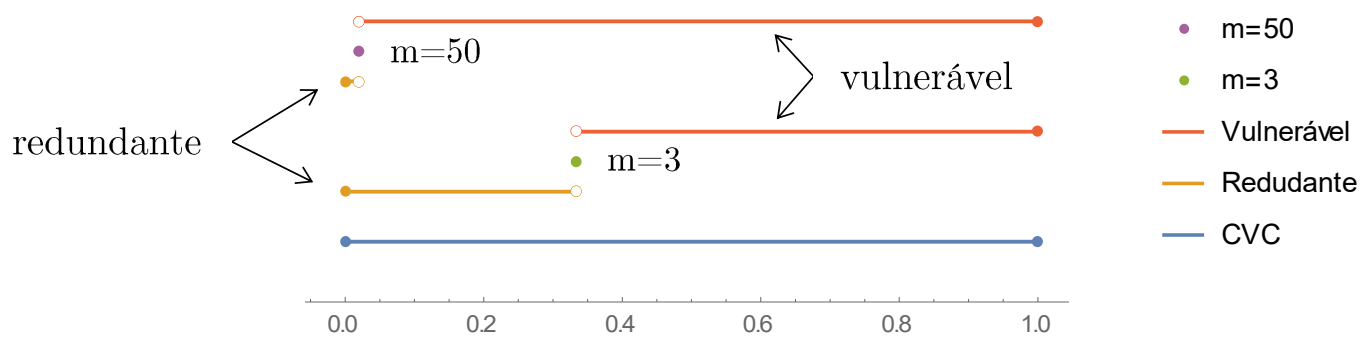

Figura 5.1 - Intervalo do CVC e dos elementos redundantes e vulneráveis. Fonte: elaborado pela autora.

Quanto maior o número de elementos na estrutura, maior é a diferença entre os tamanhos dos intervalos de redundante e vulnerável. No entanto, o número de elementos em cada intervalo não é alterado significativamente, pois a propriedade da Eq.(5.3), impede que muitos elementos sejam caracterizados como vulneráveis em estruturas com muitos elementos.

A Figura 5.2 exemplifica a distribuição dos $C V C_{i}$ para dois casos de configuração. $\mathrm{O}$ primeiro caso tem um elemento com falha bem definida resultando em CVC mais alto comparativamente aos demais. Neste caso, o valor do CVC do elemento chave $\left(C V C_{E C}\right)$ é alto. O segundo caso representa uma estrutura com probabilidades de falha próximas, na qual o elemento chave tem CVC próximo ao dos demais $\left(C V C_{E C}\right.$ baixo).

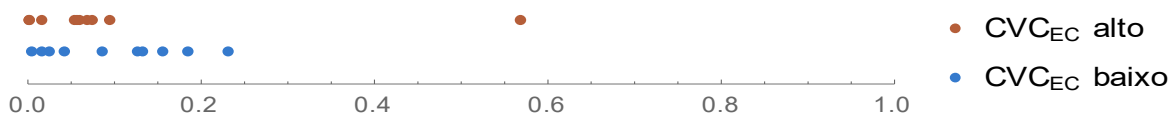

Figura 5.2-CVC dos elementos para estruturas: com elemento chave de CVC alto e baixo. Fonte: elaborado pela autora. 


\section{Pseudo-gradiente baseado em CVC}

De posse dessas observações, e sabendo que o gradiente de uma função aponta para a direção de máxima subida, o gradiente baseado em CVC deve considerar dois sentidos:

- (+) positivo para elementos redundantes pois o acréscimo de área desses elementos reflete no aumento direto de todos os custos e;

- (-) negativo para elementos vulneráveis (chave) pois a redução de área desses elementos aumenta abruptamente a probabilidade de falha e consequentemente os custos esperados de falha.

Tal como:

$$
\left(\hat{\nabla}_{C V C}\right)_{i}=-\left(C V C_{i}-p\right) \quad i=1, \ldots, m
$$

A intensidade do gradiente deve ainda, ser normalizada para evitar direções muito próximas de zero (estacionariedade), ou seja, alterações de configuração não significativas. Dividindo a Eq.(5.12) pelo mínimo valor do vetor $(\boldsymbol{C V} \boldsymbol{C}-p)$ e englobando o sinal negativo deste denominador no numerador, temos:

$$
\left(\hat{\nabla}_{C V C}\right)_{i}=\frac{C V C_{i}-p}{\min _{j}\left(C V C_{j}-p\right)} \quad \operatorname{para}_{j=1, \ldots, m}^{i=1, \ldots, m}
$$

A intensidade do vetor se alinha as características da estrutura analisada. Quando o $C V C_{E C}$ é demasiadamente alto, deve-se alterar o elemento chave (vulnerável) de forma mais abrupta que no caso $C V C_{E C}$ baixo, cuja alterações são mais suaves.

(a)

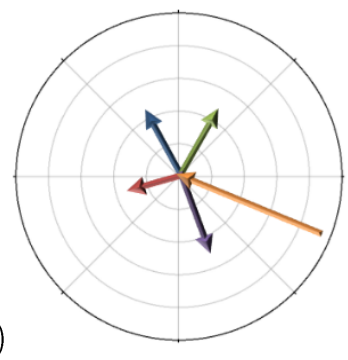

(b)

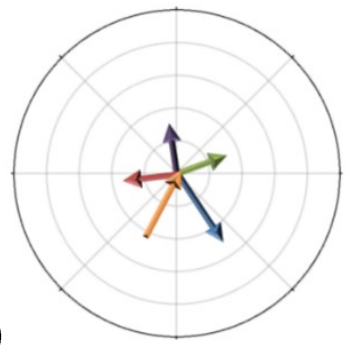

Figura 5.3 - Direções e intensidades de $\hat{\nabla}_{C V C}$ para $C V C_{E C}$ (a) alto e; (b) baixo. Fonte: elaborado pela autora. 
Para uma estrutura isostática com alto grau de redundância, $C V C_{i=1, m}=1 / m$, o denominador de $\left(\hat{\nabla}_{C V C}\right)_{i}$ se anula e a Eq. (5.13) assume valor unitário.

$$
\text { Se } \max _{i} C V C_{i}=1 / m \rightarrow\left(\hat{\nabla}_{C V C}\right)_{i=1, m}=1
$$

Nestas ocasiões, todas as barras sofrem a mesma redução de área até que um elemento apresente uma $P_{f}$ mais acentuada que os demais. A Eq. (5.13) e a condição (5.14) garantem um mínimo na direção $(+)$ unitário e um máximo igual à $(1-m)$ na direção $(-)$.

\section{Direção de máxima descida}

Para obtenção da direção de máxima descida $\alpha_{k}$ utiliza-se a direção do anti-gradiente.

$$
\alpha_{i_{0}}=-\widehat{\nabla}_{C V C}
$$

Outras métricas para a direção $\alpha_{i_{0}}$ que combinam informações passadas da direção, como a obtida a partir dos gradientes conjugados, de Hestenes e Stiefel (1952), não são relevantes, no problema em questão, pois as direções de busca anteriores se referem a informações de configurações estruturais diferentes das atuais.

Se analisarmos o $\alpha_{k}$ como uma porção de área $d A$, a ser substituída na Eq. (5.7) com passo $t_{k}=1$, elementos redundantes com $\left(C V C_{i}<p\right)$ perdem área pois $d A<0$. Conforme o $C V C_{i}$ aumenta e ultrapassa o limite $p$, os elementos ditos chave passam a receber área, isto é, $d A>0$. Desta forma, quando se pensa na direção do anti-gradiente, a direção predominante é aquela que se afasta das configurações que resultam em falha de elementos ou da estrutura como um todo.

Para exemplificar a aplicação do gradiente baseado em CVC e da direção do antigradiente considere o seguinte exemplo: 


\section{Exemplo: Treliça de 3 barras hiperestática sujeita a colapso progressivo-}

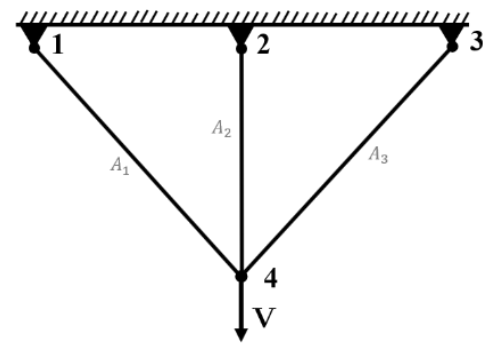

Figura 5.4 - Esquema da treliça de 3 barras. Fonte: elaborado pela autora.

O exemplo a seguir representa uma estrutura cuja configuração inicial gera probabilidades de falha altas em 2 barras. Nesta situação, o vetor de direção $-\nabla_{C V C}$ faz incrementos em elementos vulneráveis e reduções em elementos redundantes.

$$
\begin{gathered}
Z_{0}=\left\{0.110510^{-1}, 0.420310^{-1}, 0.3422\right\} m^{-2} \rightarrow C E T=800.07 \\
\text { It 1: } C V C=\{0.4984,0.5016,0\} \rightarrow \widehat{\nabla}_{C V C}=\{-0.4952,-0.5047,1\} \\
Z_{1}=Z_{0}+t\left(-\widehat{\nabla}_{C V C}\right) \\
Z_{1}=\{0.1127,0.1456,0.1369\} m^{-2}
\end{gathered} \rightarrow C E T=516.19
$$

Essa alteração reflete em diminuição efetiva da função objetivo (CET) apesar de gerar incrementos de área. Na configuração $Z_{1}$, o CVC se altera:

It 2: $\begin{gathered}C V C=\{0,1,0\} \rightarrow \widehat{\nabla}_{C V C_{i=1, m}}=\{1,-2,1\} \rightarrow Z_{2}=Z_{1}+t\left(-\widehat{\nabla}_{C V C}\right) \\ Z_{2}=\{0.06904,0.2330,0.09318\} m^{-2}\end{gathered} \rightarrow C E T=57.589$

Nesta iteração 2, a função CET é minimizada a partir de incremento na área da barra 2, e reduções nas barras 1 e 3 .

No próximo passo, com a correção da área das barras vulneráveis, não há barras em situação crítica, nesta situação intermediária, o $C V C_{i}$ é igual para todas as barras $\left(C V C_{i}<p\right)$ e a estrutura se encontra no domínio de sobrevivência. Porém esse domínio de sobrevivência pode não ser o mínimo possível. Neste caso, utiliza-se uma minimização equivalente em todos os elementos $\left(\widehat{\nabla}_{C V C}=1\right)$, dada por dada por $\alpha_{i_{0}}=-1$ multiplicada pelo passo $t$.

$$
\text { It 3: } \begin{gathered}
C V C_{i=1, m}=0.33 \rightarrow \widehat{\nabla}_{C V C_{i=1, m}}=1 \rightarrow Z_{3}=Z_{2}+t(-1) \\
Z_{3}=\{0.001,0.09321,0.001\} m^{-2}
\end{gathered} \rightarrow C E T=6.8264
$$


Após esse passo, seguem-se mais alguns passos com $\widehat{\nabla}_{C V C_{i=1, m}}=1$ buscando minimizar a área da barra restante.

A situação da iteração 3 descrita na Eq.(5.14) é a mais comum no processo de otimização, embora ela não represente uma direção específica para o algoritmo. Essa situação representa a configuração buscada pelo algoritmo, ou seja, minimização dos custos de falha. Uma direção específica é obtida a partir da verificação de falhas substanciais, nestas situações o CVC recebe o papel de redirecionar rapidamente o algoritmo para direções seguras. A escolha da proporção dessas alterações para gerar a configuração otimizada de cada iteração é determinada pelo tamanho do passo.

\section{Escolha do tamanho do passo}

A escolha adequada do tamanho de passo inicial $t_{0}$ pode reduzir substancialmente o número de avaliações da função objetivo para escolha do passo ótimo. As estimativas de passo inicial e estratégias para busca do tamanho de passo ótimo geralmente utilizadas na literatura, como a de Armijo, de Wolfe ou ainda de Goldstein, não são válidas para este problema pois a direção baseada no CVC, apesar de garantir sentidos diferentes de acréscimo/decréscimo, não garante intensidade semelhante à de derivadas.

O passo inicial, $t_{0}$, deve garantir que o fator de acréscimo $t \alpha_{i_{0}}$ tenha uma boa proporção. Considera-se que a componente máxima de $t \alpha_{i_{0}}$ deva ser equivalente a uma mudança significativa e pré-determinada nas especificações do projeto. Essa mudança assume valores da ordem de $5 \%$ a $10 \%$ das variáveis de projeto. Utiliza-se valor máximo de $d_{i}$ de forma a garantir uma mudança significativa mínima igual à escolhida.

$$
t_{0}=\rho \frac{\max _{i} d_{i}}{\max _{i}\left|\alpha_{i_{0} i}\right|}
$$

Caso o passo não minimize a função, ele é decrescido pela metade. A avaliação dessas estruturas cujo passo é muito maior que o necessário representa um acréscimo de custo 
computacional, no entanto, essas estruturas muitas vezes resultam em estruturas com probabilidade de falha conhecida (ex: estruturas hipostáticas).

Os limites para o tamanho do passo emergem da análise da estabilidade da estrutura. O tamanho do passo é restringido superiormente para que não ocorra retirada do i-ésimo elemento que extingue a estrutura, ou seja, quando a área de todos elementos se iguala ao limite lateral mínimo da otimização.

$$
t^{\text {sup }}<\min _{i=1, m}\left|\frac{d_{k_{i}}-d_{\min _{i}}^{l a t}}{\alpha_{i_{0}}}\right|
$$

onde $t^{\text {sup }}$ é o limite superior do tamanho do passo, $k$ é o iterador da busca pelo tamanho do

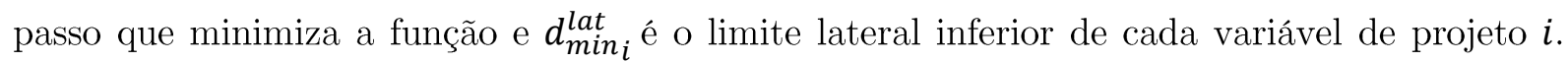
Essa restrição é avaliada calculando $d_{k+1}$ por meio de $t_{0}$ e avaliando a estabilidade da estrutura (não mecânica). Caso o passo ultrapasse o limite, ele é decrescido pela metade.

As estruturas instáveis ou hipostáticas geometricamente não são descartadas nesta etapa pois a instabilidade física depende da avaliação das probabilidades de falha.

Logicamente, o tamanho do passo deve ser positivo, para que a próxima iteração seja diferente da anterior. A partir da tolerância de convergência das variáveis de projeto tol $l_{d}$ (única para todas as variáveis de projeto) é possível definir um limite inferior mais específico:

$$
t^{\text {inf }}>\max _{i=1, m}\left(\frac{\operatorname{tol}_{d}}{a_{i_{o i}}}\right)
$$

onde $t^{\text {inf }}$ é o limite inferior do tamanho do passo e $m$ o número de elementos da estrutura.

A condição que descreve esse limite é obtida pela comparação entre a diferença entre a média dos valores de $d_{k+1}$ e $d_{k}$ e a tolerância de convergência das variáveis de projeto tol $l_{d}$ :

$$
\text { Se } \max _{i=1, m}\left|d_{k_{i}}-d_{i_{o} i}\right| \leq \operatorname{tol}_{d} \rightarrow \text { EXIT } \rightarrow i_{o}=i_{o}+1
$$

a verificação positiva dessa condição cessa a busca pelo tamanho do passo, e uma nova direção de busca é avaliada na próxima iteração da otimização. 


\subsection{CVC-pseudo-gradiente - Otimização Local}

O método do CVC-pseudo-gradiente é válido para problemas nos quais as variáveis de projeto são exclusivamente a área da seção transversal dos elementos. Problemas de posicionamento de elementos podem ser abordados com a criação de barras complementares, sendo responsabilidade do algoritmo atribuir maiores áreas àquelas de melhor posição. Todos os elementos estruturais devem ser considerados, porém cada elemento pode possuir uma descrição diferente de falha, material ou seção. As variáveis de projeto podem ser determinísticas ou aleatórias, podendo existir ambas.

Embora o CVC-pseudo-gradiente seja relativo ao colapso progressivo, o cálculo dos coeficientes de vulnerabilidade ao colapso considera falhas individuais de componentes. A função objetivo do problema, no entanto, pode considerar um conjunto maior de falhas, como falhas de serviço sem deixar de incluir a falha por colapso. Neste caso, o método ainda é válido pois a escolha do passo é determinada segundo a variação da função objetivo.

\subsubsection{Fluxograma da otimização de risco com CVC-pseudo-gradiente}

A aplicação do algoritmo de busca linear baseado no CVC ao problema de minimização da função de custos esperados totais de treliças sujeitas a colapso progressivo é delineada pelo fluxograma da Figura 5.5. 


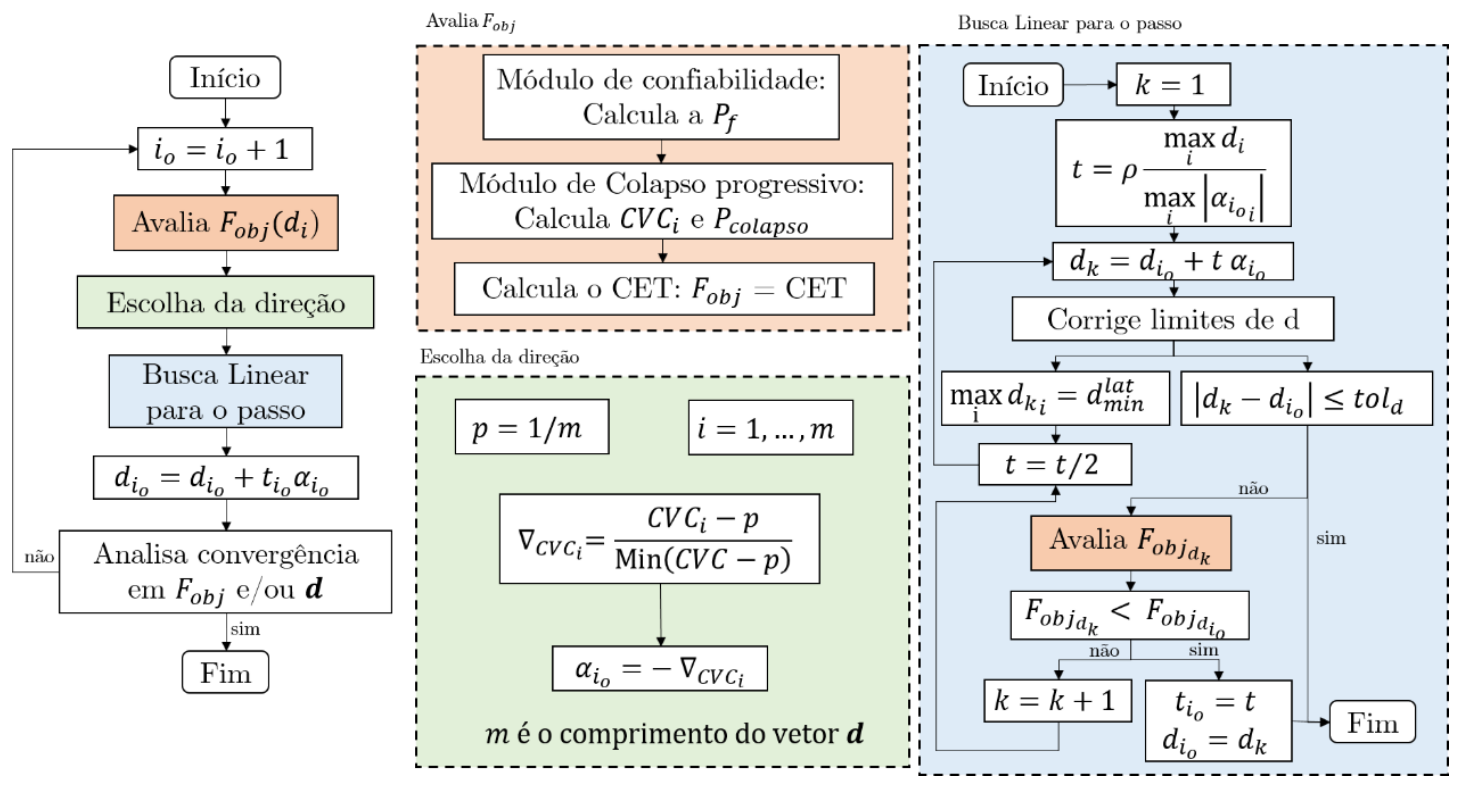

Figura 5.5 - Fluxograma da otimização baseada no CVC. Fonte: elaborado pela autora.

Problemas probabilísticos podem ser analisados de maneira semelhante à determinística a partir da consideração da parte probabilística na avaliação do CVC-pseudo-gradiente e da função objetivo. Mesmo bem delimitado pelos parâmetros de direção e passo, o algoritmo de busca direcionado pelo CVC percorre configurações próximas à inicial convergindo para mínimos locais. Esses resultados possuem reprodutibilidade apesar de apresentar pequenas flutuações devido a precisão na estimativa das $P_{f}$. O algoritmo pode ser combinado a uma estratégia de múltiplas inicializações para se aproximar de uma solução independente da configuração inicial.

\subsubsection{Estudos mais específicos sobre o método}

Para realizar os primeiros estudos com o método de otimização baseado no CVC-pseudogradiente, utiliza-se, como comparação simplista, o método de otimização global baseado em enxame de partículas (Particle Swarm Optimization - PSO). Nestas simulações, a eficiência do PSO não é alvo do estudo, portanto, são fixados os parâmetros disponíveis na Tabela 2.1.

Considera-se a estrutura hiperestática da Figura 5.4 composta por 3 barras com 3 apoios fixos e ponto de aplicação da carga livre. Os nós 2 e 4 são posicionados no centro do vão e o elemento 2 é vertical com comprimento unitário. 
O algoritmo baseado em CVC, no problema em questão, é usado em 4 tipos de problemas com relação aos tipos de variáveis adotadas. O caso $i$ considera somente variáveis determinísticas, os casos ii a $i v$, consideram variáveis aleatórias em ordem crescente de complexidade: (ii) de resistência; (iii) de projeto e; (iv) ambas. Todos os casos avaliam a confiabilidade por Monte Carlos com LHS.

Considera-se um cenário de falha com custos relativos ao tipo de falha. Falhas por compressão ou esmagamento possuem baixa consequência de falha sendo adotado $\alpha_{\text {comp }}=5$. Já o modo de falha por tração é mais abrupto e opta-se por $\alpha_{\text {tração }}=20$. Os modos de falha de flambagem e instabilidade recebem $\alpha_{\text {flamb }}=\alpha_{\text {instab }}=10$.

Os dados estocásticos da treliça de 3 barras encontram-se na Tabela 5.1. As variáveis aleatórias são: de resistência $\{\sigma, E\}$; de solicitação $\{V\}$ e; parâmetros geométricos $\left\{d_{1}, d_{2}, d_{3}\right\}$. As variáveis sombreadas à esquerda, indicam presença de incertezas.

Tabela 5.1 - Parâmetros aleatórios: Treliça de 3 barras. Fonte: elaborado pela autora.

\begin{tabular}{|c|c|c|c|c|c|c|c|}
\hline$i$ & $i i$ & $i i i$ & $i v$ & & Distribuição & Média & $\begin{array}{l}\text { Coef. de } \\
\text { variação }\end{array}$ \\
\hline & & & & Tensão de Escoamento $\sigma$ & Log-Normal & $74510^{6}$ & 0.1 \\
\hline & & & & Módulo de Elasticidade $E$ & Log-Normal & $20510^{9}$ & 0.05 \\
\hline & & & & Força vertical $V$ & Normal & $-110^{6}$ & 0.2 \\
\hline & & & & Diâmetro $d_{1}$ & Log-Normal & 0.1 & 0.1 \\
\hline & & & & Diâmetro $d_{2}$ & Log-Normal & 0.1 & 0.1 \\
\hline & & & & Diâmetro $d_{3}$ & Log-Normal & 0.1 & 0.1 \\
\hline
\end{tabular}

\section{Das diferentes configurações iniciais}

Para comparações com o PSO, o algoritmo baseado em CVC será combinado a múltiplas inicializações que utilizam a posição inicial das mesmas 10 partículas $^{1}$ do PSO. No entanto, a busca com CVC não utiliza comunicação entre as partículas.

A área inicial das barras dessas 10 configurações iniciais foi determinada utilizando variáveis aleatórias uniformemente distribuídas nos limites laterais das variáveis de projeto. A

\footnotetext{
${ }^{1}$ Número suficiente para efeitos comparativos e factível para o problema NLG.
} 
Figura 5.6 a) mostra a oscilação dentro do domínio das variáveis de projeto escolhidas. A média dos conjuntos amostrais não é semelhante e; igual ao centro do intervalo, pois o número de amostras é baixo. A Figura 5.6 b) mostra a abrangência dos CET iniciais para o caso de resposta linear.

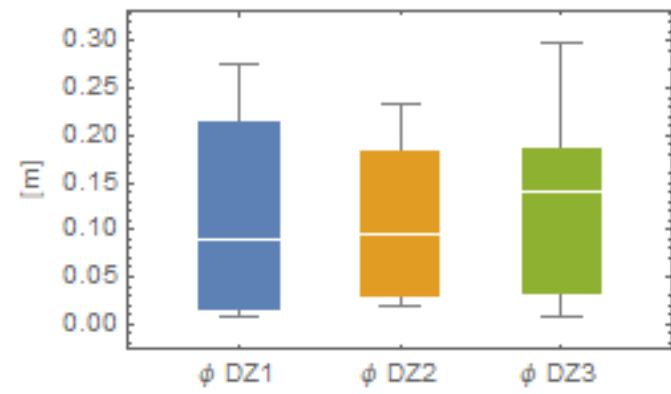

a)

Figura 5.6 - a) Dispersão das variáveis de projeto iniciais; b) CET das configurações iniciais.

Fonte: elaborado pela autora.

As simulações com custos mais altos correspondem a estruturas com alta $P_{f}$ em um ou mais elementos. Para evitar a dependência de $C_{R E F}$ (proporcional à configuração inicial) usouse valor arbitrário igual para todas as simulações.

\section{Do tamanho de passo}

A eficiência do método de otimização com CVC-pseudo-gradiente depende da escolha de um bom tamanho de passo. As análises não mostraram um comportamento claro e constante de $\rho$, pois a eficiência depende da configuração inicial, do tipo de problema e das incertezas consideradas. A Figura 5.7 mostra o comportamento da variância dos mínimos encontrados a partir da mudança dos valores de $\rho$. Ao aumentar o tamanho do passo, aumenta-se a variância dos resultados, porém pode-se chegar em mínimos menores.

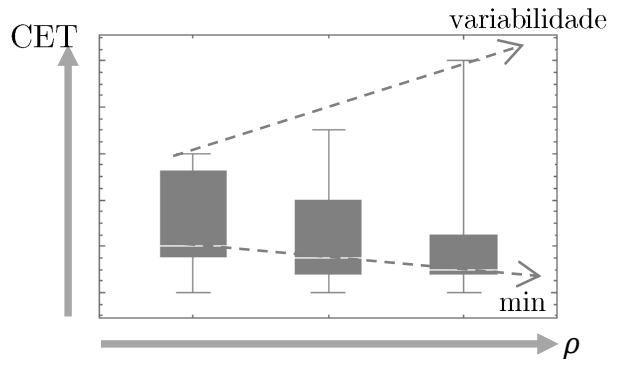

Figura 5.7 - Comportamento esquemático de $\rho$. Fonte: elaborado pela autora. 
Porcentagens menores (p.ex. $\rho=0.05$ ) fazem uma busca mais próxima ao ponto inicial podendo convergir para mínimos locais. Esses valores são bons quando o projeto ótimo desejado está próximo às configurações iniciais. Porcentagens maiores (p.ex. $\rho=0.9$ ) podem ser usadas para aumentar o domínio de busca e conseguir configurações distintas com mínimos menores, porém a variabilidade das respostas aumenta.

\section{Resposta mecânica}

O algoritmo baseado no CVC não possui restrições quanto ao tipo de resposta mecânica da estrutura. Esse algoritmo mostrou-se capaz de minimizar tanto casos lineares quanto não lineares independente das incertezas associadas. No entanto, respostas não lineares demandam mais esforço computacional. Como exemplo, comparamos as melhores respostas mecânicas linear e NLG para o caso mais complexo, caso iv. As configurações com somente uma barra, apesar de serem geometricamente hipostáticas são isostáticas do ponto de vista do carregamento aplicado. Este problema, com somente uma força vertical, é simétrico, portanto, as barras 1 e 3 estão sujeitas a esforços semelhantes, as respostas irão depender das variações estatísticas de resistência e solicitação. As configurações com mais de uma barra, ainda assim, apresentam diâmetro pelo menos 5 vezes maior que da barra secundária.

Tabela 5.2 - Valores otimizados para o caso iv. Fonte: elaborado pela autora.

\begin{tabular}{|c|c|c|c|c|c|c|c|c|c|c|}
\hline$i v$ & & \multicolumn{3}{|c|}{ CVC $\rho=0.5$} & \multicolumn{3}{|c|}{$\mathrm{CVC} \rho=0.9$} & \multicolumn{3}{|c|}{ PSO } \\
\hline \multirow{3}{*}{ 苞 } & $C E T_{\min }\left(10^{-3}\right)$ & \multicolumn{3}{|c|}{3.4173} & \multicolumn{3}{|c|}{3.2106} & \multicolumn{3}{|c|}{3.743} \\
\hline & Config. (m) & 0.001 & 0.06449 & 0.001 & 0.001 & 0.06245 & 0.005453 & 0.006522 & 0.06439 & 0.001 \\
\hline & Beta & \multicolumn{3}{|c|}{2.87} & \multicolumn{3}{|c|}{2.65} & \multicolumn{3}{|c|}{2.87} \\
\hline \multirow{3}{*}{$\begin{array}{l}\underset{G}{G} \\
\text { 乙 }\end{array}$} & $C E T_{\min }\left(10^{-3}\right)$ & \multicolumn{3}{|c|}{3.1923} & \multicolumn{3}{|c|}{3.2814} & \multicolumn{3}{|c|}{3.5452} \\
\hline & Config. (m) & 0.001 & 0.05948 & 0.01016 & 0.001 & 0.06245 & 0.01034 & 0.001 & 0.0629 & 0.007572 \\
\hline & Beta & \multicolumn{3}{|c|}{2.51} & \multicolumn{3}{|c|}{2.87} & \multicolumn{3}{|c|}{2.87} \\
\hline
\end{tabular}

A Figura 5.8 exibe os dados da Tabela 5.2 com a dispersão, no caso CVC de todas as 10 configurações iniciais testadas, e no caso do PSO, para as 10 simulações usando as mesmas 10 configurações do CVC. Os algoritmos foram capazes de propor configurações semelhantes com CET próximos para ambas as respostas mecânicas. 


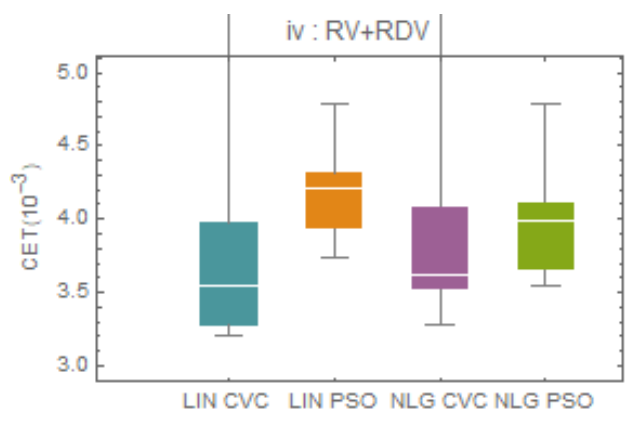

a)

Figura 5.8 - Caso iv linear e NLG com PSO e CVC com $\rho=0$,9. a) CET otimizados; b) Diâmetros. Fonte: elaborado pela autora.

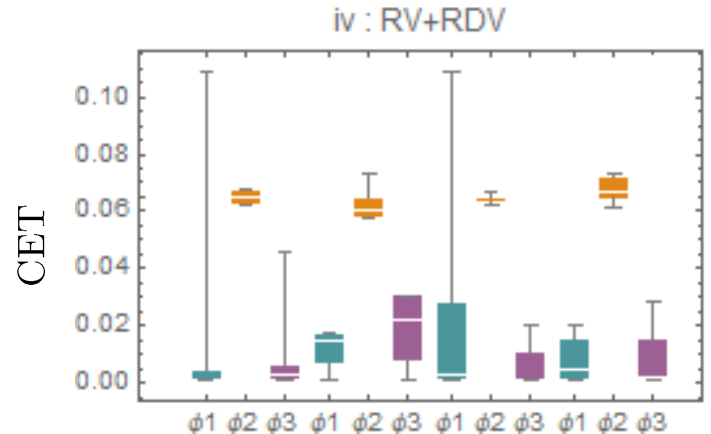

b) 
A curva de convergência da função objetivo (CET) é decrescente em todos os casos. A convergência das áreas, no entanto, apresenta comportamentos distintos entre os métodos de otimização utilizados. A Figura 5.10 apresenta a convergência de uma simulação com CVC e com PSO para as três variáveis de projeto.

No PSO, o valor das variáveis de projeto oscila pouco durante as iterações intermediarias, indicando que não houve concorrência entre partículas. Já no algoritmo de otimização baseado em CVC, a próxima configuração otimizada é sugerida a partir de alterações na seção transversal dos elementos (direção em função do CVC), consequentemente, a convergência das variáveis de projeto por iteração é suave para elementos redundantes e oscilatória para elementos vulneráveis. Ou seja, no PSO a oscilação nas variáveis de projeto deriva da concorrência entre partículas, e no CVC, deriva da vulnerabilidade do elemento.

a)

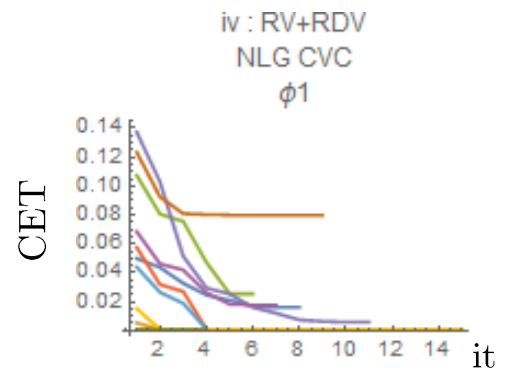

$$
\begin{aligned}
& \text { iv : RV+RDV } \\
& \text { NLG PSO }
\end{aligned}
$$

$\phi 1$

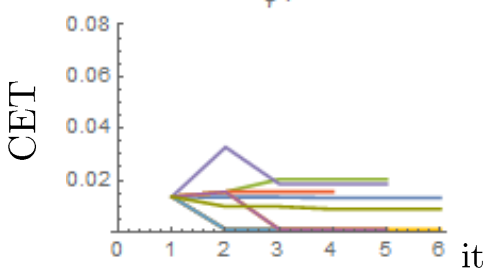

iv : RV+RDV

NLG CVC

$\phi 2$

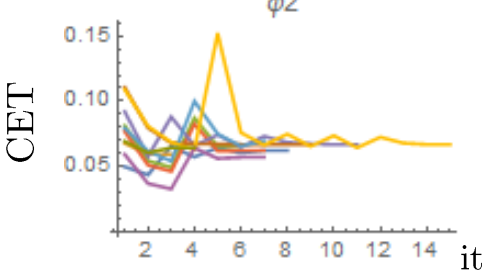

it

iv : RV+RDV

NLG PSO

$\phi 2$

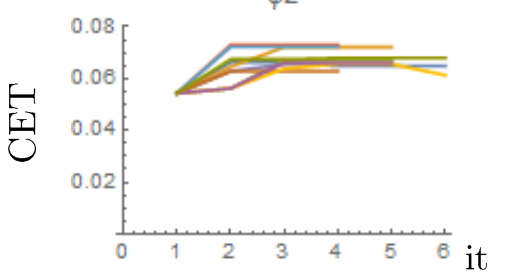

iii: DV+RDV

NLG CVC

$\phi 3$

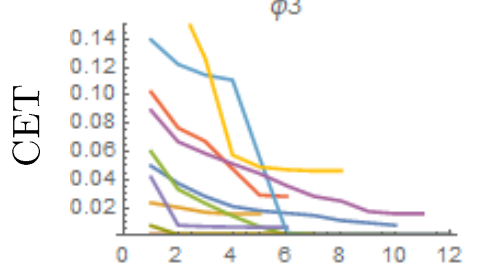

iv : RV+RDV

NLG PSO

$\phi 3$

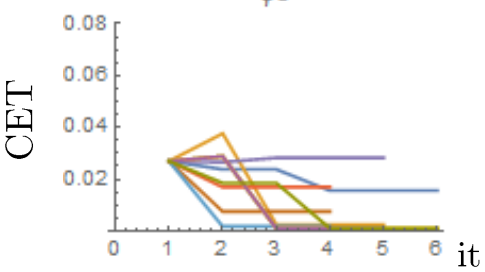

b)

Figura 5.10 - Convergência das variáveis de projeto, a) CVC $\rho=0.5$; b) PSO.

Fonte: elaborado pela autora. 



\section{PARTE II. APLICAÇÕES E CONCLUSÕES}

Esta parte se divide em dois capítulos. No primeiro são resolvidas algumas estruturas de treliça considerando os métodos de otimização propostos e ainda as diferentes respostas mecânicas. As peculiaridades da otimização de risco são discutidas a partir de estudos comparativos. No segundo são apresentadas as conclusões. 



\section{APLICAÇÕES DA FORMULAÇÃO}

\subsection{Otimização de tamanho utilizando formulação de risco}

Neste primeiro item, analisamos as estruturas com o método de otimização PSO, já consolidado na literatura, para apontar as singularidades da otimização baseada em risco.

\subsubsection{Influência da resposta mecânica no projeto otimizado: Treliça de 2 barras}

Para comparar as soluções otimizadas de acordo com a mecânica do problema, usa-se o exemplo simples da treliça abatida de 2 barras bi apoiada, mostrada esquematicamente na Figura 6.1. A distância entre os apoios é de 2 metros, a altura é $0.17 \mathrm{~m}$. As forças aplicadas correspondem a $V=750 \mathrm{kN}$ e $H=4500 \mathrm{kN}$. A seção transversal e os dados de resistência e solicitação seguem os parâmetros aleatórios, segundo o JCSS (2001), mostrados na Tabela 6.1. Tabela 6.1 - Dados estatísticos das variáveis de resistência e solicitação. Fonte: elaborado pela autora.

\begin{tabular}{|c|c|c|c|}
\hline & Distribuição & $\begin{array}{c}\text { Bias }= \\
\text { média/nominal }\end{array}$ & C.V. \\
\hline Propriedades geométricas & Log-Normal & 1.0 & $10 \%$ \\
\hline Módulo de Elasticidade $\boldsymbol{E}$ & Log-Normal & 1.0 & $5 \%$ \\
\hline Tensão de Escoamento $\boldsymbol{\sigma}_{\boldsymbol{y}}$ & Log-Normal & 1.0 & $10 \%$ \\
\hline Forças & Normal & 1.10 & $20 \%$ \\
\hline
\end{tabular}

As variáveis de projeto são as áreas das seções transversais das barras 1 e 2 com suas distribuições respectivas. Por lidarmos sempre com o mesmo material neste trabalho, os valores nominais do material são: $\sigma=7.45 * 10^{8} \frac{\mathrm{N}}{\mathrm{m}^{2}}$ e $\mathrm{E}_{\mathrm{y}}=205 * 10^{9} \frac{\mathrm{N}}{\mathrm{m}^{2}}$.

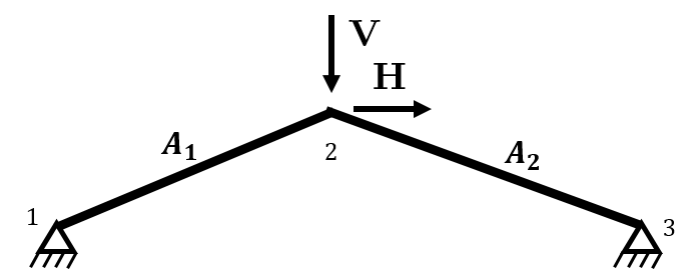

Figura 6.1 - Treliça de duas barras. Fonte: elaborado pela autora. 
O mesmo algoritmo foi utilizado para as simulações, alterando-se somente o tipo de resposta (linear e NLG). Para a avaliação dos custos de falha, foi mantido um valor igual de custo de referência relativo à configuração inicial sugerida e todos os custos de falha foram consideradas com $(\alpha=10)$. Cada caso é analisado 10 vezes para as mesmas 10 configurações iniciais, a Figura 6.2 apresenta a dispersão dos resultados.

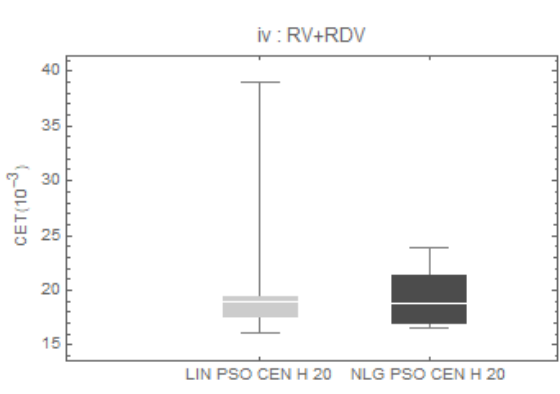

a)

Figura 6.2 - Dispersão das configurações otimizadas. a) CET otimizado; b) Diâmetros das barras.

A consideração dos efeitos de segunda ordem na resposta mecânica NLG altera a avaliação dos custos esperados de falha, e consequentemente, as configurações finais podem variar. A média de ambos os casos é similar, a dispersão do caso linear se deu a probabilidades de falhas mais elevadas na barra 1. A Figura 6.3 mostra as configurações de menor CET dentre as simulações, as estruturas são plotadas na configuração deformada final com espessura proporcional à seção transversal.

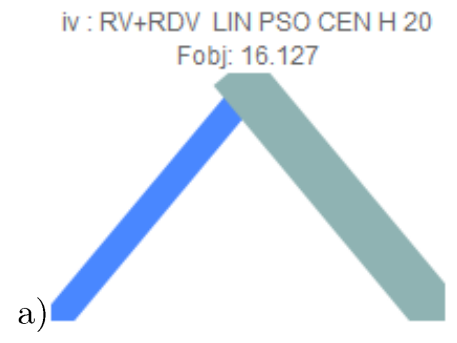

Figura 6.3 - Melhor configuração final. a) Linear ( $a=20)$ b) $N L G(a=20)$. Fonte: elaborado pela autora. 


\subsection{2 Índice de confiabilidade otimizado e cenários de falha}

Ao contrário da RBDO onde a restrição é dada por $\beta_{\text {alvo }}$, na $\mathrm{RO}$ os índices de confiabilidade de cada modo de falha também são resultados da otimização. Não existe uniformidade nos valores de $\boldsymbol{\beta}$ associados a diferentes modos de falha. Isto ocorre porque a RO engloba não só a segurança, mas também o custo a ela atrelado. Os valores de $\beta$ da RO carregam o trade-off das consequências de falha, falhas associadas com custos de falha altos tendem a apresentar probabilidade menores e vice-versa.

A Figura 6.4 mostra a média e a variância de $\beta^{*}$ para o caso mecânico NLG, para o cenário homogêneo, cujas consequências de falha são iguais para todos os modos $(\alpha=10)$ e para o cenário $(\alpha=\{10,10,5,1\})$. O cenário homogêneo é mostrado com cor mais clara à esquerda, e outro à direita, seguindo as cores para cada modo de falha.

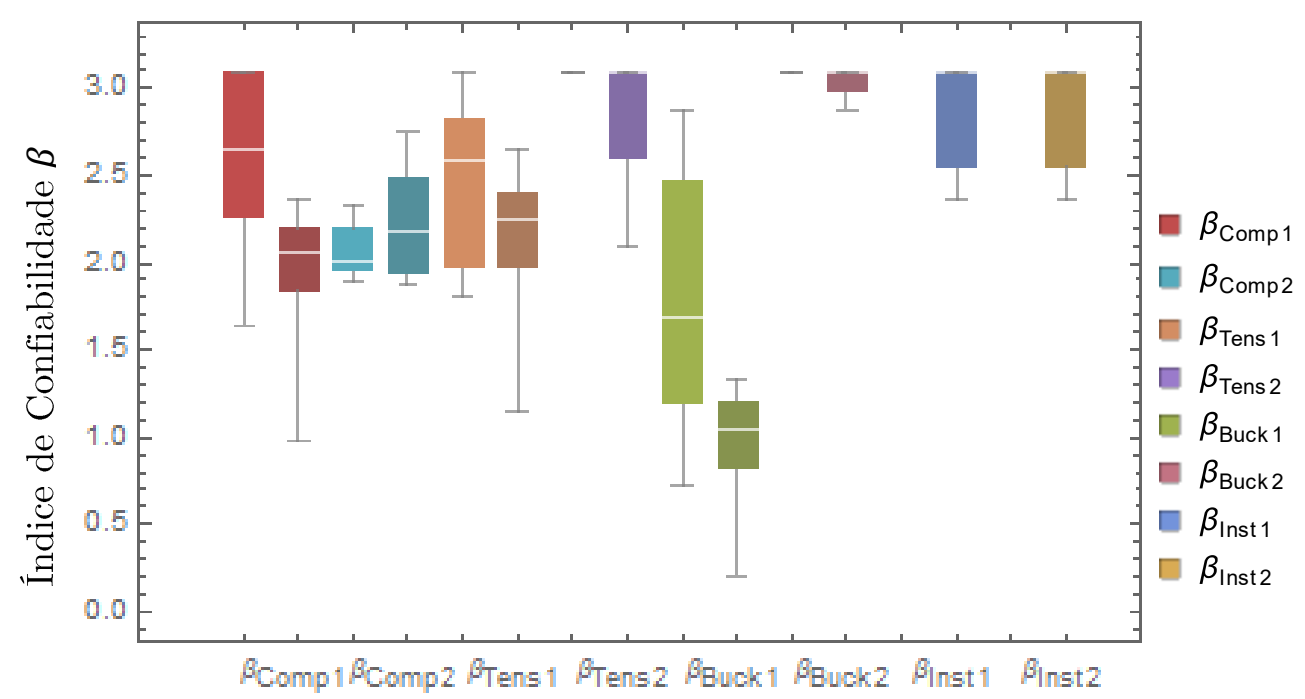

Figura 6.4- $\beta$ otimizados para modos de falha caso NLG (cenário homogêneo, cenário proporcional). Fonte: elaborado pela autora.

A consideração de custos diferentes e/ou proporcionais aos tipos de falha resulta em mudanças no $\beta$ otimizado da configuração final. Um custo menor para a flambagem (de 10 para 5) possibilita uma $P_{f}$ maior, como resultado, os valores otimizados de $\beta_{b u c k}$ foram menores. $\mathrm{O}$ mesmo ocorreu para custos de instabilidade. Neste problema, a falha por flambagem na barra 1, está claramente limitando o valor de $\phi_{1}$. E a compressão limita $\phi_{2}$. Observa-se também 
mudanças nos $\beta$ otimizado de modos que não tiverem os custos alterados em virtude da alteração das configurações finais otimizadas.

A Figura 6.5 a) mostra a dispersão dos CET otimizados e dos diâmetros de cada uma das barras para ambos os cenários do caso NLG via PSO. A Figura 6.5 b) mostra que houve adaptação dos diâmetros após a mudança de cenário. Mudanças mais significativas seriam obtidas caso os custos de falha fossem relativos a cada barra. A utilização de custos de falha de ordem de grandezas distintas, traria mudanças ainda mais significativas.

a)
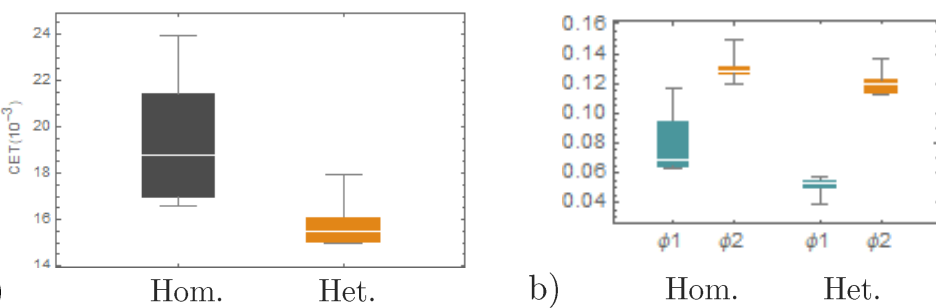

b)

Hom. Het.

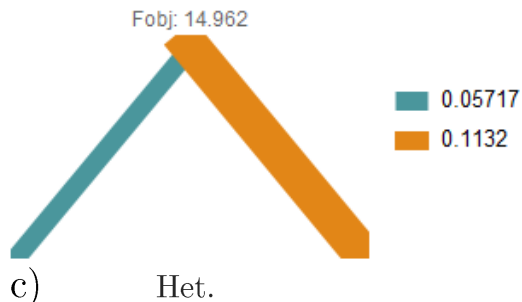

Figura 6.5 -a) CET otimizados; b) Diâmetros otimizados e; c) Configuração otimizada. Fonte: elaborado pela autora.

A RO permite a determinação dos modos de falha predominantes (no caso de custos similares) ou limitantes (no caso de custos distintos) para a otimização. Assim, medidas preventivas pontuais (reforço estrutural) podem ser tomadas e o custo total reavaliado.

\subsection{Otimização de risco com colapso progressivo}

Neste item, incluímos a avaliação do colapso progressivo na avaliação das falhas e também a inclusão do método de otimização baseado no CVC-pseudo-gradiente. São apresentados alguns problemas que permitem analisar aspectos como influência das incertezas na configuração otimizada e a avaliação de falhas por respostas mecânicas lineares e NLG. 


\subsubsection{Incertezas nas variáveis: Treliça de 3 barras}

No problema de duas barras, avaliamos somente as respostas com incertezas tanto nas variáveis de resistência e solicitação quanto nas variáveis de projeto (RV + RDV). Neste item, é feito um estudo mais detalhado sobre o efeito das incertezas na configuração otimizada, seguindo os casos expostos na Tabela 5.1. Este estudo compreende além do PSO, o algoritmo de otimização desenvolvido e a avaliação de falhas por colapso progressivo.

Para verificar a influência das incertezas em cada tipo de variáveis do problema, considera-se a estrutura hiperestática composta por 3 barras com 3 apoios fixos e ponto de aplicação da carga livre. Os nós 2 e 4 são posicionados no centro do vão e o elemento 2 é vertical com comprimento unitário. A distância entre os nós fixos é unitária. As forças aplicadas correspondem a $V=-1000 k N$. A seção transversal e os dados de resistência e solicitação seguem os parâmetros aleatórios da Tabela 6.1.

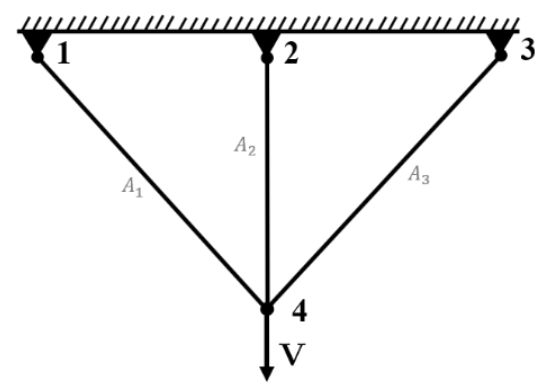

Figura 6.6 - Sistema de 3 barras sujeito a tração. Fonte: elaborado pela autora.

O Quadro 6.1 mostra a dispersão de custo das configurações otimizadas por cada uma das simulações considerando as respostas mecânicas linear e NLG. Observa-se que a variação ao longo das incertezas do caso linear se mantem quando a NLG é incluída. A maior dispersão do CVC-pseudo-gradiente se deve às múltiplas configurações iniciais. No PSO, a dispersão é devido a flutuações na estimativa da $P_{f}$ podendo conduzir o algoritmo a configurações distintas. 
Quadro 6.1 - Distribuição dos resultados para os 4 casos. Fonte: elaborado pela autora.

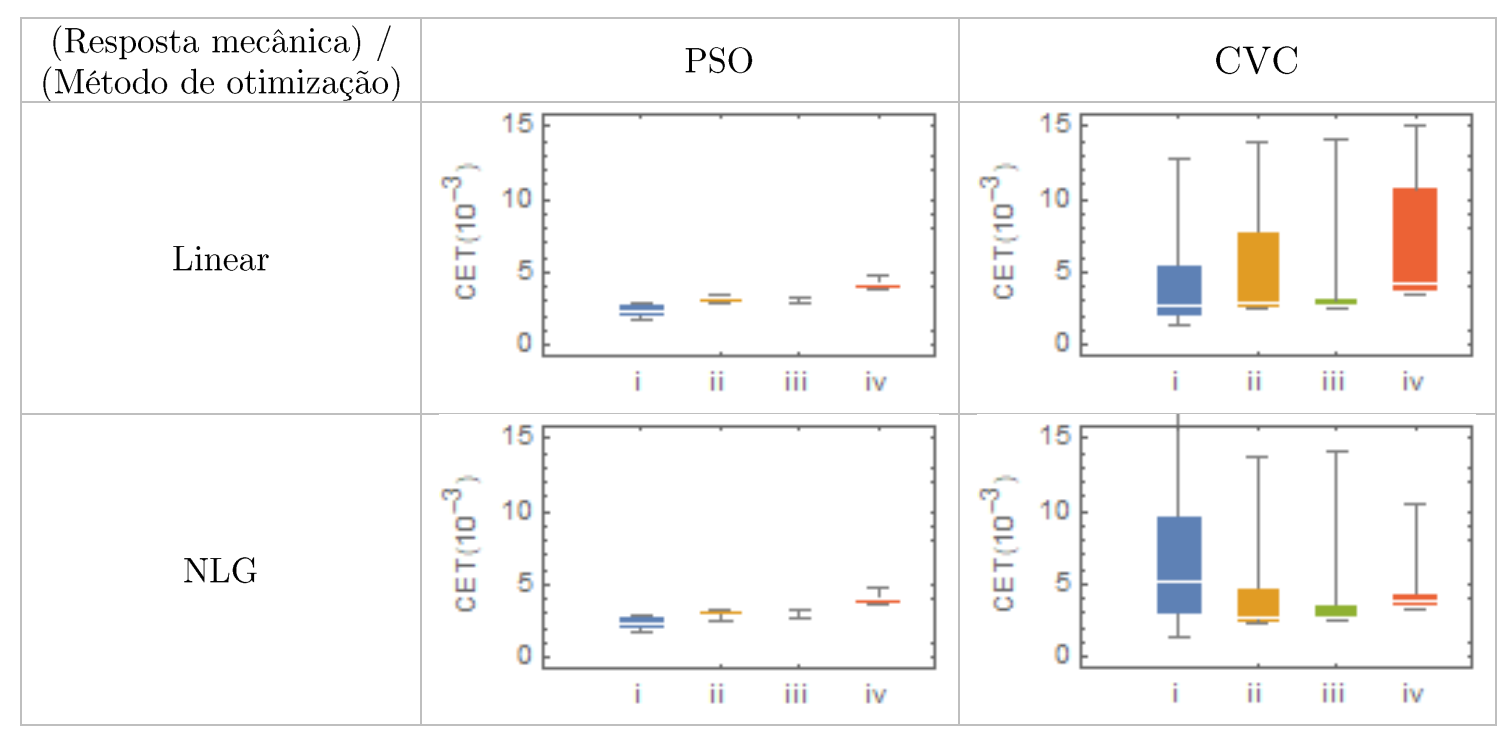

A Tabela 6.2 mostra que não foram constatadas probabilidades de falha significativas nas configurações otimizadas mínimas.

Tabela 6.2 - Valores de beta nas configuraçôes otimizadas mínimas. Fonte: elaborado pela autora.

\begin{tabular}{|c|c|c|c|c|}
\hline & IN CVC & IN PSO & ILG Cl & NLG \\
\hline$i: D V+D D V$ & $\infty$ & $\infty$ & $\infty$ & $\infty$ \\
\hline$i i: R V+D D V$ & 2.87816 & $\infty$ & 3.09023 & $\infty$ \\
\hline ii: $D V+R D V$ & 2.87816 & $\infty$ & $\infty$ & 2.87816 \\
\hline iv : $R V+R D V$ & 2.87816 & 2.87927 & 2.51144 & 2.87816 \\
\hline
\end{tabular}

Vale apontar que o caso $i$, determinístico, é simulado com as mesmas equações de estado limite, que neste caso admitem probabilidades binárias ( 0 ou 1), atuando como restrições de custo. No caso $i$, somente um único valor, o valor médio das variáveis é adotado. Nos demais casos, as incertezas expressam variações que podem refletir em melhoria ou decréscimo da resistência e também em aumento ou diminuição de solicitações. Portanto, o caso $i$, determinístico, não é necessariamente contra a segurança.

Embora os resultados de custo pareçam similares, o Quadro 6.2 exibe as melhores configurações encontradas. O algoritmo do CVC-pseudo-gradiente resultou em mais estruturas isostáticas que o PSO, tanto no caso linear quanto no NLG. Verifica-se que o custo tende a aumentar com as incertezas. 
Quadro 6.2 - Configurações otimizadas para os 4 casos. Fonte: elaborado pela autora.

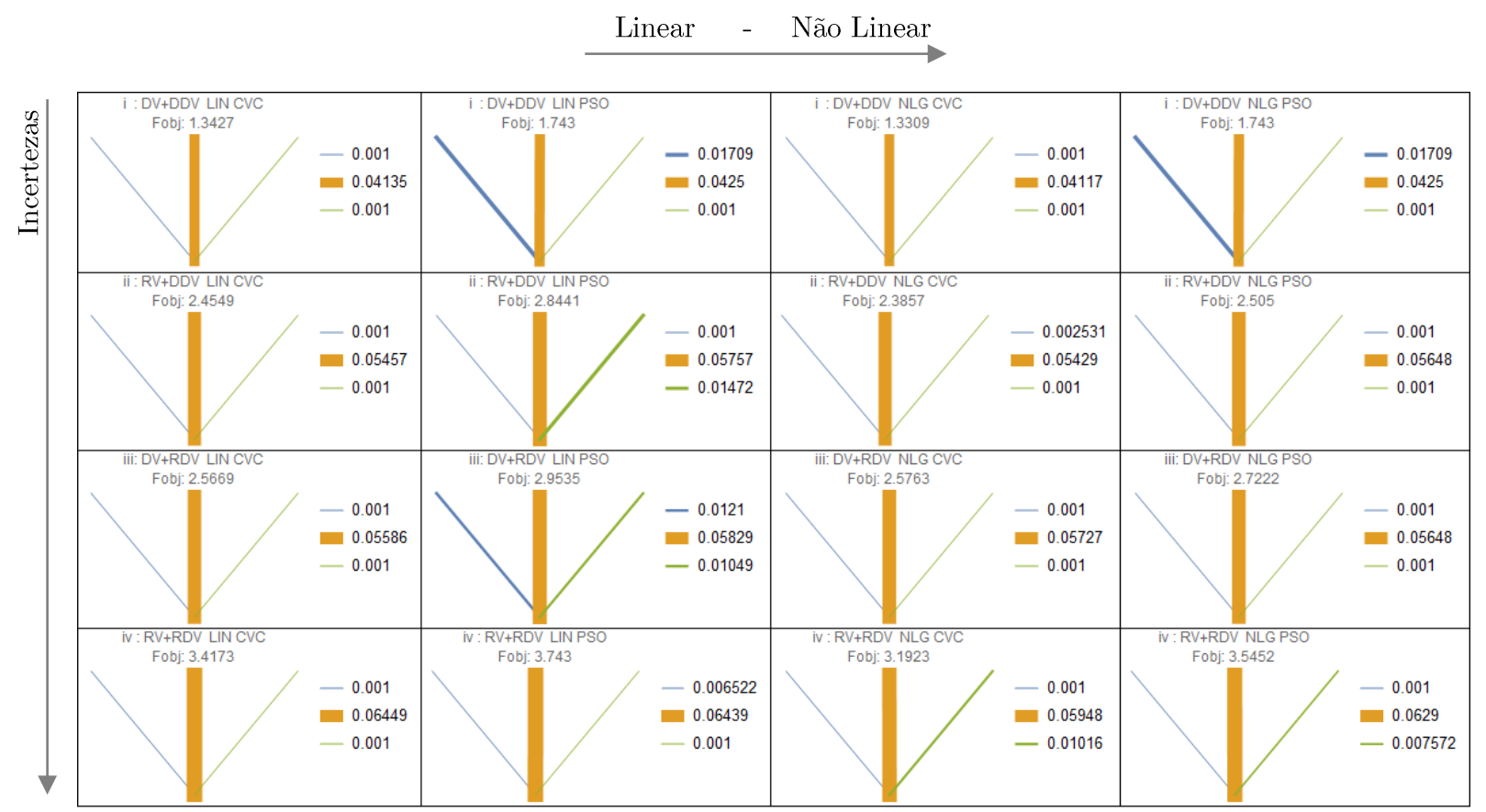

\subsection{Estudos comparativos}

\subsubsection{Influência do RAPC no ótimo do PSO: Treliça de 6 barras}

A treliça de 6 barras é um exemplo significativo relativo a colapso progressivo. Neste item, utiliza-se a treliça pelo PSO com e sem a utilização do RAPC para avaliação do colapso progressivo. A treliça é hiperestática com comprimento $\mathrm{L}=1 \mathrm{~m}$ com vinculações e forças externas conforme a Figura 6.7.

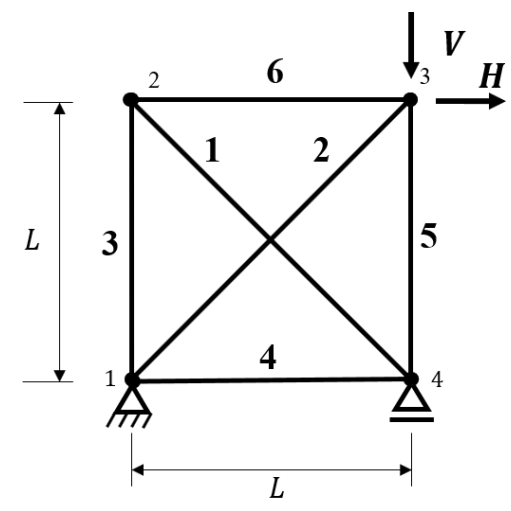

Figura 6.7 - Treliça hiperestática de 6 barras. Fonte: elaborado pela autora. 
As propriedades de resistência do material e a intensidade do carregamento são descritas na Tabela 6.3. As unidades padrão são metro e Newton. As variáveis de projeto também apresentam coeficiente de variação de 10\%, conforme apontado pelo JCSS (2001), referindo-se ao caso 4 de incertezas.

Tabela 6.3 - Variáveis aleatórias e seus parâmetros para treliça de 6 barras. Fonte: elaborado pela autora.

\begin{tabular}{|c|c|c|c|}
\hline Variável & Distribuição & Valor Nominal & Desvio Padrão \\
\hline Módulo de elasticidade $\boldsymbol{E}$ & Log-Normal & $2.050 * 10^{11}$ & $1.5 * 10^{10}$ \\
\hline Tensão última $\boldsymbol{\sigma}_{\boldsymbol{u}_{\boldsymbol{i}}}$ & Log-Normal & $2.5 * 10^{8}$ & $1.25 * 10^{7}$ \\
\hline Força H & Normal & $1.0 * 10^{4}$ & $3.0 * 10^{3}$ \\
\hline Força V & Normal & $-1.0 * 10^{4}$ & $2.0 * 10^{3}$ \\
\hline
\end{tabular}

Foram realizadas 10 simulações com análise não linear geométrica para cada caso, utilizando as mesmas 10 partículas iniciais e o mesmo conjunto de pontos amostrais. A Figura 6.8 mostra a dispersão nos resultados para ambos os casos.

Na Figura 6.8 a), o CET da simulação com RAPC mostrou-se maior por contemplar todas os modos de falha individuais de componentes, quando se ignora falhas por colapso progressivo, na simulação sem RAPC, o CET final das estruturas é menor devido a ausência de custos de falha por colapso na função objetivo e às diferenças na configuração otimizada. A Figura 6.8 b) e c) mostram a variação nos diâmetros finais de cada uma das barras para ambos os casos, evidenciando que as simulações resultam em configurações otimizadas distintas. Verificou-se, no decorrer de múltiplas simulações e exemplos que a consideração do colapso progressivo gera configurações otimizadas com diferentes CET e, em geral, com um número maior de barras atuantes. 
a)
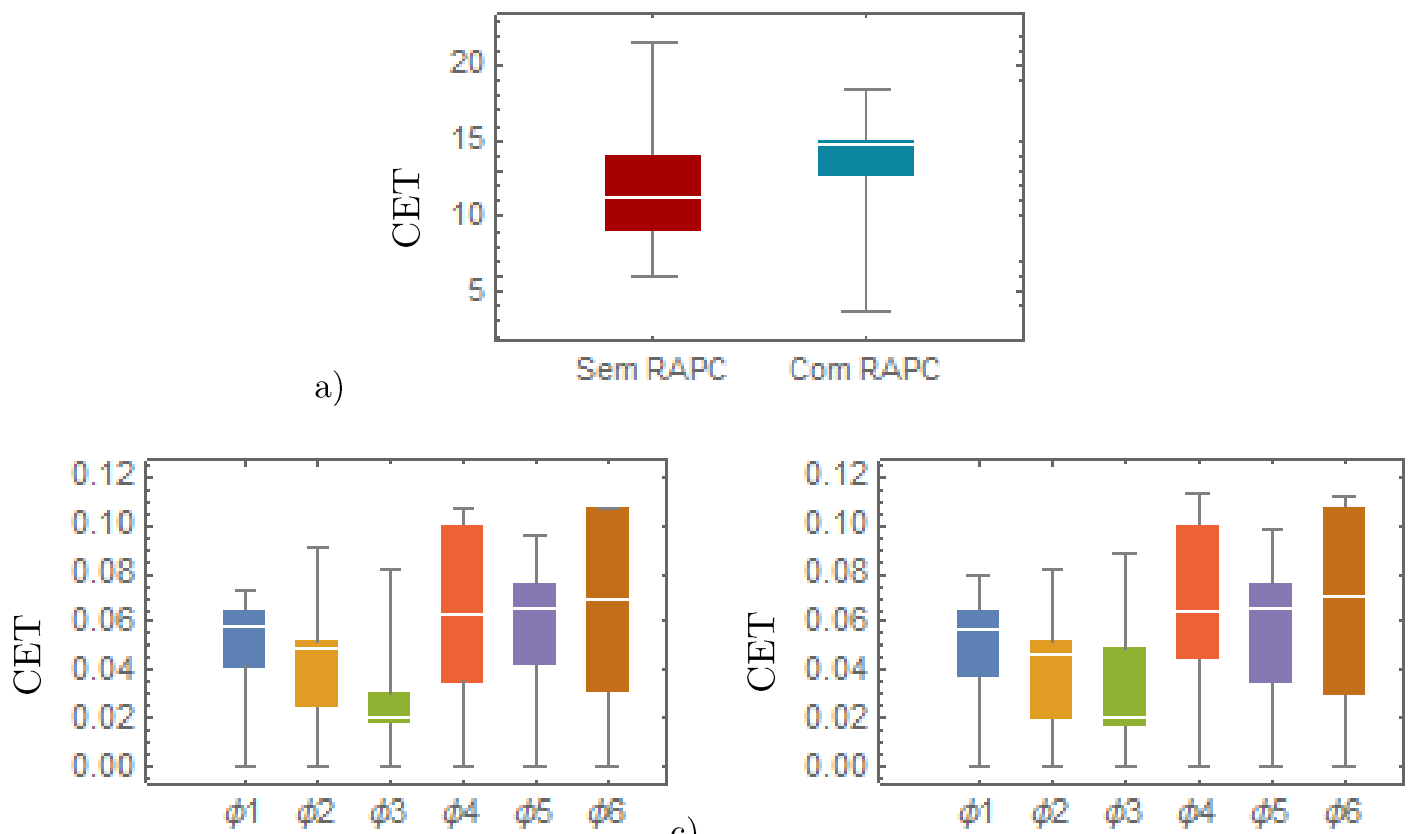

b)

c)

Figura 6.8 - a) Dispersão dos CET finais; Dispersão dos diâmetros finais para b) Sem uso do RAPC e; c) com implementação do RAPC. Fonte: elaborado pela autora.

As configurações do Quadro 6.3 não representam configurações ótimas globais devido ao baixo número de partículas considerado. O objetivo aqui é apenas mostrar análises similares com e sem a consideração do colapso progressivo através da avaliação pelo RAPC.

Quadro 6.3 - Configurações finais para os 2 casos em duas das simulações. Fonte: elaborado pela autora.

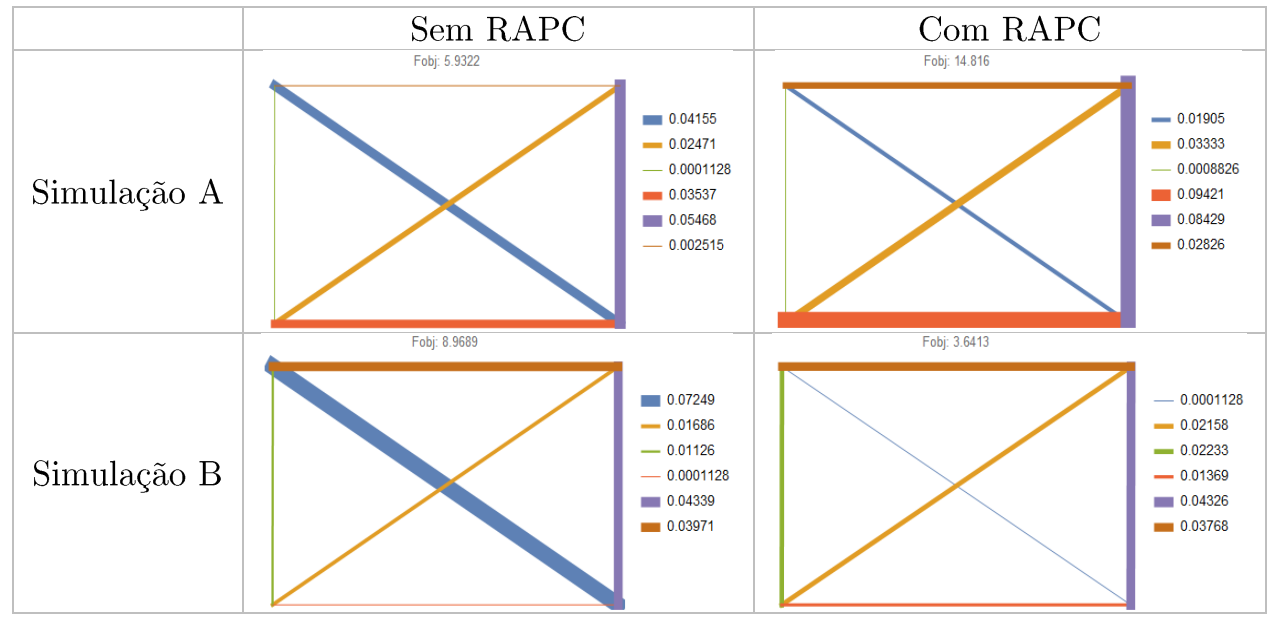




\subsubsection{Influência do passo no CVC-pseudo-gradiente: Treliça de 10 barras}

Neste item, a treliça de 10 barras da Figura 6.9 é utilizada para mostrar a convergência do algoritmo de otimização baseado no CVC-pseudo-gradiente para diferentes tamanhos de passo. A treliça possui distância entre nós do mesmo eixo unitária e no nó 6 são aplicadas duas cargas, de acordo com a Tabela 6.4 (unidades padrão metro e Newton). As variáveis de projeto também apresentam coeficiente de variação de 10\%, referindo-se ao caso 4 de incertezas.

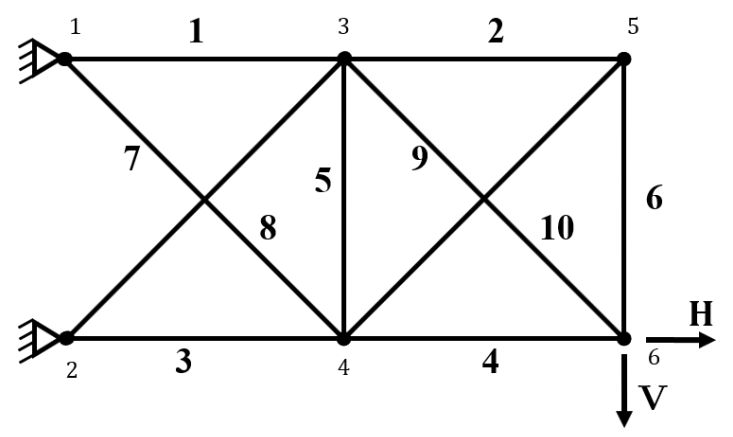

Figura 6.9 - Treliça plana de 10 barras. Fonte: elaborado pela autora.

Tabela 6.4-Variáveis aleatórias e seus parâmetros para treliça de 10 barras.

Fonte: elaborado pela autora.

\begin{tabular}{|c|c|c|c|}
\hline Variável & Distribuição & Valor Nominal & Desvio Padrão \\
\hline Módulo de elasticidade $\boldsymbol{E}$ & Log-Normal & $2.050 * 10^{11}$ & $1.5 * 10^{10}$ \\
\hline Tensão última $\boldsymbol{\sigma}_{\boldsymbol{u}_{\boldsymbol{i}}}$ & Log-Normal & $7.45 * 10^{8}$ & $7.45 * 10^{7}$ \\
\hline Força H & Normal & $1.0 * 10^{4}$ & $2.0 * 10^{3}$ \\
\hline Força V & Normal & $-1.0 * 10^{6}$ & $2.0 * 10^{5}$ \\
\hline
\end{tabular}

Foi analisada a estrutura com mecânica NLG e configuração inicial na qual todas as barras possuem a mesma seção transversal, equivalente a área da seção circular com $\phi=0.1 \mathrm{~m}$. No algoritmo de otimização foram testados três tamanhos de passo definidos por $\rho=$ $\{0.1,0.2,0.5\}$. A Figura 6.10 a) mostra a convergência do valor de CET para as três simulações.

A variação no tamanho dos passos tem influência na configuração final da estrutura. Tanto passos muito pequenos quanto muito grandes podem convergir para mínimos locais. Neste caso, verificou-se que o tamanho de passo $\rho=0.2$ foi o de melhor desempenho dentre os analisados para esta configuração inicial.

A Figura 6.10 (b) exibe a configuração otimizada com $\rho=0.2$ que indica provavelmente um mínimo local. Conforme expresso anteriormente, a utilização de múltiplas inicializações do 
algoritmo pode se aproximar mais do mínimo global, chegando a estruturas de melhor configuração.

a)
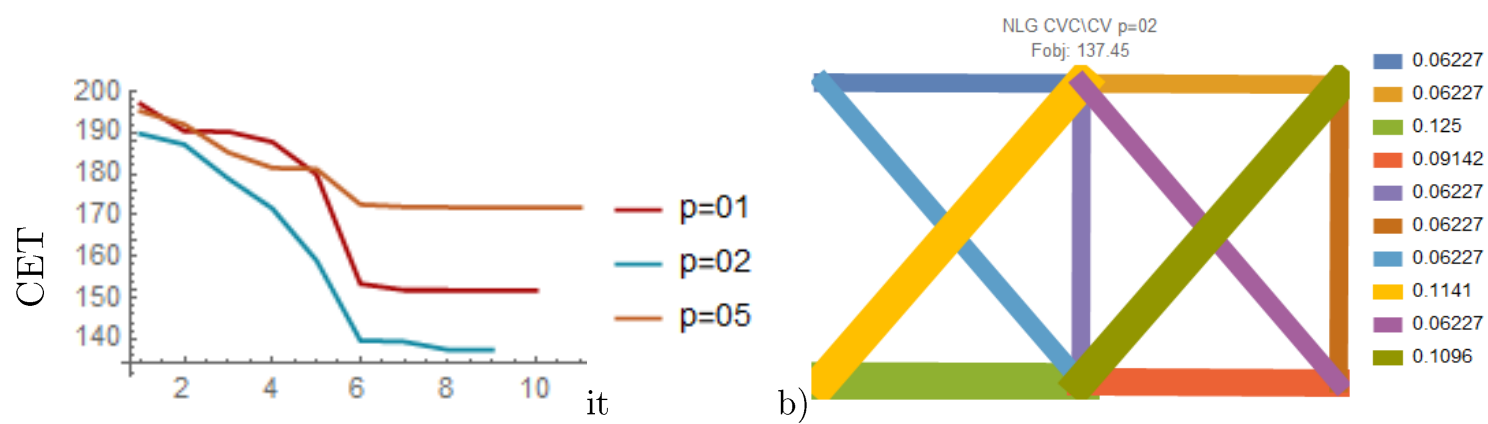

Figura 6.10 - a) Convergência do CET otimizado para os três casos de passo inicial testados: $\rho=\{0.1,0.2,0.5\}$; b) Configuração otimizada para o caso $\rho=0.2$. Fonte: elaborado pela autora.

A convergência dos diâmetros em cada caso segue comportamentos semelhantes. As barras 3,8, 10 e 4 destacam-se como barras vulneráveis convergindo para áreas maiores. Em razão da direção coincidente avaliada pelo CVC, barras redundantes convergem em conjunto mostrado na linha mais grossa nas partes inferiores dos gráficos da Figura 6.11.

a)

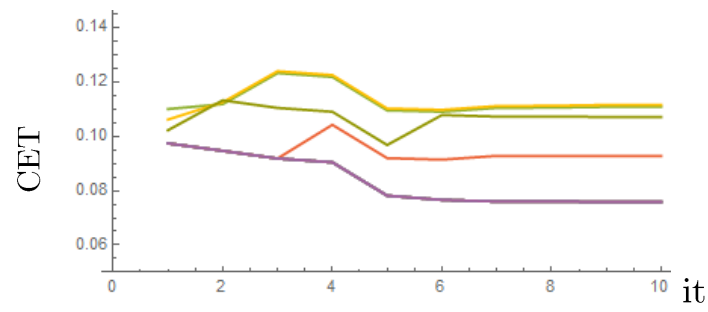

b)

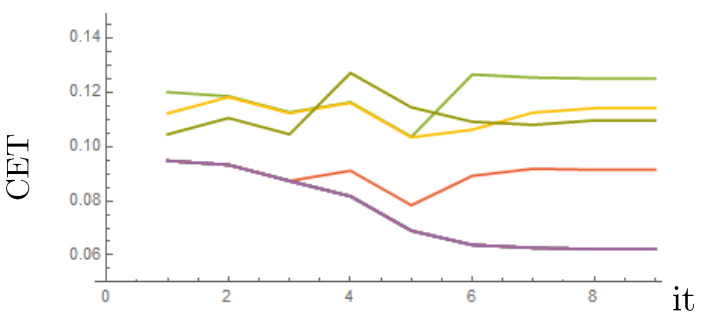

c)

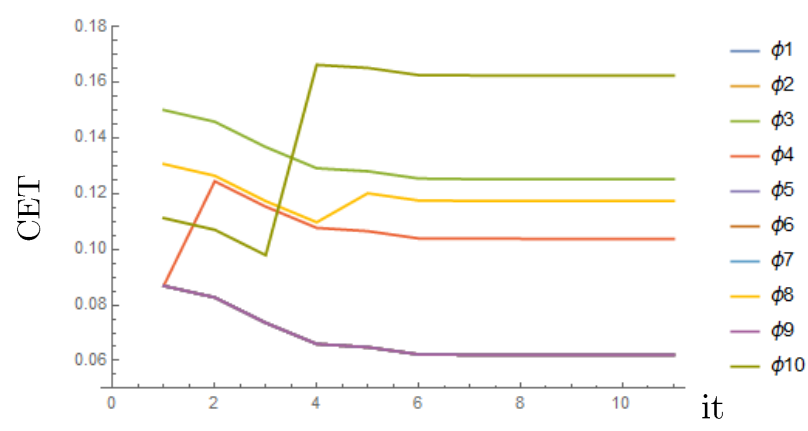

Figura 6.11 - Convergência do diâmetro da seção transversal para os casos: a) $\rho=0.1$; b) $\rho=0.2$ e; c) $\rho=0.5$. Fonte: elaborado pela autora. 



\section{CONCLUSÕES}

A otimização de risco de estruturas treliçadas foi abordada para problemas mecânicos lineares e NLG. A consideração da não linearidade geométrica, a depender do problema, ocasiona mudanças significativas na configuração otimizada e no custo esperado total da mesma. A implementação do algoritmo de previsão de falha progressiva foi essencial para identificar elementos estruturalmente vulneráveis e redundantes, permitindo quantificar, de modo mais preciso, a probabilidades de falha ao colapso durante mudança nas configurações na otimização.

O tipo de problemas de otimização estrutural estudado se apoia em um número elevado de análises de confiabilidade estrutural e análises de mecânica estrutural principalmente após implementação da RAPC para avaliação do colapso progressivo. Essa característica aumenta drasticamente o custo computacional, visto que os empecilhos não são teoria, mas sim numéricos. Para viabilizar a otimização estrutural sob incertezas com consideração do colapso progressivo e da não linearidade geométrica na resposta mecânica, por meio de qualquer método de otimização heurístico ou não, é fundamental que se desenvolvam técnicas mais eficientes do ponto de vista computacional para aplicação da formulação em problemas reais.

Com relação ao método de otimização baseado no CVC-pseudo-gradiente, sua dependência a parâmetros como o tamanho do passo limitou os resultados obtidos causando convergência para mínimos locais e ruídos nos resultados. No entanto, a métrica desenvolvida mostrou-se capaz de lidar com a minimização de custos de estruturas sujeitas a colapso progressivo de forma única. Como ponto forte destaca-se a propriedade da métrica baseada no coeficiente de vulnerabilidade ao colapso de indicar com base em cada elemento da estrutura a direção de minimização dos custos. Outros métodos heurísticos que dispõem de parâmetro relativo à direção podem se beneficiar dessa métrica como, por exemplo, um operador limitante 
deste parâmetro. Portanto, a principal contribuição é o desenvolvimento de uma métrica baseada em colapso progressivo que possui características que possibilitam sua utilização como operador de outros métodos heurísticos.

A utilização tanto da métrica como da otimização de risco possibilita a inclusão de colapso progressivo na formulação mecânica e a contabilização dos custos esperados de falha e de colapso em problemas de otimização estrutural sob incerteza.

\subsection{Sugestões para pesquisas futuras}

Este item elenca uma série de bifurcações ou possibilidades que o presente trabalho poderia ter tomado. Tais itens não puderam ser desenvolvidos seja pelo limite do escopo, por limites de formação acadêmica ou simplesmente pelo momento tardio em que surgiram. Sendo assim, a autora encoraja a continuidade deste trabalho das seguintes maneiras:

a) Aplicar técnicas de suavização tanto da função objetivo quantos das equações de estado limite, como utilização de meta-modelagem para diminuir o custo computacional do modelo mecânico, vide Kroetz (2015).

b) Considerar cenário mecânico com plasticidade e não linearidade física.

c) Utilizar o método de Esposito (2016) para identificar outros modos de falhas como falhas por instabilidade.

d) Associar a otimização com a formulação para o agrupamento dos elementos proposta em Lemonge et al. (2011) visando resultados discretos que descrevem seções transversais comerciais.

e) Utilizar coordenadas nodais como variáveis de projeto, incluindo descrições de instabilidade de nós.

f) Aplicar pós-processamento das estruturas otimizadas afim de corrigir topologias inaceitáveis de acordo com Cui et al. (2018).

g) Aplicar a métrica baseada no CVC como operador em outros métodos heurísticos. 


\section{REFERÊNCIAS BIBLIOGRÁFICAS}

ACHTZIGER, W.; BENDSØE, M. P.; BEN-TAL, A.; ZOWE, J. Equivalent displacement based formulations for maximum strength truss topology design. Impact of Computing in Science and Engineering, v. 4, p. 315-345, 1992.

ANG, A. H. S.; TANG, W. H. Probability Concepts in Engineering: Emphasis on Applications to Civil and Environmental Engineering. 2. ed. John Wiley Publishers, 2007.

AOUES, Y. Optimisation fiabiliste de la conception et de la maintenance des structures. 2008. Université Blaise Pascal, Clermont-Ferrand, 2008.

BECK, A. T.; TESSARI, R. K.; KROETZ, H. M. System reliability-based design optimization and risk-based optimization: a benchmark example considering progressive collapse. v. 51, n. 6, p. 1000-1012, 2019.

BEndsøE, M. P., \& SIGMUND, O. Topology Optimization: Theory, Methods and Applications. Berlin: Springer Berlin Heidelberg, 2000.

BICHON, B. J.; MCFARLAND, J. M.; MAHADEVAN, S. Efficient surrogate models for reliability analysis of systems with multiple failure modes. Reliability Engineering and System Safety, v. 96, n. 10, p. 1386-1395, 2011.

CERVEIRA, A.; AGRA, A.; BASTOS, F.; GROMICHO, J. A new Branch and Bound method for a discrete truss topology design problem. Computational Optimization and Applications, v. 54, n. 1, p. 163-187, 2013.

CHANG, S. E.; SHINOZUKA, M. Life-Cycle Cost Analysis with Natural Hazard Risk. Journal of Infrastructure Systems, v. 2, n. 3, p. 118-126, 1996.

CHEN, Y.; HUANG, L.; LU, Y.; DENG, L.; PH, D.; ASCE, M.; TAN, H. Assessment of Structural Robustness under Different Events according to Vulnerability. v. 30, n. 5, p. 1-13, 2016.

CHENG, F. Y. Multiobjective optimum design of seismic-resistant structures. Recent advances in optimal structural design. Reston, VA: American Society of Civil Engineers, p. 241-255, 2002.

CODA, H. B.; GRECO, M. A simple FEM formulation for large deflection 2D frame analysis based on position description. Computer Methods in Applied Mechanics and Engineering, v. 193, n. 33-35, p. 3541-3557, 2004.

CODA, H. B.; PACCOLA, R. R. AcadFrame - Software Acadêmico para análise de pórticos e treliças planas. São Carlos - SP. Grupo de Mecânica Computacional (GMEC - SET/EESC/USP), , 2009. .

CODA, H. B.; PACCOLA, R. R. A FEM procedure based on positions and unconstrained vectors applied to non-linear dynamic of 3D frames. Finite Elements in Analysis and Design, v. 47, n. 4, p. 319-333, 2011.

COELLO, C. A. C.; REYES-SIERRA, M. Multi-Objective Particle Swarm Optimizers: 
A Survey of the State-of-the-Art. International Journal of Computational Intelligence Research, v. 2, n. 3, p. 287-308, 2006.

CUI, H.; AN, H.; HUANG, H. Truss topology optimization considering local buckling constraints and restrictions on intersection and overlap of bar members. Structural and Multidisciplinary Optimization, p. 1-20, 2018.

DIMOU, C. K.; KOUMOUSIS, V. K. Reliability-Based Optimal Design of Truss Structures Using Particle Swarm Optimization. Journal of Computing in Civil Engineering, v. 23, n. 2, p. 100-109, 2009.

DITLEVSEN, O.; MADSEN, H. O. Structural Reliability Methods. Mechanical Engineering, n. September, p. 361, 2007.

DORN, W.; GOMORY, R.; GREENBERG, M. Automatic Design of Optimal Structures. J. de Mechanique, v. 3, p. 25- 52, 1964.

DU, X.; CHEN, W. Sequential Optimization and Reliability Assessment Method for Efficient Probabilistic Design. Journal of Mechanical Design, v. 126, n. 2, p. 225, 2004.

ESPOSITO, A. Otimização do risco de estruturas redundantes considerando os efeitos das não linearidades e múltiplos modos de falha. 2016. Universidade Federal do Rio Grande do Sul, 2016.

FELIPE, T. R. C. Novo Método para a Avaliação do Risco de Colapso Progressivo em Edifícios de Alvenaria Estrutural. 2017. Universidade de São Paulo, 2017.

FELIPE, T. R. C.; HAACH, V. G.; BECK, A. T. Systematic Reliability-Based Approach to Progressive Collapse. v. 4, n. 4, p. 1-9, 2018.

FIONDELLA, L.; XING, L. Discrete and continuous reliability models for systems with identically distributed correlated components. Reliability Engineering \& System Safety, v. 133, p. 1-10, 2015.

FOURIE, P. C.; GROENWOLD, a. a. The particle swarm optimization algorithm in size and shape optimization. Structural and Multidisciplinary Optimization, v. 23, n. 4, p. 259-267, 2002.

FRANGOPOL, D. M.; LIN, K.-Y.; ESTES A.C. Life-cycle cost design of deteriorating structures. J. Struct. Engng ASCE, v. 123, n. 10, p. 1390-1401, 1997.

FRANGOPOL, D. M.; MAUTE, K. Life-cycle reliability-based optimization of civil and aerospace structures. Computers and Structures, v. 81, n. 7, p. 397-410, 2003.

GOMES, W. J. D. S.; BECK, A. T. Global structural optimization considering expected consequences of failure and using ANN surrogates. Computers and Structures, v. 126, n. 1, p. 56-68, 2013.

GRECO, M.; GESUALDO, F. a R.; VENTURINI, W. S.; CODA, H. B. Nonlinear positional formulation for space truss analysis. Finite Elements in Analysis and Design, v. 42, n. 12 , p. 1079-1086, 2006.

HAGISHITA, T.; OHSAKI, M. Topology optimization of trusses by growing ground structure method. Structural and Multidisciplinary Optimization, v. 37, n. 4, p. 377393, 2009.

HASANÇEBI, O.; ÇARBAS, S.; DOGAN, E.; ERDAL, F.; SAKA, M. P. Performance evaluation of metaheuristic search techniques in the optimum design of real size pin jointed structures. Computers and Structures, v. 87, n. 5-6, p. 284-302, 2009. 
HESTENES, M. R.; STIEFEL, E. Methods of conjugate gradients for solving linear systems. Journal of Research of the Natural Bureau of Standards, v. 49, n. 6, p. 409436, 1952.

JOINT COMMITTEE ON STRUCTURAL SAFETY - JCSS. Probabilistic Model Code - Part 1. Structural Safety, n. March, p. 65, 2001.

KENNEDY, J.; EBERHART, R. Particle swarm optimization. Neural Networks, 1995. Proceedings., IEEE International Conference on, v. 4, p. 1942-1948 vol.4, 1995.

KHARMANDA, G.; OLHOFF, N.; MOHAMED, a.; LEMAIRE, M. Reliability-based topology optimization. Structural and Multidisciplinary Optimization, v. 26, n. 5, p. 295-307, 2004.

KIM, D.; OK, S.; SONG, J.; KOH, H. System reliability analysis using dominant failure modes identified by selective searching technique. Reliability Engineering and System Safety, v. 119, p. 316-331, 2013.

KROETZ, H. M. Meta-Modelagem em Confiabilidade Estrutural. 2015. Universidade de São Paulo, 2015.

LAND, A. H.; DOIG, a. G. An automatic method for solving discrete programming problems. Econometrica, v. 28, n. 3, p. 497-520, 1960.

LEMOnge, A. C. C.; BARBOSA, H. J. C.; COUtinho, A. L. G. A.; BORGES, C. C. H. Multiple cardinality constraints and automatic member grouping in the optimal design of steel framed structures. Engineering Structures, v. 33, n. 2, p. 433-444, 2011.

LI, L. J.; HUANG, Z. B.; LIU, F. A heuristic particle swarm optimization method for truss structures with discrete variables. Computers and Structures, v. 87, n. 7-8, p. 435443, 2009.

LI, L. J.; HUANG, Z. B.; LIU, F.; WU, Q. H. A heuristic particle swarm optimizer for optimization of pin connected structures. Computers and Structures, v. 85, n. 7-8, p. 340$349,2007$.

LUENBERGER, D. G.; YE, Y. Linear And Nonlinear Programming. 3. ed. Springer Berlin Heidelberg, 2008.

MADSEN, H. O.; KRENK, S.; LIND, N. C. Methods of structural safety. Courier Corporation, 2006.

MARTHA, L. F. Ftool - Two-Dimensional Frame Analysis Tool. Rio de JaneiroTechnical-Scientific Software Development Institute (Tecgraf/PUC-RIO), , 2018. .

MARTÍNEZ, P.; MARTÍ, P.; QUERIN, O. M. Growth method for size, topology, and geometry optimization of truss structures. Structural and Multidisciplinary Optimization, v. 33, n. 1, p. 13-26, 2007.

MELCHERS, R. E.; T. BECK, A. Structural reliability analysis and prediction. Third Edit ed. Hoboken, NJ: John Wiley, 2018.

MOGAMI, K.; NISHIWAKI, S.; IZUI, K.; YOSHIMURA, M.; KOGISO, N. Reliabilitybased structural optimization of frame structures for multiple failure criteria using topology optimization techniques. Structural and Multidisciplinary Optimization, v. 32, n. 4, p. 299-311, 2006.

MORENO-DE-LUCA, L.; CARRILLO, O. Multi-Objective Heuristic Computation Applied To Architectural And Structural Design: A Review. International Journal of Architectural Computing, v. 11, n. 3, p. 363-392, 2013. 
MORTAZAVI, A.; TOĞAN, V. Simultaneous size, shape, and topology optimization of truss structures using integrated particle swarm optimizer. Structural and Multidisciplinary Optimization, p. 1-22, 2016.

MUROTSU, Y.; SHAO, S.; WATANABE, A. An approach to reliability-based optimization of redundant structures. Structural Safety, v. 16, p. 133-146, 1994.

NGUYEN, T. H.; SONG, J. H.; PAUlinO, G. H. Single-Loop System Reliability-Based Design Optimization Using Matrix-Based System Reliability Method: Theory and Applications. Journal of Mechanical Design, v. 132, n. 1, p. 1-11, 2010.

OHSAKI, M. Optimization of Finite Dimensional Structures. CRC Press, 2010. v.1.

OKASHA, N. M. An improved weighted average simulation approach for solving reliability-based analysis and design optimization problems. Structural Safety, v. 60, p. 47$55,2016$.

PARSOPOULOS, K. E.; VRAHATIS, M. N. Recent approaches to global optimization problems through Particle Swarm Optimization. Natural Computing, v. 1, n. 2-3, p. 235306, 2002.

PEDROSA, T. G.; BECK, A. T. Progressive collapse on risk topology optimization. Proceedings of the joint ICVRAM ISUMA UNCERTAINTIES conference, 2018.

PEREZ, R. E. E.; BEHDINAN, K. Particle swarm approach for structural design optimization. Computers \& Structures, v. 85, n. 19-20, p. 1579-1588, 2007.

PETERSSON, J. On continuity of the design-to-state mappings for trusses with variable topology. International Journal of Engineering Science, v. 39, n. 10, p. 1119-1141, 2001.

PINTÉR, J. D. Global optimization: software, test problems, and applications. In: Handbook of global optimization. Springer, 2002. p. 515-569.

POSPÍSILOVÁ, A.; LEPS, M. Branch and Bound Method For Global Optima Of Size Optimization Benchmarks. 18 th International Conference Engineering Mechanics 2012, p. 1049-1059, 2012.

QU, X.; HAFTKA, R. T. Reliability-based design optimization using probabilistic sufficiency factor. Structural and Multidisciplinary Optimization, v. 27, n. 5, p. 314$325,2004$.

RASHKI, M.; MIRI, M.; AZHDARY MOGHADDAM, M. A new efficient simulation method to approximate the probability of failure and most probable point. Structural Safety, v. 39 , p. $22-29,2012$.

RASHKI, M.; MIRI, M.; MOGHADDAM, M. A. A simulation-based method for reliability based design optimization problems with highly nonlinear constraints. Automation in Construction, v. 47, p. 24-36, 2014.

SAAD, L.; AISSANI, A.; CHATEAUNEUF, A.; RAPHAEL, W. Reliability and life cycle cost optimization of reinforced concrete structures under coupled corrosion-fatigue deterioration process. 11th International Conference on Structural Safety and Reliability (ICOSSAR), p. 4743-4750, 2013.

SAFAEIAN, N.; MIRI, M.; RASHKI, M. New simulation-based frameworks for multiobjective reliability-based design optimization of structures. Applied Mathematical Modelling, v. 62, p. 1-20, 2018.

SANTOS, K. R. M. dos. Técnicas de amostragem inteligente em simulação de 
Monte Carlo. 2014. Escola de Engenharia de São Carlos, Universidade de São Paulo,São Carlos, 2014.

SARMA, K. C.; ADELI, H. Life-cycle cost optimization of steel structures. International Journal for Numerical Methods in Engineering, v. 55, n. 12, p. 1451$1462,2002$.

SCHUTTE, J. F.; GROENWOLD, a. a. Sizing design of truss structures using particle swarms. Structural and Multidisciplinary Optimization, v. 25, n. 4, p. 261-269, 2003.

SHAO, S.; MUROTSU, Y. Approach to failure mode analysis of large structures. Probabilistic Engineering Mechanics, v. 14, n. 1-2, p. 169-177, 1999.

SHI, Y.; EBERHART, R. C. Parameter Selection in Particle Swarm Optimization. Evolutionary Programming VII SE - 57, v. 1447, p. 591-600, 1998.

SONG, J.; KANG, W. H. System reliability and sensitivity under statistical dependence by matrix-based system reliability method. Structural Safety, v. 31, n. 2, p. 148-156, 2009.

STOLPE, M. Truss optimization with discrete design variables: a critical review. Structural and Multidisciplinary Optimization, p. 349-374, 2015.

SVANBERG, K.; WERME, M. On the validity of using small positive lower bounds on design variables in discrete topology optimization. Structural and Multidisciplinary Optimization, v. 37, n. 4, p. 325-334, 2009.

TADA, T. PSO (Particle Swarm Optimization) - Fortran90 source (OpenMP)Kanagawa, Japão.

TESSARI, R. K. Projeto Baseado em Performance, de torres metálicas sujeitas à ação do vento. p. 142, 2016.

Thampan, C. K. P. V.; KRISHnAmOORTHY, C. S. System Reliability-Based Configuration Optimization of Trusses. Journal of Structural Engineering, v. 127, n. 8, p. 947-956, 2001.

VANDERPLAATS, G. N. Numerical optimization techniques for engineering design: with applications. McGraw-Hill Ryerson, Limited, 1984.

WANG, X.; WANG, L.; QIU, Z. Safety estimation of structural systems via interval analysis. Chinese Journal of Aeronautics, v. 26, n. 3, p. 614-623, 2013.

WEN, Y. K. Minimum lifecycle cost design under multiple hazards. Reliability Engineering and System Safety, v. 73, n. 3, p. 223-231, 2001. 